\title{
Review
}

\section{The Limits of Criminal Law Scholarship}

\author{
John Griffiths*
}

The Limits of the Criminal Sanction. By Herbert L. Packer. Stanford: Stanford University Press, 1968. Pp. xi, 385. \$8.95.

\section{Introduction}

This is a very disappointing book. It is not just "not so good as it might have been," but rather, in my opinion, very, very bad indeed. For the general reader, the following short notice is all that it requires:

The ultimate thesis of this book is that we are using the criminal law too much and too heedlessly. This has been said many times in many places. It does not warrant a book now unless it is to be restated with special depth of human feeling, or special insight, or special rigor, or special forcefulness. This book has none of these. In style, it is soporific. In argument, it is variously platitudinous, unoriginal, and confused-often all at the same time. As propaganda, it is ineffective. I know of no class of reader who would profit from the reading of it. All this is subject to a qualification in favor of the central third of the book, reprinted here practically verbatim from an important law review article entitled "Two Models of the Criminal Process,"1 which can as easily and far more cheaply be read where it first appeared.

But for readers with a special interest in criminal law scholarship (and particularly for those already familiar with the book), I am impelled to annotate that notice in some detail.

Several considerations justify an extended review, even for a limited audience: First, the book was written by a man who is widely regarcled as one of our leading scholars in the field. Second, the appearance of a would-be major contribution to the scholarly literature of criminal law is a rare enough event that it warrants an examination both more

- Assistant Professor of Law, Yale Law School. B.A. 1962, University of California (Berkeley); LL.B. 1965, Yale University.

1. 113 U. PA. L. REV. 1 (1964). 
intensive and more extensive than is common in book reviews. Third, the mistakes and confusions which so thoroughly vitiate Packer's book are generally characteristic-although rarely in such extreme concentration-of the low state of criminal law scholarship, ${ }^{2}$ and it seems to me instructive not just to let them all pass once again, but to seize this chance to focus insistently upon them.

The book is "addressed, with affectionate respect, to the Common Reader," because, Packer says, the kinds of issues it raises are "too important" to be left to lawyers, philosophers and social scientists, respectively. ${ }^{3}$ I do not take Packer to mean by this, horvever, that the book is to be judged according to popular rather than scholarly canons. If he did, my criticism would be that one does the "Common Reader" no service by overwhelming him with mistake, confusion and nonsequitur, nor by pretending that difficult or subtle problems are simple and their resolutions obvious, ${ }^{4}$ nor by misrepresenting critical matters of fact on which the "Common Reader" is likely not to be independently informed. In any case, Packer plainly has a professional audience in mind: he refers to the book as a "scholarly" one," for example, and he claims to have attempted a "resolution" of the twin problems of justifying the criminal law and justifying the act of punishment, ${ }^{\tau}$ an effort one would hardly undertake in a popularizing

2. Packer often indicates that he disagrees with this assessment of criminal law tcholarship. For example, he seriously refers to "the masterly legislative construct" underlying the mens rea provisions of the Model Penal Code, H. PACKER, THE Limits of the Cruminal SasicITON 107 (1968) [hereinafter referred to by page number only], and to the Code's "high degree of analytic rigor" (p. 105)-although the Code in general, and its mens rea provisions in particular, is a patchwork of inconsistencies and compromises, almost the caricature of what a "model" code should be. He seriously describes Jerome Fall's Genieral Princaples of CRIMTNAL LAw (1947) as our "major work" of "doctrinal clarification" (p. 370)-although in fact it is surely among the most confused books ever addressed to jurisprudential questions. One despairs at the decline since Stephen and Holmes.

Perhaps I should invoke Beccaria and Bentham as well, insofar as Packer treats of the "preventive and treatment dimensions" of criminal law- for as $\mathrm{N}$. Morris and $\mathrm{G}$. Hawkins have observed (THE HONEST POLITICIAN's GurDE TO CRIME CONTROL 120 (1970)), on those questions, too, we have learned very little in recent generations, and "[t]he quality of the discussion . . . has if anything deteriorated."

Cf. also Packer, Mens Rea and the Supreme Court, 1962 SUP. CT. REv. 107, 137 commenting on "the decadence of substantive criminal law," and the "dispiriting chapter in the history of Anglo-American legal scholarship" which an account of that failure would entail.

3. P. 5 .

4. For refreshing contrast to Packer's evident condescension see the preface to $\mathbf{N}$. MorRIs \&: G. Hawkins, supra note 2, at ix-si.

[W] do not, as some writers do, assume that the general reader is a naĩre simpleton capable only of absorbing predigested material served with a dressing of rhetoric We assume, what will in many cases undoubtedly be true, that he is better read and intellectually more sophisticated than we are.

5. See, e.g., p. 1423 and note 309 infra.

6. P. viii.

7. P. 370. 
book. Whatever it may mean to insist that an issue is "too important" to leave to those professionally interested in it, no liberation from the fruits of their work is thereby effected. Many centuries of thought by lawyers, philosophers and social scientists impose considerable constraints upon anyone who writes about criminal law, and Packer is not free from them.

\section{General Remarks}

The book is divided into three parts. The first "is essentially an extended essay on the nature and justification of the criminal sanction." The second analyzes "the characteristic processes through which the criminal sanction operates." And the third, starting from "the constraints of rationale and process" delineated in the first two, "deals directly with the central problem of defining criteria for limiting the reach of the criminal sanction."8 Part II of the book, as I have already indicated, previously appeared as "Two Models of the Criminal Process," in the University of Pennsylvania Law Review. ${ }^{0}$ That article enjoys a deserved reputation, and since it figures prominently in a recently-published article of my own-"Ideology in Criminal Procedure, or, A Third 'Model' of the Criminal Process"10_I shall address this review to the first and third Parts of the book.

The book presents itself as an analytic, even jurisprudential, essay, and hence the mode of my review. I do not want to leave open the implication, in so reviewing it, that I underrate the worth of other sorts of efforts in this field. Quite the contrary-I am thoroughly convinced that the traditional jurisprudence of criminal law has reached essential sterility. This is particularly true on the most basic level of all, without firmness and clarity about which we can build nothing: no one is presently capable of giving an adequate, intelligible and coherent account of why it is useful and right to punish men, and a fortiori, no one can explain which men ought to be punished in which circumstances. Packer sets about to analyze the criminal law from this bottornmost level up. Even though my task is an essentially negative one, it seems to me critical to isolate and to emphasize the mistakes which are responsible for this ultimate failure, as a sort of mind-cleansing precondition to any future effort to come to a coherent account of the criminal law.

8. P. 4.

9. IIS U. PA. L. REV. 1 (1964).

10. 79 YALE L.J. 359 (1970). 
What is desperately needed is not just more lawyerish jurisprudence-as-usual, but the sort of radically new conceptualizations and theoretical formulations which can only come by taking basic intellectual risks and from opening the mind to fundamentally new ways of comprehending the phenomena of criminal law. I doubt that the jurisprudence of criminal law will see any more progress in the next hundred years than it has in the last unless use is made of the insights, concepts, and theoretical formulations of adjacent disciplines. But Packer's book is doggedly conformist. There are no flashes of insight into the nature of criminal law and its position in the whole fabric of society. No use is made of modes of understanding from outside the customary corpus; Packer proceeds, in the lawyer's habitual fashion, as if anthropology and sociology, political theory and psychology, even history and philosophy and theology, barely existed..$^{11}$ So it is as a re-treading of the traditional ground in the well-worn boots that we must evaluate this book. ${ }^{12}$

My objection-even in those limited terms-is not that Packer's argument fails to compare favorably with Bentham, despite what one reviewer, ${ }^{13}$ and apparently Packer himself, ${ }^{14}$ seem to think, but that it falls below. the minimum level of craftsmanship that I believe we are entitled to insist upon. "In both substance and method," Packer writes, "the shades I invoke, not without presumption, are those of Bentham and Mill."15 Substance will occupy the bulk of this review, but it is important to make some preliminary, if at this point conclusory, remarks on method (remarks which I hope to be able to vindicate concretely at the end of the review). For Packer's failings in respect of method render the book so thoroughly and consistently defective on the level of the elements of argument that it is frequently impossible to come to terms with anything on the level of substance.

11. Nor does Packer address himself to the humane heart and attempt to involve his reader in a specially intense sympathy with the human frailties and crises on which the criminal law comes to bear. Contrast, in this regard, the works of Tony Parker: TuE Courage of his Convictions (with $R$. Allarton) (1962); ThE UNRniown Crtizen (1963); Women in Crise (1965); A MAN of GoOd ABILITIES (1967); THE HIDDEN WORLD Of SEX OFFENDERS (1969).

12. Two methods of criticism are possible in such a case. One could approach the book externally, as it were, and try to show the places at which it is unsatisfactory for failure to come to terms with available theory or information from other disciplines. To a limited extent, I try to do that (see, e.g., notes 38, 111, 272, and 316 infra). But on the whole, the book fails so completely on its own terms that there secms litule point to go beyond internal criticism.

13. "One reader" is quoted on the dust jacket as having said of it: "In a way, its nearest competition is Jeremy Bentham's Principles of Morals and Legislation."

14. Pp. 5, 369.

15. P. 5 . 
If there was anything Bentham despised it was ipse dixitism about ethical questions-use of the "principle of sympathy and antipathy."10 If there is a single jurisprudential fault which predominates in Packer's argument-despite his repeated invocations of Utilitarianism-it is the regular substitution of ipse dixitism for ethical argument. At almost every place where Packer could have made some contribution to the jurisprudence of criminal law by answering the question "why" which he seems to be posing, all he in fact offers is sympathy or antipathy, often dressed up in rhetoric of a banal and complacent sort.

Packer's analytical chaos is the diametric opposite of Bentham's disciplined, methodical rigor. ${ }^{17}$ He shows no respect for the elemental tools of the craft: words and concepts are regularly used in total disregard of whatever clarity and precision, and patina of acquired meaning, they have accumulated in the last hundred years or so of criminal law jurisprudence; and even words which he explicitly sets about to define are thereafter used in wholly inconsistent ways. The simplest canons of grammar and of the straightforward presentation of an argument get ignored. Propositions that are dubious on their face are advanced with an off-hand "of course" and with no supporting argument whatever. Important empirical information bearing on jurisprudential questions is the subject of misrepresentation. Received notions are pressed into service as arguments at just those points where the need for something more than the transmission of dogma cries out loudest. And finally, statements so nonsensical that one feels transported into the jurisprudence of the absurd, and logical mistakes so primitive and so apparent that one winces with embarrassment to read them, make whole stretches of the book simply and irretrievably unintelligible.

Somewhere on the borderline between method and tone, and perhaps most damaging of all to Packer's right to expect the serious respect of his reader, is his obvious conception of himself as an

16. See J. Bentham, AN Introduction to the Principles of Morals and Législation 15-16 (1823).

17. Packer makes no use at all of Bentham's cardinal principle of method: díchotomy. See, e.g., J. BenthaM, supra note 16, at $204 \mathrm{n} .1$ (1823). One example of a major oversight which careful use of this principle might have avoided lies in Packer's unexamined characterization of criminal procedure as "dependent and instrumental." (p. 17) Benthamite method would have required the dichotomy: procedure can be either completely instru* mental or not completely instrumental with respect to the objectives of the substantive criminal law. Merely to have stated the question in that form would have made it altnost obvious that there are non-instrumental functions of criminal procedure, and that the process is, to that extent, not merely "dependent and instrumental." See Griffiths, Ideology in Criminal Procedure, or, $A$ Third 'Model' of the Criminal Process, 79 YArE' L.J. 859, 388-91 (1970). 
"authority."18 One manifestation of this syndrome is the regular substitution of pronunciamento for argument-a serious and perfectly respectable position with which he happens to disagree will be dismissed with the single word "wrongheaded," to cite one example.10 Another manifestation derives from the sense that, since one is an "authority," the things one says have an importance which goes beyond their scholarly substance, and that one is therefore obliged always to be "responsible" in a sense which goes beyond intellectual responsibility to one's discipline. Hence much of what Packer advocates on the purported level of principle seems to reflect little more than advance accommodation to his own judgment as a practitioner of the "art of the possible." One has no idea how accurate a political seer he may be, but a more fundamental cause of my disquiet at such a scholarly procedure is my conviction that clear thinking about ultimately difficult questions is not helped by the creation of "models built on the sand of anticipated compromises." 20

\section{Part I-The Nature and Justification of Punishment}

\section{A. The Relationship of "Rationale" to Doctrinal Content}

It is not until pages 71-72 that the objective of the first third of the book is made explicit. Packer will try to derive "a model of the minimal doctrinal content of a criminal law belonging to no particular time or place" 21 from the "rationale of the criminal- law."22 The first half of the Part consists of Packer's statement of that "rationale," and the latter half treats its doctrinal derivations-the rules of criminal responsibility (that is, the rules which determine liability to punishment).

Packer claims originality for the exercise, 23 but I think this claim is

18. This conception vas recently sanctified on the editorial page of the New Yor: Times by Anthony Lewis: "[A] moderate man of the highest reputation for professional care in what he says ...."Feb. 23, 1970, at 26, col. 4.

19. See note 210 infra and accompanying text. Cf. also Packer's review of $K$. MlEsninger, The Crime of Punlshaient (1968), Enemies of Progress, N.Y. Review of Books, Oct. 23, 1969, p. 17, for an extreme example of the combination of authoritative tone and lack of substance.

20. R. Donneliy, J. Goldstem \& R. Schwartz, Crammal Lay 4 (1962).

21. P. 71.

22. P. 70.

23. P. 72. ("The originality, such as it is, inheres in the view that they [culpability doctrines] are joined and should be judged by their common propensity to adjust the dictates of crime prevention to the demands of a legal system that makes individual freedom the prime value.") 
unwarranted. $\mathrm{He}$ is by no means original in trying to connect the rules of criminal responsibility with a conception of the way in which the practice of punishment can be justified. Holmes' elegant attempt, for instance, is famous. Holmes sought to reduce the theoretical structure of criminal law to a Justifying Aim of Prevention by Deterrence. The rules of criminal responsibility that followed from such a "rationale" were qualified only to the extent of allowing excuses for mishaps which the "reasonable man" could not, with reasonable prudence, have avoided, because Holmes believed that without such assurance against liability the "reasonable men" who compose the bulk of the community would find the criminal law intolerable. ${ }^{24}$ Nor is Packer original in deriving the rules of criminal responsibility from the particular conception of the "rationale" of the criminal law which he propounds (i.e., that while the "central goal [is the] prevention of socially undesirable behavior, [it must be] limited [in its implementation] by restrictions of culpability"). ${ }^{25}$ H.L.A. Hart has done the same thing, in a far more sophisticated way, in two well-known articles. ${ }^{20}$

It is essential, when beginning the sort of jurisprudential effort which Packer undertakes, to have a clear idea of the basic logical structure of the argument which is the object of the enterprise. It is quite apparent from the book, however, that Packer did not address himself with any care to this preliminary sine qua non. This failure reflects itself in a critical grammatical mistake -and bad grammar, like the maltreatment of words, is intimately connected with bad thinking.27 On the very first page of the book, Packer introduces his central concept-the "criminal sanction"-in a passage in which a demonstrative adjective's unclear referent initiates an obscurity of meaning which persists throughout the rest of the book. He will discuss, he says, "the problem of trying-to control anti-social behavior by imposing punishment on people found guilty of violating rules of conduct called crim. inal statutes. This device I shall call the criminal sanction." Which device? Sometimes Packer seems to mean "criminal punishment" when

24. O.W. Holmes "The Criminal Law," in The Common LAw (1881).

25. P. 71.

26. H.L.A. HART, Prolegomenon to the Principles of Punishment, and Legal Respon. sibility and Excuses, in PUNISHMENT AND RESPONSIBInTY (1968) [hereinafter citations to this collection of essays will be by page number only unless identification of a particular essay is necessary]. Hart's views in this regard are discussed more fully at pp. 1418, 1451-53 infra. Cf. also H. Hart, The Aims of the Criminal Law, 28 L. \& Conremp. Prous. 401 (1958).

27. See ORwerc, Politics and the English Language, in 4 CoLLECTED EssaYs, ETC. 127 (1968).

28. P. 3 (emphasis added). 
he says "criminal sanction."28 Sometimes he seems to mean the entire complex of the criminal law-the substantive prohibitions, the procedural structure of enforcement, and the use of punishment as the means of enforcement. ${ }^{30}$ Other times he seems to mean the substantive law and the penalties for its violation, by contrast with procedural law. ${ }^{31}$ Thus encapsulated in a grammatical oversight is a failure to make some elementary distinctions between different aspects of his subject matter. ${ }^{32}$ The discussion of justification can hardly proceed when it is at all times unclear precisely what it is that is to be justified.

Another reflection of Packer's inattention to the logical structure of the enterprise is his persistent misuse of words like "purpose" and "justification," his tendency to obscure all distinctions with words like "rationale," and his frequent failure to perceive the difference between an argument and a definition. For example, toward the beginning of the book he says that on the Retributive view, "The purpose of punishment is to inflict deserved suffering." 33 But this is not the purpose of punishment, it is one version of its definition. Infliction of deserved suffering might be thought to be the justifying purpose of the criminal law, but not of punishment. ${ }^{34}$ In making this basic mistake, Packer obscures the fact that on the pure Retributive view there is no purpose of punishment-punishment is the purpose, because infliction of "deserved suffering" is a moral imperative. To speak of the "purpose of punishment" on the Retributive view is therefore to speak about the "purpose" of the purpose of the criminal law. This mistake is crucial since it underlies Packer's inability to give a coherent account of Retributivism ${ }^{344}$ or to understand the relationship of Retributivism,

29. E.g., pp. 3, 250-51.

30. E.g., Part III.

31. E.g., p. 4.

32. An analogous confusion occurs on pp. 9.11, where "punishment," "the criminal process" and "the criminal sanction" are used interchangably in a discussion of "justifications" and "purposes"- which are also used as if they meant the same thing. "The reader is left with only the vaguest idea as to what is being compared with what.

33. P. 10.

34. Packer repeats this error later on when he refers to "the deseried infliction of suffering" and "the prevention of crime" as the only ultimate "purposes" of criminal punishment, and says he disagrees with the view that "one or the other of these purposes must be justifiable to the exclusion of the other." (p. 30) It is ccrtainly a confusion to think that there is any "justification" for the "deserved infliction of suffering" in quite the same sense that there is a "justification" for "the prevention of crime." And it is mistaken to think of the former "justifying" something in the same sense that the latter can. Cf. Benn, An Approach to the Problems of Punishment, 33 Pulosophy 325, 327 (1953). At $p$. 33, the same confusion is built into the very definition of punishment. Note that Packer is also failing, here, to apply the General Justifying Aim/Distribution distinction -see p. 1418 infra. And see pp. 1418-19 infra for discussion of Packer's accoune of Retribution.

34A. See pp. 1418-19 infra. 
as a purported justification of the practice of punishment, to the Utilitarian insistence that suffering is in itself an evil and that there must therefore always be some justifying purpose for the intentional infliction of suffering - a future-looking objective, some way in which the world will be a better place as a consequence. The confusion of definition with purpose is endemic in the book-another example occurs when, having argued that the justifying purpose of punishment is the prevention of offensive behavior, Packer is thereupon wont to describe any sort of practice with such a purpose (e.g., civil commitment) as "punishment," 35 overlooking the important possibility that a single justifying purpose might well underly a number of different practices. ${ }^{36}$ This kind of primitive logical mistake is like concluding from the fact that the purpose of a roof is to keep out the rain, that all things which keep out rain (raincoats, umbrellas) are really roofs.

The elementary logical form of the intended argument is as follows: Given an acceptable justifying purpose (such as the reduction of defined types of offensive behavior or the proportional infliction of evil for evil committed) can the practice of punishment, defined in terms of its rules of implementation (i.e. the "doctrinal content" of the criminal lawthe rules of responsibility), be justified-that is, can it be shown that such a practice will serve the justifying purpose, without disproportionate sacrifice of other purposes (e.g. avoiding an undue "chilling effect" upon activities contiguous to those which are prohibited), and (perhaps) without conflicting (unduly) with whatever fundamental nonUtilitarian principles may obtain as limitations on the pursuit of the justifying purpose with such a practice. ${ }^{37}$ Or, in the slightly different

35. See pp. 1408-09 infra.

36. See pp. 1409-11, 1451-53, and note 62 infra.

37. I add this last qualifying, and explicitly non-Utilitarian consideration in deference to H.L.A. Hart's views (see his Prolegomenon to the Principles of Punishment) and to my own uncertainty concerning the nature of and the need for any such consideration (see notes 38, 219, and 270 infra). My own view is that most-and perhaps all-of the excusing conditions which Hart thinks can only be accounted for on the basis of non. Utilitarian restrictions on the Distribution of punishment in fact serve extremely im. portant Utilitarian ends, and thus are to be accounted for as qualifications on maximization of Prevention as the purpose of the practice because of the impingement of other purposes which would unduly be sacrificed by the single-minded pursuit of Prevention. Sce note 38 infra.

To the extent to which fundamental principles account for restrictive rules in the implementation of a practice, those rules can be derived by purely logical means-whlch is what Packer apparently thinks he is trying to do. To the extent to which it is the impingement of other purposes which requires that the practice of punishment optimize the total mix of purposes, of which prevention is only one, rather than maximizing prevention (see note 38 infra), the enterprise of accounting for the rules of criminal responsibility will have to have a heavily empirical orientation: we will have to find out exactly what the effects on other purposes would be of different possible rules of criminal responsibility. Practically nothing is known, in criminal law scholarship, about such 
format of Packer's discussion, given a purpose such as prevention and a generically-defined practice such as punishment, what more specific rules of implementation are required in order that other purposes not be unduly sacrificed and that relevant fundamental principles not be compromised (i.e. what "doctrinal content" can be derived from the "integrated rationale"). I shall keep to this simple analytic outline hereafter-even though to do so while discussing Packer's argument is usually to impose upon it a coherency not its own-because this is the only way to avoid analytic chaos.

With that clearing of the logical decks, we can turn to the argument of Part I. It is substantially vitiated by a fundamental circularity, which is concealed from the reader (and, one gathers, from Packer himself) by the argument's chaotic organization. Packer says that because of the "moral ambiguity of punishment" we cannot accept any "purely Utilitarian" practice of punishment (by which he means such a practice designed only for maximization of "the narrow Utilitarian objective of reducing the incidence of criminal behavior")..$^{38}$ In order

a fundamental question-and this puts us, I suppose, in a condition roughly analogous to that of Mercantilist economic theory.

38. P. 63. Note that even in this phrase there is important circularity: how do we know what behavior we are trying to prevent until we know what it is to be "criminal"? Even "the narrow Utilitarian objective" includes, that is, principles of responsibility. This is a fundamental point-one which underlies my disagrecment with H.LA. Hart, and, to the extent that Packer intelligibly follows Hart, with Packer. See pp. 1451-53 infre. It will not do to say that "criminal behavior" refers only to certain externally. describable kinds of conduct, because there is little or no such conduct that we could possibly want to prevent altogether.

\section{Note: Toward a Restructured Utilitarian Account of the Mode-of-Culpability Excuses}

To follow Calabresi's terminology from torts (see Calabresi, The Decision for Accidents: An Approach to Nonfault Allocation of Costs, 78 HLRv. L. REv. 713, 716-21 (1965)), we seek to optimize the amount of conduct likely to lead to undesirable ends, not to minimize it. The criminal law is the archetypical case of what Calabresi calls "specific deterrence"-of seeking to prohibit an activity altogether, rather than merely to the extent it cannot bear its "costs." Hence our device for optimization cannot be the market; that role in criminal law is played by the rules of responsibility.

We do not want, for example, to prevent or even to discourage all kinds of conduct that predictably lead to death. Winfield tellingly observed of the idea of strict liability. of making a man "act at his peril," that

[I]t means that whatever a man does will, if it injures someone else, make the doer guilty of a breach of law for every conceivable harm which he inflicts on another ... Such a proposition is merely ridiculous. Life would not be worth living on such terms. Life never has been lived on such terms in any age in any country.

If a man always acted at his peril, the whole community would be in gaol but for three obstacles. No one could legally build the gaol, no one could legally send people to it, and no one could legally keep them there.

Winfield, The Myth of Absolute Liability, 42 L.Q.R. 37, 38 (1920). The point is that we have to leave room for the inevitable untoward consequences of desirable behavior: for accidents, for self-defense, etc. The business of the rules of responsibility, in law and in morals, is to determine the point at which the risk of obnoxious consequences outweighs the importance of the behavior involved (with its associated "mental" element). Intentional killing without excuse or justification is the clear case; reclilessness with 
to safeguard fundamental principle, we have to qualify, in the rules of implementation, our pursuit of such a Utilitarian (Preventive) justify-

respect to the death of another is also usually separable from any activity which we regard as desirable. Negligence is a harder case, and may, if adopted as the mode of culpability, involve a significant "chill" on desirable activity, since, as H.L.A. Hart has argucd, the ability to predict freedom from criminal responsibility is important to people. This relationship between modes of culpability and the willingness of people to cugage in desirable activities is occasionally recognized explicitly in our jurisprudence. See New York Times Co. v. Sullivan, 376 U.S. 254 (1964); Garrison v. Louisiana, 379 U.S. 64 (1961). See generally, for the analysis in torts, G. CalanRest, THE Costs of Accidents (1970). Cf. also Michael \& Wechsler, $A$ Rationale of the Law of Homicide I, 37 ColUM. L. IRev. 701, 749-52 (1937).

Another, more general way of stating the above point is to observe that "crime is the price we pay for social arrangements which are dear to us." (Nils Christie, in a Russell Sage Program seminar, Yale Law School, Fall, 1969; cf. also N. Mokkis \& G. HiwkiNs, supra note 2, at 48.49.) It is very close to absurd to speak of creating "on a large scalc the essentials of a society that produced no crime" (p. 55), even as an ideal. The "soclal arrangements" whose cost is crime are of two sorts: those extrinsic to the crimillal law (e.g., the way goods are displayed in department stores; see M. Cameron, TIIE

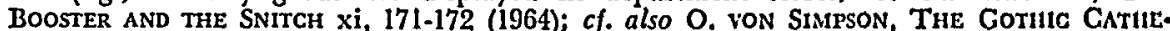
DRAL 167 (paper ed. 1964) and see, for the relevance of extrinsic factors genterally, Schwartz, Social Faclors in the Development of Legal Control, 63 YALE L.J. 471 (1951); W. Bonger, Criminality and Economic Conditions (Turk ed. 1969), and those intrin sic to it, such as the law of excuses.

The above suggestions toward a Utilitarian account of some excusing conditions (of the mode-of-culpability sort-cf. p. 1443 and note 219, infra, for the distinction between these excuses and those of the opportunity-to-conform varicty) opens up many avenues for inquiry. The problem is to discover precisely what the differences are between the modes of culpability, so that we can isolate the Utilitarian considerations involved in the choices among them (cf. note 37 supra). It is symptomatic of the analytic slovenliness characteristic of criminal law scholarship that it is almost impossible to find any discussion of such a basic question, at least since Holmes, which goes much bcyond propositions of the sort: crimes of negligence differ from crimes of intent in that a person is liable if he causes harm negligently. Surely it is clear that no genulne understanding can be built upon that sort of phlogiston-analysis.

To begin with, let us get our archetypes of the modes of culpability straight:

(1) $\Delta$ shot his pistol; $V$ died.

(2) $\Delta$ shot his pistol; without due care; $V$ died.

(3) $\Delta$ shot his pistol; with intent to kill $V_{i} V$ died.

These archetypes of strictness, negligence, and intentionality as modes of culpability in homicide make several things clear. $\triangle$ 's activity (let me call it that) is the same-shooting his pistol. The consequence on which liability turns is the same- $V$ must dic. (1 put "danger delicts" and the like to one side.) The archetypes look as if they highlight what is different about strict liability: in archetype (1), nothing intervenes in the formulation between activity and result-the two together are sufficient.

Two preliminary points: There is action-at-one's-peril in all three cascs-if $\Delta$ "does" everything up to the final semi-colon, he does so "at his peril," since from then on his liability is out of his control and depends on the fortuity of V's death. Liability is "subjective" to some extent in all three cases, if it is in any. $\Delta$ has, for cxample, to have known he was shooting. Cf. Wasserstrom, Strict Liability in the Criminal Law, 12 STAN. L. Rev. 731, 742 (1960); cf. also The Limits of the Criminal Sanction 126, and noto 233 infra.

A major point of Wasserstrom's article, supra, is that despite superficial appearances, negligence and strict liability actually differ only in the description of the conduct from which liability (absolutely) follows if the evil materializes ("V dies"). Id. at 744.45. The "negligence" part of archetype (2) ("without due care") is simply a refinement of the activity which the actor does at his peril. Archetype (2) can be reformulated: " $\triangle$ shot his pistol without doing $a, b$ and $c ; V$ died" ("a, b and $c$ " being the things one has to do not to be negligent in the shooting of a pistol-that is, the conditions absent which the risk of death is unreasonably high). Cf. pp. 1446-48 infra, for the conception of negligence from which this follows.

Wasserstrom concludes that liability for negligence is not morally different from strict 
ing purpose by the "concept of culpability" - "the criminal law's traditional emphasis on blameworthiness as a prerequisite to the imposi-

liability because neither, by contrast with a crime of intention, involves as an element "the defendant's state of mind." Id. at 744. I have observed above that actually both involve one sort of "subjective" element in the same way that crimes of intent do. But Wasserstrom is suggesting that there is an additional "state of mind" clcment for crimes of intention, going beyond the excuses which form part of the definition of the prohibited activity itself (e.g., shooting the pistol, or doing so without doing $a, b$, and c). This can only be true if we cannot reformulate archetype (3) so as to include only a statement of an activity and a result (as we were able, following Wasserstrom, to do for archetype (2)). I believe we can make such a reformulation, and that in doing so we will see that Wasserstrom's failure to extend his analysis to crimes of intention is based on an inappropriate idea of the place of the mental element in the statement of an offense, and an implicit failure to perceive the Utilitarian function of the mental clement.

But first we must return briefly to negligence and strict liability. As Wasserstrom observes, crimes of strict liability can be divided into those in which we wish to deter the activity out of which they come, and those in which ve do not-let an instance of the latter be called a "neutral" activity. In the former case, the traditional Utilitarian arguments against strict liability do not work, as Wasserstrom shovs. Id. at 786-40. Our objections to R. v. Prince, [1875] L.R. 2 Cr. Cas. Res. 154, if we have any (cf. note 219 infra), cannot be that strict liability would not effectively deter, because it would (cf. pp. 1445-46 infra), nor that it would over deter (the activity of taking a girl from her father's custody without his consent not, the court held, being a neutral onc). In the case of a neutral activity (take "shooting a pistol" to be one), strict liability differs from negligence in that one cannot state precautions that the actor can take in engaging in the activity which will guarantee him safety from liability. That is just another vay of saying that it is the base activity ("shooting a pistol") plus the conditions of negligence in doing it, which are the relevant "activity" - the activity from which liability strictly follows-if negligence is the mode of culpability. A person who wants to shoot his pistol without doing $a, b$ and $c$ cannot-when negligence is the mode of culpability -be told what precautions he can take to guarantee himself freedom from libbility: And there is no Utilitarian objection a priori to such strictness because the base activity plus the conditions which make it negligent is not neutral, it is undesirable. If, in short, we prefer negligence to strict liability for the base activity "shooting a pistol" it is because we only want to deter that activity when it is not neutral, when the negligenceconditions exist. We want the neutral activity to be freely open to those who believe they can satisfy the conditions of non-negligence. Hence the Utility of negligence as a mode of culpability: because it focuses on a narrow activity as the object of deterrence (or, to use a more familiar locution, focuses on an activity only if done in a particular way), it does not have a "chilling" effect on activities that we deem neutral. But it does not differ from absolute liability in any fundamental way-it is simply another way of describing the activity which an actor engages in at his peril.

Returning to crimes of intention: is it not now apparent that intentionality as a mode of culpability does not have to be accounted for in terms of a "state of mind"- -that it is a further, more refined focusing, a further limitation on the chilling elfect of deterrence? Negligence differs from strict liability in that the conditions under which the base activity can be freely engaged in can be stated. But there is always the risk of failure: with the best of will, careless accidents and mistakes will happen; $\mathbf{a}, \mathrm{b}$ or $\mathrm{c}$ will be omitted; and if injury follows there will be absolute linbility for it. Negligence as a mode of culpability is likely to deter the timid from engaging in the ncutral base activity. If we do not care much that such chilling take place with respect to the neutral activity, we will be satisfied with negligence despite the chill. But if the neutral activity is one we do not want to chill, we will have to specify further the activity which is done at peril, so that the risk of criminal liability, which one is freely engaged in the underlying neutral activity, will be easier to avoid with relative certainty than it viould if the mode of culpability were negligence. We can translate the middle element of archetype (3): "intent to kill $V$ " is the negation of a varicty of excusing conditions (mistake, accident, etc.). Only if a person "shoots a pistol" and satisfies the conditions of non-mistake, non-accident, and the like, does he act at his peril. When these conditions are satisfied, the behavior concerned is most highly associated with the ultimate evil and punishing it will have the least chilling effect on the underlying neutral activity; thus 
tion of punishment." 39 His definition of the principle of "culpability" as a limitation in implementation on the justifying purpose of maximum Prevention is: "those aspects of human conduct, as defined by the legal system, that serve, or ought to serve, as excuses for exemption from criminal punishment." 40 Through the murkiness of this sentence, one thing at least is fairly clear: his "integrated rationale" is Utility as justifying purpose, limited in implementation by the principle of Culpability; and Culpability consists of the law of excuses. Naturally it takes very little argument to derive the "minimal doctrinal content" of the criminal law from a "rationale" which includes it from the first.

What is missing from Packer's argument is a middle-step-a funda* mental limiting principle of culpability whose importance he can demonstrate and which is independent enough of particular rules of implementation- "doctrinal content"- so that it is possible to derive what those rules ought to be by reference to the underlying principle. There are two ways in which one might seek to reconstruct such a middle step from Packer's meanderings, so as to save his argument from a trivial circularity.

First, perhaps he never meant to suggest that there is a general limiting principle, called the "concept of culpability," but only to refer to an assortment of particular limitations on the maximization of Prevention. If so, the second half of Part I cannot be a "derivation" from an independently established principle; it has to be a series of separate arguments for discrete rules of exculpation. The trouble is, there are no such arguments; each piece of "doctrinal content" is justi-

intentionality is the clear case for the Utilitarian justification of the use of punishment as a means of social control.

If this is correct, it is apparent that Wasserstrom's argument has to be carried forward to the proposition that it is considerations of relative Utility which ought to underlle choices from among all three modes of culpability. He is wrong in putting intentionality in a special category, involving the unique element of a "state of mind." (Cf. pp. 1440.41 infra on the notion of a "state of mind" and its relation to the internal/extcrnal standard confusion.) The mental element is attached to the activity which is done at one's peril, in each of the three archetypes. It is applicable to the underlying activity (shooting a pistol-e.g., knowledge) and to the additional conditions which may go to produce an undesirable, done-at-one's peril, activity (checking out the surroundings, or aiming at $\mathrm{V}$, for negligence and intentionality, respectively-knowledge, e.g., is an clement of both).

It does not seem to me it is necessary, for purposes of the argument sketched here, to settle the question whether the "mental element" which all three modes involve is the same (I suspect knowledge and capacity for control are all that is required, and that things like further intentions can be formulated as part of the additional conditions which intentionality adds to an underlying neutral activity-cf. note 194 inf/ra); nor whether it is to be "objectively" or "subjectively" determined (cf. in this last regard, O.W. HoLmes, supra note 24; Hughes, One Further Footnote on Attempting the Impose sible, 42 N.Y.U.L. REv. 1005 (1967)). It is, however, necessary to accept the proposition that sufficient knowledge of probable consequences amounts to intentionality, for this analysis to work. $C f$., in this connection, H.L.A. HART, supra note 26, at 120.27 .

39. Pp. 65.66.

40. P. 64 . 
fied only in terms of its supposed relation to "culpability." On the assortment interpretation of Packer's culpability limitation, his argument thus ultimately rests on a series of simple and identical ipse dixits. For instance, culpability, one of whose constituents is the limitation of the criminal law to conduct, is important, Packer tells us, because "it establishes a firm basis for resisting the attenuation of the offense as a component in the definition of punishment ... unless [a man] has committed an offense, unless he has done something rather than merely been something, we cannot say that he has been culpable." 41 The conduct limitation, to be shorter and blunter, is important because it restricts the criminal law to conduct.92 In a similar way, mens rea is important because otherwise we would punish people who are not culpable-i.e., who lack mens rea. ${ }^{33}$

The second way to try to give content to Packer's "concept of culpability" is to sift through his writing looking for fragments of an argument for a general principle of "culpability" from which particular excuses (rules of implementation) could be derived. Such an argument woud have, necessarily, to give some concrete content to "culpability"- -that is, to define it-so that it could be used as a starting point for the derivation of particular excuses. We are, therefore, considerably discouraged in our search when Packer announces that he will "not try to define culpability," but will only "describe" it by pointing to the excuses of which it consists.4" If we get over the hurdle that Packer seems to be denying the existence in what he writes of just the sort of argument we need to find, I think it is possible to discover hints of two quite different accounts of "culpability."

First, there is his idea that culpability is a principle which prevents us (those who punish or justify punishment) from being hypocrites. $\mathrm{He}$ invokes the theme of "hypocrisy" several times during his discussion of excuses. For example, of the claim of excuse based on the actor's reasonable but mistaken belief in the necessity of what he did, Packer observes: "If the actor has behaved like a reasonably prudent but unheroic man, it would be hypocritical for other reasonably prudent but unheroic men to punish him." 45 Such use of the notion

\footnotetext{
41. P. 68 .

42. See also pp. 74-76, discussed pp. 1432-33 infra.

43. At several places Packer virtually concedes that nothing more than ipse dixitism underlies the law of excuses which he purportedly derives from his "rationale." For example: "It is only because we choose to indulge our sense of moral fitness that we reoognize this particular excuse." (p. 118)

44. P. 64.

45. P. 119.
} 
of "hypocrisy" in discussion of criminal responsibility-as if its meaning were clear and its relevance obvious-is a sort of received tradition, and Packer subjects it to no critical analysis. However, there are at least two doubts to be raised about it. First, rejection of such an excuse is not necessarily hypocritical at all: If I refuse to acknowledge the adequacy of a particular excuse I may do so on the ground that if I were to exhibit the same failing I ought to be punished too. Second and more importantly, is it really so clear that anything the man of ordinary prudence and resolution might find himself doing ought not to be punished? Starting at least with Holmes ${ }^{46}$ this has been assumed, variously on Utilitarian or Retributionist grounds. The assumption seems to be connected with our inclination, in punishing, to condemn the man instead of the crime. ${ }^{47}$ We could not think in this way so easily if we entertained the possibility of an ordinary man being the object of punishment. I should like to raise two questions about the assumption. Without getting into the elaborate question of how far the law ought to try to effect changes in common morality, are there not times when both the law and common morality insist that, however understandable, the weaknesses of the common man are to be condemned? Is there not wisdom which deserves consideration in the observation of Lord Coleridge, in Regina v. Dudley ir Stephens, ${ }^{48}$ that a judge should not necessarily hesitate to condemn weaknesses he himself might have suffered from in the same circumstances? Is there not a kind of hypocrisy in our current insistence that a judge must not participate in original sin?-prehaps the idea of criminals convicting criminals is not fantastic at all, but attractive. If we recognized the common man (or the common judge or the common politician) as a potential criminal, we might treat him more fairly and more reasonably when his potentiality matured. But the received assumption which Packer uncritically repeats forecloses this by making the "criminal" necessarily an uncommon sort of person; the "ordinary man," almost by definition, cannot be a "criminal," and he can therefore all too easily think that crimes are exclusively the affairs of extraordinary men.

The second questionable feature of Packer's assumption that something the ordinary man might do ought not to be punished is the curious paradox at the heart of the matter of excuses which the invocation obscures. On the one hand, we can only punish a person if-in a certain sense-we can imagine ourselves doing the same thing in the same sit-

46. O.W. HoLmes, supra note 24.

47. See Griffiths, supra note 17 , at $385-86$.

48. 14 Q.B.D. 273 (1884). 
uation; if we cannot, the man is mad and gets treatment instead of punishment. To recognize an offender as responsible, that is, is to recognize him as like oneself in the relevant respects.40 On the other hand, it is just those situations in which we feel that we, too, might easily have fallen (e.g., negligently, or under provocation), in which we are inclined to allow excuses or to inflict only a small punishment. Our sense of the things for which a man ought to be held accountable thus seems to occupy some mysterious space between what we cannot imagine ourselves doing and what we can imagine ourselves doing. Our sense of this space, I suggest, is mentally labelled: "I doubt I would do it, but I might; and if I did, I ought to be punished."

Still, perhaps it is possible to discern in Packer's concern about what he calls hypocrisy the germ of a Holmsian thesis: "culpability" is the law's deference to the weaknesses and the morality of the ordinary man, lest he come to think its rules too much for him to bear-a mitigation of Prevention in the name of tolerability.51 That would give us a definite principle of culpability and thus a clear indication as to how to set about deriving particular excuses. But Packer does not in fact try to show a Holmsian necessity for the excuses he insists upon. Furthermore, a Holmsian principle of culpability is not a non-Utilitarian principle imposing a constraint on the maximization of the justifying purpose of Prevention: it is simply a prudential caution concerning the appropriate design of a practice of punishment in order to achieve such maximization.2 Hence the notion of hypocrisy does not afford a basis for the sort of "integrated rationale" Packer seeks to create.

The second possible hint toward an account of the principle of culpability resides in Packer's frequent invocation of the word "autonomy." Unfortunately, although it may be an essential link in the

49. Cf., for the opposite side of this coin, Schwartz, supra note 38 , at 483 ("viarious learning depends upon the extent to which an observer perceives himself as similar to an observed actor").

There is a negative pregnant in the received dogma about hypocrisy which $\rightarrow$ on a moment's reflection-is obviously false: that things the ordinary man would not have done, we do punish. Plainly many excuses go to things that the ordinary man would not have done. It is probably the case, even, that most succesful "accident" cxcuscs are invoked by extraordinary men-thus it is the well-known problem of accident-proneness which, among other things, underlies Barbara Wootton's argument that the inens rea excuses should be eliminated so that we can deal with the social danger presented by the peculiarities of those people who have preventable "accidents." See B. Woorron, Crime and the Criminal Law (1963).

50. The paradox mentioned in this paragraph was first brought to my attention by A. Freedman, during a discussion in a Criminal Law class at the Yale $L a w$ School.

51. O.W. Holmes, supja note 24, at 50-51, 56-57. See also Michael \&. Wechsler, supra note 38 , at 749 .

52. See note 38 supra. 
understanding of his argument, he never makes an effort to give it any substantial content. The law of excuses, he tells us, has "to do with preserving human autonomy and with maximizing the opportunity to exercise choice," rather than with the Utilitarian goal of crime prevention. ${ }^{53}$ Culpability rests upon "the notions ... of free will and human autonomy ... [not] in any deep philosophical sense but in a contingent and practical social sense ... . Very simply, the law treats man's conduct as autonomous and willed, not because it is, but because it is desirable to proceed as if it were." ${ }_{54}$ The criminal law is restricted to voluntary conduct "primarily in response to the simple intuition that nothing would more surely undermine the individual's sense of autonomy and security than to hold him to account for conduct that he does not think he can control."vs These quotations show both his use of the concept in his account of culpability, and his failure to indicate what he has in mind by it.The "autonomy" which the culpability rules preserve is, one gathers, related in some way to the notion of "free will" and to the individual's belief that he has "control" over some (but not all) of his behavior and its results. The nature of this "autonomy" and the reasons for respecting it are discussed only in a few brief sentences:

People ought in general to be able to plan their conduct with some assurance that they can avoid entanglement with the criminal law .... It is precisely the fact that in its normal and characteristic operation the criminal law provides this opportunity ... to people in their everyday lives that makes it a tolerable institution in a free society .... If we leave to a purely utilitarian calculus the decision whether a man's innocence or ignorance shall count for him, the answer on any occasion will be uncertain. Only by pro. viding the shield of the culpability requirement can this desirable aspect of the criminal law be preserved. ${ }^{50}$

53. P. 112. Elsewhere he observes that "the test of law, including the criminal law, must in a free society be ... its success in promoting human autonomy and the capacity for individual human growth and development." (p. 65)

54. Pp. 74-75. The circularity of the reasoning by which he purports to support this idea is discussed pp. 1432-33 infra.

55. Pp. 76-77. In this respect, he says, "the criminal law is far more respectful of human autonomy than is the law dealing with mental health." (p. 77)

56. Pp. 68-69. N.B. the question begged with the word "innocence." It secms these sentences must be intended to elucidate his notion of "autonomy," although he does not invoke that otherwise overworked word in this particular passage.

Packer not only leaves the critical concept of "autonomy" almost wholly undeveloped, he affirmatively confuses it by also using the same word for another purpose, whose connection with its use as the crux of his account of "culpability" is unclear. See pp. 94, 96 (the power to "call conduct into question as criminal" imports "the destruction of human autonomy"; it is the "uneasy role" of law enforcement officials "to interfere with human autonomy'”. 
H.L.A. Hart, in several passages from which this plainly derives, has argued that the law of excuses in the rules of implementation (Distribution) of the practice of punishment can be accounted for in terms of the importance of the non-Utilitarian principle of respect for the individual's sense of his capacity to exercise choice and his power to control his behavior so as to steer clear of the criminal law if he so chooses.57 That is a position from which one could perhaps derive a set of rules of criminal responsibility. But Packer does not elaborate upon the ideas of choice and control at all nor show why they deserve respect, and he never makes any effort to show how the excuses he takes up are part of a general scheme in which the individual's sense of his powers of choice and control is respected. In short, if Packer is advocating a coherent single principle as the underlying basis for the law of excuses, and if that principle is what he has in mind when he uses the word "autonomy," he has failed the reader in several respects: (1) in not saying so clearly; (2) in failing to elucidate the notion of autonomy; (3) in failing to show that, whatever it is, it is important and is related to the "rationale" of the criminal law; and (4) in failing to show how the law of excuses derives from the principle.

To recapitulate: The central theme of the first Part is the derivation of the doctrines of criminal responsibility (rules of implementation of the practice of punishment) from the "integrated rationale" of the criminal law (prevention as a justifying purpose, limited by the dictates of a non-Utilitarian principle of culpability). Packer's effort to do so is vitiated, however, in one of two ways. On the preferred reading, his argument is fundamentally circular, because the fundamental principle of culpability which, as part of the "integrated rationale" of punishment, requires that excuses be allowed in implementation, is itself defined only in terms of the excuses themselves-that is, in terms of the very things which are to be accounted for. On the alternative reading, the principle of culpability does have some independent existence, so that excuses are not derived from it by trivial circularity, but that independent existence lies latent in the notions of "hypocrisy" or "autonomy," either of which might contain the germ of an interesting account of the principle of culpability from which rules of implementation of the practice of punishment might be derivable, but neither of which receives any elucidation nor is made the basis for a systematic law of excuses. ${ }^{58}$

57. See H.L.A. HART, supra note 26, at 22-24, and 44-50. But I do not agree with Hart that such a non-Utilitarian principle is required. See pp. 1451-53 infra.

58. Excuses by no means exhaust the rules of implementation (the ex post facto restric- 


\section{B. The Definition of "Punishment"}

Having discussed the basic flaw at the center of Packer's argument, it is possible to turn to the argument's two parts: "rationale" and "doctrinal consequences" of "rationale."

Packer's discussion of "rationale" begins with a definition of the key word "punishment"- the name of the practice whose justifiability and whose rules of implementation are at issue. Packer begins by adopting but misinterpreting H.L.A. Hart's definition. He thereafter makes a superfluous and mistaken addition to Hart, criticizes others for defining punishment in the same way he himself does, violates his own bit of added definition, and worst of all, violates the central restriction of the Hart definition he adopts. The consequence of all of this confusion is both obscurity and failure to confront some of the basic jurisprudential problems concerning the nature of the justification of punishment.

Packer tentatively adopts the definition of the "standard case" of punishment given by H.L.A. Hart (as derived from others), which, in condensed relevant part is: a pain or other unpleasant consequence imposed on an offender for his offense against legal rules. ${ }^{69} \mathrm{He}$ finds, however, that it gives rise to "formidable difficulties that have been surprisingly ignored in recent discussions of the subject." 00 He puts three cases-injunctions, tort recoveries, and civil commitments-and contends that although they do not properly qualify as "punishment," they fit the proposed definition. ${ }^{01}$ "It is," he says, "undeniable that [the defendants involved] are being subjected to unpleasant consequences 'for an offense." "62 I think, on the contrary, that the restriction

tion, for example, is such a rule-but it is not an excusc), but Packer procceds as if they were, so I have followed the equation for present purposes.

59. P. 21. See H.L.A. HART, supra note 26, at 4-5.

60. P. 21 .

61. P. 22.

62. Pp. 22-23. In a footnote, Packer says he will not allow "that philosophical ploy known as the "definitional stop" " to preclude him from quarreling with the meaning put on the words "of an offender for his offense" in H.L.A. Fart's account of the meaning of the word "punishment." (p. 22 n.3) Packer thus uses the concept of a "definitional stop" to refer to a mere disagreement over the adequacy of a word to convey a substantive meaning about which, it subsequently appears, there is no dispute. Flis invocation of the concept is in apparent oblique reference to an argument made by Hartnamely that the problem of the justifiability of the punishment of an innocent person for the public good (the favorite bone between the contenders for Utilitarian and Retributive positions on criminal punishment) cannot be settled for the Utilltarians by the "definitional stop" of arguing that knowing infliction of pain on an innocent man is not "punishment." (H.L.A. HART, supra note 26, at 6.) The term "definitional stop" thus denotes a definitional escape from a substantive question.

A few pages later, Packer again invokes the concept, this time in the text, with respect 
to offenders for their offenses is quite adequate. At the very least, the restriction contemplates the supposed existence of an antecedent offense as a necessary condition for a case of punishment; and it supposes some sort of relationship between the nature and severity of the sanction, and the offender and his offense. ${ }^{63}$ Injunctions are not granted because of an offense, but to prevent threatened offenses (the existence of an offense is not a necessary condition, although it is often probative as to the threat). The same is true of civil commitment. Tort recoveries are not "for an offense," either in the sense that proof of an offense is always a prerequisite (at least since the day when the Ives case ${ }^{\text {ot }}$ was good law) or in the sense that damages are assessed in relation to the offender and his transgression.

To meet the supposed difficulties in distinguishing injunctions, tort recoveries and civil commitment from punishment as Hart defined it, Packer adds to Hart's definition the requirement that punishment "must be imposed for the dominant purpose of preventing offenses against legal rules or of exacting retribution from offenders, or both."05 To the extent that this merely emphasizes that an offense is a necessary prerequisite, and that there must be a relation between offense and deprivation, it is merely redundant. To the extent that Packer thinks this added language restricts punishment to Prevention and Retribu-

to Barbara Wootton's observation that even an enlightened lawjer like H.I.A. Hart is "wholly unable to envisage a system in which sentence is not automatically equated with "punishment.'" (B. Wootron, supra note 49, at 50.) Taking her to be making the merely definitional claim that any sanction with a non-Retributive purpose is not properly called "punishment," he disagrees, and concludes that "the point of word usage does not [require extended analysis], for the issues are not such as can be settled by a definitional stop." (p. 27) This sentence is characteristically obscure, although it seems that the concept is being employed in roughly the proper way. I doubt that a reader who is unfamiliar with H.L.A. Hart's use of the concept, and has not thought his way through Packer's earlier misuse of it, will understand that probably all he means to say is that the question of justification of a sanction is the same whether it is alled "punushment" or "treatment"-a point which is in any case not altogether correct. Justifying the ap. plication of a practice, in a particular case, may involve satisfaction of quite different criteria under different practices whose ultimate purposes are the same. It is therefore not a matter of indifference whether a practice is considered "punishment" or "treatment." (See pp. 1396, 1412-13, 1451-53 and note 68 infra.)

63. Packer admits as much: "One feature that always distinguishes a case of Punishment from one of Treatment is the nature of the relationship between the offending conduct and what we do to the person who has engaged in it." (p. 26) This is precisely the idea so nicely captured in the phrase "of an offender for his offense," and so absent from Packer's notion that the purpose of the infictor is the relevant criterion.

See also p. 25 (treatment, unlike punishment, does not focus on "conduct," past or future), p. 26 (the difference between treatment and punishment is that in the case of the latter "we are dealing with a person because he has engaged in offending conduct' $)$, p. 29 (even in a utopia of psychological predictability-and prevention of offenses by prophylactic treatment- "treatment will not be 'for' conduct any more than it is now.").

64. Ives v. So. Buffalo R. Co., 201 N.Y. 271, 94 N.E. 431 (1911).

65. P. 31 . 
tion, ${ }^{66}$ he is begging the question of the justification of punishment in its very definition. ${ }^{67}$

The only respect in which Packer's conception of punishment seems to me to differ importantly from that of H.L.A. Hart lies in his repeated assertion that any pain inflicted primarily for the purpose of advancing the social good must be considered "punishment," "particu* larly if its imposition has been triggered, as is commonly the case, by the occurrence of disturbing conduct." ${ }^{.68} \mathrm{He}$ seems to think this is

66. On p. 26 , in the course of his discussion leading up to his contribution to the definition of punishment, he observes that "Punishment .. . has onc or both of two justifying aims: the prevention of individual conduct, and retribution for percelved wrongdoing." "Punishment" for the good of the offender (as in the case of a child), for example, is excluded.

67. Alternatively one could read him as having denied that pain inflicted on an offender for his offense, but to some end other than Prevention or Retribution, is "punish. ment," by definition, but (if justifiable at all) is something else. He gives no argument for any such arbitrary restriction, so I prefer to read him simply as assuming in his definition what he ought later on to try to prove, but does not-that only Prevention and Retribution can justify inflicting pain on an offender for his offense.

68. P. 28. This last restriction is essential to meet the "of an offender for his offense" part of the definition Packer takes from H.L.A. Hart. Packer secms at times to lose sight of this. See p. 1412 infra.

Packer takes Hermann Mannheim severely to task for defining punishment in a way that, so far as I can see, is not significantly different from his own. Mannhelm says punishment must be intended to be an evil, and that things done with the intent that they be "purely beneficial" do not count as punishment. (p. 31) Packer starts off on the wrong foot by assuming that "evil" is the same as "hurtful" (i.e., the same as the "palin or other consequences normally considered unpleasant" of H.L.A. Hart's definition), (p. 21) This is not the case (and it destroys the opposition between "evil" and "benc. ficial") since treatment is often "hurtful"; punishment must therefore be not only "hurtful," but an "evil" sort of "hurt." He goes on to criticize Mannheim for maling the definition of punishment turn on its applier's "motive" (which he apparently treats as equivalent to "intent"- cf. p. 33 where he gives a lay psychogenetic annalysis of those who adopt the position he ascribes to Mannheim), and for focusing "on what an in. terested party intends rather than on what a detached observer thinks." (p. 82) I cannot make any sense of these objections. It seems pretty clear to me that whether we are concerned with Mannheim's "evil" or with the "hurt" which Packer confuses it with, it must be the intention and understanding of the inflictor which is critical Something is not punishment unless its inflictor thinks of it as "hurtful" (otherwise, it is a mis. guided something-else: an unlucky attempt to help, for example; and if the inflictor thinks it is hurtful, it may be attempted punishment, even if, unknown to him, his victim enjoys it). Nor is something punishment unless the inflictor thinks of it as "cvil" rather than "beneficial" to the victim (treatment does not become punishment mcrcly because it is worthless; nor does punishment become treatment because of an unknown beneficial effect-cf. THE AuTOBIOGRAPHY of MALCOLM X (1965)).

Packer's counterinstances to Mannheim's definition are utterly inapposite: he cites cases of things denominated "treatment" even though done to the victim "not primarily for his benefit" (p. 33) - which Mannheim would clearly agree with him in calling punishment. His objection to Mrannheim is particularly obscure since he himself distinguishes "treat. ment" from "punishment" on the ground that "the primary purpose of "Treatment is to benefit the person being treated," (p. 25) and defines punishment in terms of its "dominant purpose." (p. 31) Perhaps he thinks that "purposes" (unlike "motives" and "intents") exist "objectively"-apart from those (punishers or treaters) who have them; or perhaps he thinks the difference between himself and Mannheim lies in some other distinction (which he does not identify) between "purpose" and "intent."

Packer's criticism of Mannheim is rendered especially peculiar when he concludes hils discussion by observing that "The point is, of cottrse, one of word usage." (P. 39-italics added.) One wonders whether Packer has the slightest comprehension of the argument 
implicit in his addition to Hart's definition, but that is not the case: Hart could agree that every case of punishment is a case of Retribution or attempted Prevention, which is all that Packer's addition requires, without agreeing that every case of attempted Prevention is a case of punishment. The main applications of this latter idea are to civil commitment, ${ }^{69}$ particularly following an insanity acquittal, ${ }^{70}$ and to the mandatory treatment programs for addicts. ${ }^{71}$ Packer follows Dean Francis Allen in the insistence that civil commitment is "really" punishment rather than treatment. Allen has observed that "There is one proposition which, if generally understood, would contribute more to clear thinking on these matters than any other .... The mere deprivation of liberty, however benign the administration of the place of confinement, is undeniably punishment." "72 As far as one can tell, it is only a political-rhetorical purpose which underlies Allen's and Packer's desire to incorporate treatment imposed for the general benefit within the concept of punishment: they hope thereby to borrow from the established limitations, substantive and procedural, which attach to the practice of punishment, in order to ward off what they see as dangers to human liberty inherent in the enthusiasm for "treat-

he is engaged upon-for whatever else it may or may not be, the point is, "of course," precisely not one of word usage, except in the trivial sense that ve might stipulate to call "punishment," "cabbage" and "treatment," "sheep." It males a great deal of difference whether probation, for example, is properly regarded as an instance of the practice of punishment or as an instance of treatment. Mannheim was not trying to alter the meaning of those words but to argue for a new conception of things like probation-that they be considered (i.e., be implemented according to the rules of the practice of treatment instead of punishment. Unless we have utterly purged the words "treatment" and "punishment" of the meanings they commonly carry, we cannot regard it as a matter of indifference which one is used of a particular practice, since the two involve different implicit rules for implementation. See also note 62 supra. And since the particular nature of the rules of implementation of a practice is essential to its justifiability the question whether probation could not be considered "treatment" is not a verbal question at all. The issue raised is whether probation, implemented and attempted to be justified as treatment, is justifiable. Packer's criticism of Mannheim is also not verbal-he is implicitly suggesting that probation is only justifiable as punishment (or, perhaps, that it is in fact so implemented) and that it is a form of lying about what is going on to all it treatment. $C$. note 82 infra (and see p. 1396 supra and pp. 1451-53 infra on the nature of the justification of practices). Here, as elsewhere, Packer's uncritical indulgence in the modish notion that words are fungible and most disputes merely "verbal" leads him away from the heart of the matter.

69. On civil commitment in general, Packer's views are obscure-at times he refers to it as treatment (e.g., pp. 22, 25) and at times as punishment (e.g., pp. 28, 33). Perhaps he thinks everything turns on the purpose-beneficial or preventive-of the inflictor. $C f$. note 68 stupra.

70. P. 28.

71. Pp. 334-35.

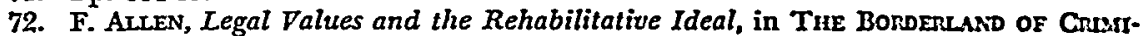
NAL JUSTICE 25, 37 (1964).

Much as I admire Allen's book, it does not seem to me that he gives us any reason what. ever in favor of the suggested usage, and I cannot see that clarity of understanding is promoted by calling something by a name which it does not deserve. 
ment."73 I certainly share their sense of the danger, consequent upon the fact that these other practices share with punishment the particularly troublesome feature of coercion. But I do not think the way to meet the danger is to obscure the differences between different coercive ways society can seek to prevent disturbing conduct. ${ }^{74}$ I would prefer to speak directly and distinctly to the problems involved in civil commitment of the dangerously mentally ill, for example, rather than to obscure those problems by pretending that they are the same as those involved in punishing an offender for his offense. I cannot see much to be said for Packer's apparent refusal to recognize that there may be something to be said for non-punitive ways of dealing with offenders because, he insists, it is all "really" punishment. ${ }^{75}$ This kind of propagandistic obscurantism comes with particularly little grace from one who casts aspersions on the unconsciously punitive motives which might underlie the enthusiasm for "treatment" of some who prefer that word to "punishment."70 This seems like a case of a man in a semantic glass house throwing stones at a man in a brick one. What needs to be said is not that "treatment" is "really" "punishment" but that treatment is dangerous in ways that punishment is not-and that perhaps some persons whom treatment enthusiasts want to treat ought to be punished instead. ${ }^{77}$

I do not mean to suggest that real problems can be solved by definition. Ultimately, it is how a practice functions, not how it is defined, which must count in its justification. What I do mean to say, however, is that it is in failure at the preliminary task of definition of a practice

73. P. 33 .

74. Among other things it seems to me useful to preserve the vocabulary which permits us easily to discuss the punitive purposes and motives which may underlie what is ostensibly treatment. Packer and Allen would force us into circumlocutions for which I can see nothing to be said.

75. See, in addition to the passage discussed here, his consideration of treatment as an "alternative" to punishment, discussed at pp. 1459.62 infra. Cf. his revicw of $K$. MEnninger, The CRIME of PUnishment (1968), supra note 19. Packer argues clscwhere that true treatment must necessarily be voluntary, as a general rule (see pp. 1459.01 infra); and he maintains in this discussion that it must be for the benefit of the person concerned. (p. 25) Even if both positions were correct, it would not follow that anythingt which is not "treatment" is necessarily "punishment."

76. P. 60 .

77. It is of course true that it is not always possible clearly to distinguish treatment from punishment-both involve prevention and coercion; some of the treatment-is-rcallypunishment impetus seems to come from the commonplace fallacy of supposing that the existence of a grey zone proves there is no real difference. But I also believe that the extent of the difficulty of distinguishing punishment from other practices has been enormously exaggerated, and that when punishment is analyzed as a practice it will be seen to have quite different implications, costs and benefits from other practices from which it is often believed in large part indistinguishable. One of the many virtues of H.L.A. Hart's essays on criminal responsibility is the way they begin to point out the possibilities in this direction. 
that escape from a proper functional analysis of it often occurs. Once we have a clear definition of the practice we are evaluating, we can start to appraise its costs and benefits, and we can compare them with the costs and benefits of other practices with the same ultimate purpose without getting entangled instead in futile disputes of a merely terminological sort (e.g., whether "civil commitment" is "really" "punishment"- when the important functional question is not what its name is but whether it is a justifiable practice, and how its costs and benefits compare with those of practices with different rules of implementation). What we need by way of definitional preliminaries are clear words which give separate names to practices which differ enough in their rules of implementation that their appraisal has to proceed differently. In this light, I see nothing but confusion in trying to "justify" something which includes torts, injunctions, civil commitment, and ordinary punishment all mixed up together. Perhaps none, or some, or all are justifiable ways of accomplishing Prevention in particular circumstances. But we will never be able to find out until we separate the separable in terms of rules of implementation, and evaluate them separately. Hence the importance of clear and useful definitions of practices.

So much for Packer's foray into the problem of giving content to the concept of "punishment." It is not a triumphant one. Worst of all, however, is the fact that having established a definition at some length, he continually violates it. Thus, at one point he says that "the way the framers of the Model Penal Code put the issue [of the place of the insanity defense] could hardly be improved upon." 78 But the quote he endorses says that the purpose of the defense is to distinguish between penal sanctions "in which there is inescapably a punitive ingredient (however constructive we may attempt to make the process of correction) and modes of disposition in which that ingredient is absent."79 Having argued, that commitment after an insanity acquittal constitutes "punishment," it is hard to see how he can find no fault with a conception of the insanity defense which asserts that such commitment is not "punitive."

The main respect in which Packer violates the definition lies, however, not with respect to his own peripheral (and misconceived) additions to H.L.A. Hart but with regard to the central element of Hart's formulation: punishment must be "of an offender for an offense." Since Packer does not question this aspect of the definition, what are

78. P. 131 .

79. Id. 
we to make of the long passage in which he discusses the question whether conduct is an essential prerequisite to criminal punishment? His horribles seem to be mere misnomers. Absent the conduct rule, he says, and given better predictive tests, "we would presumably not hesitate to inflict punishment on that person [i.e., "a given individual . . . likely to inflict serious physical injury on someone, someday, somewhere"] for his propensities, or, as the old cliche has it, for thinking evil thoughts." 81 This is a standard red herring thrown at Utilitarians. The response, on Packer's own terms, should have been: First, you are not describing a case of punishment, but of something else, because no offense is involved in your hypothetical. Second, there is nothing horrible at all-intrinsically, at least-in the idea of prophylactic measures; that is what civil commitment is, and subject to qualifications based upon our lack of knowledge and upon the dangers to other values involved, it seems a good and justifiable practice; those who throw the horrible of "punishment" for propensities in the face of Utilitarians do not seem to have any qualms about civil commitment, or if they do they fail to say so. Third, it follows that the fuss and bother is simply based on misuse of the word "punishment"--the point is not that the practice to be justified is awful, but that it is not an instance of the practice of punishment. ${ }^{82}$

80. Pp. 73-79. See also, e.g., p. 35. There may be a strained sense of "offense" in which an offense can exist without any conduct by the offender, but Packer docs not sectn to bo using the word in such a sense, nor does he note H.L.A. Hart's caveat that there are secondary uses of the word punishment in which the feature of an offense comprisingt some conduct is absent. H.L.A. HART, supra note 26 , at $\mathbf{5}$.

81. P. 73. Thinking evil thoughts is not the same thing as having a propensity. It is at least an occurrence, if not conduct. Whether one could sensibly describe such an occurrence as an offense seems an arguable point. After reading R. LIFToN, Titougtr It:* FORM AND THE PSYCHOLOCY OF TOTALISM (1961), one is inclined to believe that thought: may well be subject to much the same sort of self-control that actions arc. It may not be linguistically inappropriate, in that light, to speak of "punishment for thoughts." Cf. Morris, Punishment for Thoughts, 49 THE MONIST 342 (1965). The condtct limitation, to the extent it precludes "punishment for thoughts," does so for reasons derived not from the character of the practice of punishment, but from fundamental Constitu. tional principle. Cf. Note, The Serpent Beguiled $M e$ and I Did Eat: The Constitutional Status of the Entrapment Defense, 74 YALE L.J. 924 (1965); note 175 infra.

82. This is not a verbal point. Much evil is done in the world through lying uses of the word "punishment." The favorite Retributive debating point (that Utilliarianism can justify "punishment" of the innocent) poses the problem of justifying the lic that a person is being punished (with all that that implies) rather than of justifying a Utilitarian account of punishment itself. See Quinton, On Punishment, in LASLET, Eb., Philosophy, Politics and Society (Ist series) (1956); Benn, An Approach to the Problems of Punishment, 33 PHILosopHx 325, 331-32 (1958). Utilitarianism might well justlfy doilty horrible things to "innocent" people; it might perhaps, in extreme cases, justify lying to the effect that an (actually) innocent person is being "punished" (e.g., the stock case of a scapegoat "punished" to calm racial passions after an inter-racial crime), although the occasions on which this sort of lie might be justifiable in Utilitarian terms have been greatly exaggerated. See Sprigge, A Utilitarian Reply to Dr. McCloskey, 8 Inqum 204, 
My point is that given the definition of punishment he borrows from Hart, Packer himself ought to have rejected the idea of "punishment" where there is no conduct as a contradiction in terms. To see that punishment is of an offender for an offense is to recognize that the practice of punishment is a very peculiar affair. It is not a collection of all the methods of social control involving unpleasantness to individuals. It is a special way of seeking social control. It therefore requires a special kind of justification. The worst kind of mistake to be made in the process of justifying the practice of punishment is to invoke as limitations on the implementation of the practice a variety of ad hoc principles supposedly extrinsic to the justifying purposes of the practice, in order to meet objections to "punishing" in a variety of situations which do not involve "punishment" anyway. To do so is to miss the nature of the practice one is justifying. When, for example, Packer insists that a fundamental principle requires that the practice of punishment include a rule of implementation which precludes the "punishment" of propensities, he conceals from himself the fact that the principle he invokes in favor of the restriction of punishment to "conduct" is not extrinsic to the practice at all, but concerns the essence of what he is seeking to justify. To think that this special rule to exclude a feature proper to quite different practices (e.g. civil commitment) is necessary before punishment can be justified is as confused as to suppose that a special rule to exclude rewards is necessary: positive sanctions-like prophylactic ones-are simply not comprehended within the practice and there is no need to invole extrinsic considerations in support of special rules excluding them. Packer ought, in short, to be asking what the point is of a practice which seeks to control behavior by implementing threats to attach pain to misbehavior, and when we should prefer such a practice to ones which, for instance, seek to prevent misbehavior by ascertaining persons likely to engage in it and incapacitating them, or by rewarding good behavior. Only when punishment is dealt with in that way, I believe, can it be properly understood-and understood, be justified. ${ }^{83}$

275-86 (1965). But to say that Utilitarianism could justify punishing the innocent is to confuse justifying a particular practice (e.g., prophylactic detention) or a lie about a practice (the statement " $\mathrm{X}$ is being punished" necessarily implies the existence of an offense, which is what the addressees of the lie are supposed to infer, while the liar knows there was none), either of which is at least analytically possible, with justifying a mere contradiction in terms.

83. H.L.A. Hart makes the same mistake-treating as extrinsic and non-Utilitarian limitations on the practice of punishment which are intrinsic to it, which are a part of the institution which is to receive a Utilitarian justification. See pp. 1451-53 infra. 


\section{The Definition of "Criminal Punishment"}

Having, by inattention to the demands of his own definition of "punishment," included within it many things not the concern of the criminal law, Packer requires an additional, more limited concept. He therefore sets about to define "criminal punishment." It is symptomatic of the book's almost total lack of systematic, organized argument, that one discovers only hundreds of pages after Packer's initial definition of "criminal punishment" that the concept apparently in. cludes elements never originally mentioned or discussed, and which to some extent conflict with the original definition. "Criminal punishment," goes his first definition, "means simply any particular dispo. sition ... that the law authorizes . . . in cases of persons who have been judged through the distinctive processes of the criminal law to be guilty of crimes." 84 In other words, it is the nature of the process by which it is imposed, and that alone, which marks a case of punishment as a case of criminal punishment. On its face this is a pretty useless definition: If, as Packer supposes, it is only "criminal punishment"

84. P. 35. Packer then pronounces that "Punishment is a concept; criminal punishment is a legal fact." (Id.) After many readings, I remain quite unable to derive any enlightenment from that sentence, although Packer insists that the distinction is an important and often obscured one.

Nothing inheres in the word "crime" in the sentence quoted in the text which mects the criticisms I am about to level. "What we mean by a crime' or an 'offense' is simply conduct that is forbidden by law and to which certain consequences, called punishment, will apply on the occurrence of stated conditions and following a stated process." (p. 18) So "criminal punishment" is that sort of punishment applied to persons who have been found by a certain process to have done the sort of things which warrant punishment.

Packer's concept of "crime" is defective in another way. On the one hand, he regards the selection of types of conduct to be described as "criminal" as a purcly Utilitiritan affair "different from and much simpler than the question of what we hope to achieve by imposing punishments." "Punishment ... involves among other things the infliction of pain, and thus brings into question the justification of inflicting pain on others. The definition of crime involves no such issue .... No one is hurt... by the announce. ment that it is forbidden .... the mere announcement that conduct is criminal scrves only a secular, utilitarian purpose." (p. 19) "Crime" is here clearly identificd as a "mere announcement." Yet on the page before, Packer had said that "A crimic is not merely any conduct forbidden by law; it is forbidden conduct for which punishment is prescribed ..." (p. 18) This is not only a radically different definition, it is one which conflicts with his claim that the justification of making something a crime, being wholly Utilitarian, is quite different from the justification of punishing to enforce it-the latter, as he hints here and argues later on, involves a Retributive elcment as a limitation on the pursuit of Preventive goals by punishment. If "crime" involves "punishment" then the justification of making something a "crime" must also involve whatever clement of Retributionism is inherent in the justification of punishment. In the confusion between his two suggestions toward a definition of "crime" lies Packer's failure to appreciate what it is to justify a practice like criminal law, which seeks to accomplish something (4.t., prevention) in a particular way. See pp. 1451-53 infra. Contrast H. Hart, The Aims of the Criminal Law, 23 LAW AND CoNTEMP. ProBs. 401, 402-06 (1958). Hart recognizes that the special problem of justifying a practice is at stake, but he locates the nature of "criminal" law in community condemnation, rather than (as $I$ would) in the practice of punishment, defined in H.L.A. Hart's terms. 
to which the ex post facto clause, for instance, applies, ${ }^{85}$ one main use we have for the concept is to tell us when "the distinctive processes of the criminal law" must be used to impose punishment; otherwise ex post facto punishments could be freely dispensed so long as "distinctive processes" were scrupulously avoided. ${ }^{86}$

Packer gives us two other versions of the concept of "criminal punishment." Each avoids the criticism just made, but raises other difficulties which he also does not discuss. At several places he suggests that "criminal punishment"- the sort of punishment which requires the distinctive criminal process and the rules of implementation which he intends to derive from the "rationale of the criminal sanction"-is severe punishment. "The combination of stigma and loss of liberty involved in a conditional or absolute sentence of imprisonment sets that sanction apart from anything else the law imposes." 87 This equation of "criminal" with "severe" is adequate so long as it is used only to suggest that when we can get along with minor penalties, particularly fines, we can also do without the paraphernalia of the criminal process and the culpability rules. But it is not much use for the reverse problem-the problem of deciding when an imposed pain (e.g., confinement for treatment/rehabilitation) has to be considered criminal in character, entitling the victim to special procedural and substantive protection. Packer himself observes elsewhere that the lifelong "treatment" of a psychotic cannot be distinguished from the thirty-day "punishment" of a petty criminal in terms of severity, 88 and since on his own account of "punishment" persons com-

85. Exegesis, pp. 79-102.

86. The procedural conception of what is essentially "criminal" manifested in Packer's account of "criminal punishment" has been characterized by Henry Hart as "So vacant a concept [that it] is a betrayal of intellectual bankruptcy." $\mathrm{H}$. Hart, The Aims of the Criminal Law, 23 LAW AND CONTEMP. PROBS. 401, 404 (1958).

Packer also argues at this point that "a formal judgment of guilt" is essential to "criminal punishment." He goes on to state that formal judgment is itself punishment. His argument for this position is unclear. He suggests that it is definitional ("in contemplation of law" the judgment of guilt constitutes punishment) but he also suggests that it rests on a contingent psychological judgment (people suffer from the mere adjudication). There are technical reasons for preferring the former (c.g., as a basis for invoking the Double Jeopardy clause against multiple convictions for a single offense, even if concurrent sentences are imposed-see Comment, Twice in Jeopardy, 75 Yare Io. 262 (1965)); but there may be equally strong reasons to prefer the latter (which seems to conform more closely to normal usage-which, I think, would say that a conviction constitutes punishment because of the stigma attached to it, 2 usage which has obvious advantages for clear discussion of the stigma problem). It is essential to keep analytic and empirical propositions about "condemnation" clearly distinct. Henry Hart, for example, treats condemnation as the essence of the "criminal" and says that the civillycommitted "patient has not incurred the moral condemnation of his community, whereas the convict has." H. Hart, supra, at 406 (italics added). He gives no indication of having considered whether this assertion is empirical or definitional in character.

87. P. 131. Compare pp. 274-75, 335 .

88. P. 25 . 
mitted after an insanity acquittal are thereby "punished" but not criminally punished, ${ }^{89}$ it is obvious that even within Packer's own definitional terms severity cannot distinguish criminal punishment.

The other criterion he suggests is that criminal punishment includes an element of "community condemnation." "10 The criminal law's use of condemnation is important to Packer, and its invocation here as part of the definition of "criminal punishment" is a necessary basis for his later argument that we should not make something a crime unless we are prepared seriously to condemn a man for doing it. ${ }^{01}$ But he never explains exactly what he means by condemnation nor what role it plays in the practice of punishment. Nor does he discuss condemnation on its merits, having included it by definition in the praca tice he seeks to justify. Perhaps condemnation and stigma are goods, to be cultivated and preserved, or perhaps they are inescapable lesser evils-a cost of the practice of punishment. But since there is much to be said against them, it is intolerable that their place in the criminal law be settled by definition. The moralizing attitude toward crime needs considerable justification. My own conviction is that a little positivism about crime is all to the good-intellectually and practically. Moral condemnation and stigma probably do much harm, far beyond that inflicted by punishment itself.92 They are aspects of the "exile function of punishment," which I have discussed elsewhere, ${ }^{93}$ and which is perhaps responsible for many of the evils of our penal system. Stigma contributes to the hypocritical fallacy that crime is a phenomenon unique to criminals, when in fact it is a phenomenon common to human beings; we will never be humane toward convicted criminals so long as we overlook the fact that the rest of us are at least potential and usually undetected criminals. ${ }^{04}$ Packer might have addressed those kinds of questions before so blithely begging them in his definition. One could not undertake such an inquiry without coming up against the sources ${ }^{25}$ and functions ${ }^{00}$ of the

89. P. 28.

90. P. 134.

91. See p. 1464 infra; p. 262.

92. Cf. J. Goldstein, Police Discretion not to Invoke the Criminal Process: Low

$V$ isibility Decisions in the Administration of Justice, 69 YALE L.J. 543, 590 (1960).

93. See Griffiths, supra note 17, at 373-75, 378-80, 385-86.

94. See pp. 1402-03 supra.

95. Cf. Strawson, Freedom and Resentment, 48 Proc. Brut. Acav. 187 (1962); H. KeL* SEN, SOcIeTY AND NATURE, 49-185 (1943); E. GofFMan, STIGMa (1963).

96. Cf. G.H. Mead, The Psychology of Punitive Justice, 23 AM. J. of Sociologr 577 (1918); Garfinkel, Conditions of Successful Degradation Ceremonies, 61 AM. J. of SoctolOGY 420 (1956); E. DURkheim, The Division OF LaBor IN SocieTY (Simpson trans. 1993); 2 J. F. STEPHEN, History of THE Criminal LAw OF ENGLANd 91 (1883). There are also well-known dysfunctions, of course. Cf. J. Goldstein, stupra note 92. 
stigma of condemnation, and the question whether a criminal justice system can be conceived in which stigma plays little or no part.

Furthermore, the "distinctive processes" criterion and the "condemnation" criterion do not necessarily always point in the same direction. It is at least an open question whether we cannot impose "criminal punishment" according to the "distinctive processes" definition without having condemnation in mind. ${ }^{97}$ Packer's failure to notice this underlies one of his criticisms of absolute liability crimes: that they use the "distinctive processes" in situations in which "condemnation" is inappropriate. .98 It is ultimately impossible to tell whether he believes all three criteria together are required to constitute a case of "criminal punishment," or whether any single one of them will do, or whether his position is that one of the three is the definitional criterion and that a case of "criminal punishment" so defined ought always to be accompanied by the other two, and that given either of the other two "criminal punishment" ought always to be insisted upon. ${ }^{99}$

Packer's troubles in defining "criminal punishment" arise, as I indicated, from his mis-defining of "punishment." Had he not included in the latter term a variety of things-such as civil commitmentdone to a person for the social good but not "for an offense," he would not have had to coin a new term to distinguish them from things distinctively "criminal." The separate concept of "criminal punishment" serves only an obfuscatory role. Given a proper account of "punishment" the issue we actually need to consider is whether it is possible to define a category of relatively trivial offenses in which the procedural and substantive paraphernalia of full-fledged crimes ought not to be prerequisite to the infliction of punishment. Severity and condemnation are central to this task, to be sure, while they are irrelevant or unhelpful to the other quite different task Packer also needs to accomplish with the concept of "criminal punishment"excluding things from consideration that aren't properly "punishment" at all.

\section{Justifying "Criminal Punishment": The "Integrated Rationale"}

Having defined "criminal punishment," the thing is to justify it as a practice. The object Packer sets himself, in attempting an "integrated

97. A similar conflict between "severity" and "distinctive processes" is patent.

98. See pp. 272-77.

99. See pp. 130-31. 
theory" or "integrated rationale" of the justification of punishment, ${ }^{100}$ is to avoid an alleged dilemma: that one must either adopt a Preventive justification for the practice of punishment, in which case the traditional culpability rules of the criminal law have no place and considerations of danger and treatability ought exclusively to govern (he calls this "behavioralism"), or one must adopt the Retributive position that deserved punishment is a good in itself. Packer tries to show that one can accept Prevention as the justifying purpose of the practice of punishment without being a "behavioralist"-without giving up the principle of culpability. He had available to him in this enterprise a powerful analytic distinction developed in this connection by H.L.A. Hart: that between justifying the practice of punishment and justifying a particular application of the practice. ${ }^{101}$ It is not enough, for example, to discuss whether Retribution justifies "punishment." There are two questions involved, and they require separate consideration: first, does Retribution justify the practice of punishment-the creation of crimes whose commission is to be punished? Second, given the existence (however justified) of an offense category, does Retribution have anything to say about the selection of persons to be punished? The requirements of justifiable Distribution (what I have been calling "rules of implementation" of a justifying purpose) may, Hart argues, include conformity to funda. mental principles which cannot be accounted for in terms of the General Justifying Aim ("justifying purpose") of the practice. Hart's position is that the relevance of Retribution to the General Justifying Aim and to the Distribution of punishment may be quite different affairs. It is out of this difference that Packer, obviously attempting to follow Hart, resolves the supposed dilemma posed by "behavioralism."

Given H.L.A. Hart's dichotomy, the first question is whether a General Justifying Aim for the practice of punishment can be found. A number of candidates are well known. Packer begins with Retribution. He describes it as resting "on the idea that it is right for the wicked to be punished: because man is responsible for his actions, he ought to receive his just deserts." 102 This notion "that the justification

100. "Integrated theory" and "integrated rationale" apparently mean the same thing. See p. 61 .

101. H.L.A. HART, Prolegomenon to the Principles of Punishment, supra notc 26. Essentially the same distinction is also made in Benn, An Approach to the Problems of Punishment, 33 Philosophy 325 (1958); Quinton, On Punishment, 14 ANalysis 183 (1951).

102. P. 37. Cf. pp. 9, 10. This is the most important element in Hart's account of the essence of the Retributive position. See H.L.A. HART, supra note 26, at 281. 
for punishing men . . . is that the return of suffering for moral evil voluntarily done, is itself just or morally good" is surely the core of Retributivism. Packer, however, no sooner states it than he confuses it with several other theories. ${ }^{103}$ Revenge as a basis for punishment, for example, is usually Utilitarian in one or another of two ways: either it is an emotional fact which the law takes account of ${ }^{104}$ and perhaps even cultivates, ${ }^{105}$ or it is a primitive version of the Deterrence idea; it may also be grounded in notions of personal honor. "Revenge," however, is not the name of a theory that it is a moral good for evil-doers to suffer. Expiation, which Packer also confuses with Retribution, is likewise quite a different account of the justifiability of punishment-it is a form of what Packer might regard as "treatment," properly so-called, since it is based upon the asserted needs (psychological or eschatological) of the defendant. Retaliation is, again, slightly different from these other theories, resting on ideas of a balance in the world which is upset by crime and ought to be restored by punishment. ${ }^{106}$ Packer apparently gets entangled in these confusions because he thinks the common thread of Retributivism, "is the thought that it is right for punishment to be inflicted on people who commit crimes." ${ }^{107}$ That it is right is a result of Retributivism and of the other theories he confuses with it, as well as of classical Deterrence-Utilitarianism. The question that Retributivism gives a special answer to is why it is right. ${ }^{108}$

Packer ultimately devotes precisely one sentence to the rejection of Retributivism. Although it (and related theories) have, in an historical sense, constituted by far the most important account of the practice, all Packer says about it is that it has "no useful place in a theory of justification for punishment because what it expresses is nothing more than dogma, unverifiable and on its face implausible." 100 "Un-

103. See, in addition to the passage discussed in the text, p. 44 (Retribution confused with Revenge and Reprobation).

104. This is commonly advanced as the main reason for punishing successful crimes more severely than attempts. See, e.g., Michael \& Wechsler, A Ralionale of the Law of Homicide II, 37 CoLuM. L. REv. 1261, 1295-98 (1937); cf. also 3 J. F. STEPHEN, HistonY of THE CRIMINAL LAW OF ENCLAND $311-12$ (1883).

105. This is the basis of Stephen's famous aphorism that "the criminal hw stands to the passion of revenge as marriage to the sexual appetite." J.F. STEPHEN, GENERAL View of the Crominal Law of ENGland 99 (1890). Packer notes that this is not really a Retributive idea at all. (P. 37; cf. p. 44.)

106. Cf. Michael \& Wechsler, supra note 104, at 1295 n.79; H. KELSEN, Socien Axid NATURE 58-60 (1943).

107. P. 38.

108. See pp. 1995-96 supra, for the confusion Packer gets into as to the "purpose" of punishment on the Retributive view.

109. Pp. 38-39. 
verifiable" and "implausible" are quite without meaning in this connection. What remains is an unadorned ipse dixit.110

Utilitarianism Packer reduces to Prevention: punishment is an evil only justified if it accomplishes offsetting good by preventing criminal offenses. Packer does not acknowledge other essentially Utilitarian objectives, such as what is sometimes called Reprobation - "the maintenance, reinforcement or 'vindication' of the morality of the society [and perhaps of the very existence of the society as one of a particular character]." ${ }^{111}$ Nor does he count as Utilitarian in character, purposes underlying some of the rules of implementation of the practice which, following H.L.A. Hart in this regard, he introduces as Distributive limitations on the pursuit of general Utilitarian purposes.112 At the very outset he says of his cramped conception of the Utilitarian purpose of punishment ${ }^{113}$ that "it [i.e., Prevention] does not suffice as a justification for punishment." 114 Although here, as elsewhere, he is not altogether explicit whether he has General Justifying Aim or only Distribution in mind, apparently he means to say that the practice of punishment cannot be justified unless its General Justifying Aim of Prevention is qualified in Distribution by non-Preventively-based rules of implementation.

Packer divides Prevention into the four classical categories of General Deterrence, Special Deterrence (which he calls "intimidation"-

110. There are good discussions, albeit critical, of Retribution as a justification of the practice of punishment, in Benn, An Approach to the Problems of Punishment, 89 Philosophy 325, 326-29 (1958); H.L.A. HART, supra note 26, at 230-37; Dworkin, Lord Deulin and the Enforcement of Morals, 75 YALE L.J. 986 (1966); H.L.A. HART, LAW, LIBERTY AND MORAlTY (1963). See, for description of the varieties of Retributive theory, J. Walker, The Aims of a Penal System (1966).

111. H.L.A. HART, supra note 26 , at 235 . This function of the social response to deviant behavior occupies an important place in sociological accounts of the criminal law. Sec E. DURkheim, The Division of LABor in Society (Simpson trans. 1933); K. Fkikson, Waytuard PuRitans: A STUdy in the Sociology of Deviance (1966). Cf. Bisilop Butler, "On Resentment," in SERMONS (Matthews ed. 1967). The role that variants of this theory have played in the effort to justify the punishment of mere immorality has been devase tatingly criticized in H.L.A. HART, LAw, LIBERTY AND MORALITY (1963); H.L.A. Hart, Social Solidarity and the Enforcement of Morality, 35 U. Cilt. L. REv. 1 (1967); and Dworkin, Lord Devlin and the Enforcement of Morals, 75 YALE L.J. 986 (1966). But these criticisms go too far, I believe: they confuse the descriplite and analylic socio. logical theory about the nature of crime and punishment and their socinl functions, with a jurisprudential theory purporting to justify punishment for particular offenses. Durkheim's theory, while sometimes misleadingly expressed, is surely of the former sort. It is adaptable to the enforcement of no matter what code. It is an account of what the function of enforcement of a moral system in a society is, not an account of what sort of a moral system ought to be enforced. It insists that we look at the functions of enforcement from a broader perspective than that merely of the cvils to be prohibitcd, but it does not insist that this larger function has to be accomplished by the prohibition of any particular evils.

112. See pp. $1451-53$ infra.

113. E.g.: "The good that is thought to result from punishing criminals is the prevention or reduction of a greater evil, crime." (p. 39)

114. P. 39. 
a distinct terminological improvement), Incapacitation, and Rehabilitation. This division is relatively unexceptionable. The thrust of his argument lies in the effort to show that General Deterrence is the only one of the Preventive goals that presents "a claim as a sufficient basis for imposing punishment."115

He properly takes to task some silly objections to General Deterrence (such as the notion that its efficacy is disproved by the fact that people commit crimes). On the other hand, he explicitly recognizes at one point that "acceptance of its existence, let alone its efficacy, involves a leap of faith."116 But nonetheless, his argument proceeds as if Deterrence were in relatively good shape in terms of empirical support, ${ }^{117}$ at least relative to other Preventive modes. His only affirmative argument in support of its efficacy is that "we are so familiar with the phenomenon [of the increase in incidence of a kind of conduct when the criminal proscription is removed] that there may be no more convincing demonstration than this of the effectiveness . . of deterrence."118 Like so much of Packer's writing, this argument is rhetorically peculiar. But I take him to assert more than just that this demonstration is better than other even more insufficient ones. I am not familiar with the phenomenon he refers to. ${ }^{110} \mathrm{I}$ know of no causal study that tends to support his conclusion, and since he gives no indication of the facts he is referring to, it is impossible to evaluate the lesson he apparently draws from them. There are, of course, analyses of the nature and effectiveness of deterrence, ${ }^{120}$ but $I$ think the only interpretation one can fairly put upon what is currently known is that while some deterrence certainly takes place, more for some crimes than for others, the extent, nature and manner of operation of deterrence are still substantially unknown. ${ }^{121}$

Packer is cautious about the empirical basis for a justification in

115. P. 53; cf. also pp. 66-67.

116. P. 63 .

117. See especially pp. 39-45.

118. P. 44. See also note 291 infra.

119. Packer himself says it does not occur in the case of repeal of anti-homoserual laws. (p. 302). Denmark reports the same experience following repeal of its anti-obscenity laws. Buckley, Oh! Copenhagen!, N.Y. Tnies MaGazine, Feb. 8, 1970, at 33, 36. But cf. (for the exceptions which seem to prove the rule) G. Clark, What Happens When the Police Strike, N.Y. Times MAgazine, Nov. 16, 1969, at 45; Andenaes, The General Preventive Effects of Punishment, 114 U. PA. L. REv. 949,962 (1960).

120. See, in particular, Andenaes, supra note 119. Cf. Chambliss, Types of Deviance and the Effectiveness of Legal Sanctions, 1967 W1s. L. REv. 703; Schwartz \& Orleans, On Legal Sanctions, 34 U. Chi. L. Rev. 274 (1967); U. Moore \& C. Callakan, Lav avid learnivic ThEORY: A STUDY IN LEGAL CoNTrol (1943).

121. Part of the reason for this surely lies in the fact that most studies to date have concerned themselves with capital punishment, and have sought to show its lack of a special deterrent efficacy. 
terms of Intimidation, although he notes that the mere existence of a generally high recidivism rate is no counter-indication of its efficacy. He does raise a problem with respect to the calculus of Intimidation: punishment sufficient to intimidate may be counter-productive because of the criminogenic effect of "the deterioration of . . . character in prison." 122 This, it seems to me, is more a problem with General Deterrence (or with Incapacitation) than with Intimidation. What he describes is really just a failure of Intimidation, ${ }^{123}$ which is a simple enough problem to comprehend (although it highlights the difficulty of treating Intimidation and Rehabilitation as separate purposes of punishment). But in the case of the calculus of Deterrence one must make the effort to balance the possible preventive effects of punishment on other people against its possible criminogenic effect on the defendant-with the usual difficulties attendant on the effort to balance incommensurables. Here is a rather typical instance of Packer's failure to see that the arguments he raises against non-Deterrent justifications apply with equal or greater force against Deterrence. ${ }^{124}$

Packer next discusses "the behavioral view," which he says, consists of "the advocacy of rehabilitation and incapacitation as complementary goals [justifying purposes] of punishment."125 What he means is that those who advocate punishment for Rehabilitative purposes necessarily believe that if treatment fails, Incapacitation comes into play: "incorrigible offenders must be kept in custody for life." 126 This is an outrageous and absurd idea, and one wonders whether Packer could actually produce a compos mentis Rehabilitationist who believes what is being put into his mouth. ${ }^{127}$ The problem stems from Packer's failure to note the way in which Rehabilitation and Incapacitation are complementary: unless there is a possibility of rehabilitating a defendant, punishment can rarely be justified by Incapacitation alone. Most defendants will be released some day, and absent rehabilitation ${ }^{128}$ the risk of a new offense at the time of release will be the same or worse as when a high risk was thought to justify incarceration. ${ }^{120}$ It is only

122. P. 47.

123. Id.

124. See the more general discussion of this, pp. 1426.27 infra.

125. P. 58.

126. P. 55. See also p. 51 ("The logic of the incapacitative position drives us to say" that until the offender stops being a danger we will continue to restrain him. What this means, pushed to its logical conclusion, is that offenses that are universally regarted its relatively trivial may be punished by imprisonment for life.")

127. Cf. however, H. Barnes \& N. Teeters, New Horizons in Criminolooy: 'Ithe american Crime Problem 953 (1945).

128. I include Intimidation here as a form of Rehabilitation, as docs Packer. (p. 56)

129. Of course, in the case of a regular recidivist there is some gain from the olferisen 
the possibility of reducing the risk which makes temporary incapacitation justifiable. I mention this rather obvious relationship only because understanding it is an essential prerequisite to any sensible discussion of the extent to which Incapacitation and Rehabilitation can constitute justifications of the practice or application of punishment.

Packer's main reason for rejecting Rehabilitation as a justifying purpose of the practice of punishment (and hence for rejecting "behavioralism") is based upon a misstatement of fact: "Very simply . . . we do not know how to rehabilitate offenders."130 He draws the conclusion that "punishment in the name of rehabilitation is gratuitous cruelty." 131 As anyone who has the slightest familiarity with the literature of Rehabilitation is well aware, the assertion is just not true; ${ }^{132}$ and the conclusion is an unwarranted insult to many dedicated people who are trying to make the criminal law a little bit more humane. Such a cavalier disrespect for the complexity of empirical fact is particularly irresponsible in a book professedly addressed to a lay as well as a professional audience. ${ }^{133}$

To begin with, there are methods of treatment which are quite effective for certain kinds of offenders under certain kinds of conditions -on the simplest level, some crimes have curable organic geneses. Despite the enormous methodological difficulties, ${ }^{13 *}$ there in fact is a

not committed while he is incarcerated; but there could never be a reason other than imminent death for releasing him consistent with the reason for having incarcerated him in the first place.

130. P. 55. Packer argues for this proposition only by non-sequilur: he says that crime has general social causes, that to eliminate it would be to remake society, and that such tasks are beyond the "competence" of the criminal law. (Id.) Pcrhaps. But these observations seem relevant, if at all, to General Deterrence as a justifying purpose. The Rehabilitative question is not whether the criminal law an reduce first offenses, but only whether it can reduce recidivism, and Packer's observations are unrelated to that question.

The objection to Rehabilitation as a justifying purpose of punishment in terms of limited "competence" (which derives from F. ALLEN, The Borderland of Cruadinat Jusmce 51-61 (1964)) seems to me to overlook entirely the individual factor in crime: not all of the poor and oppressed, or whatever, commit offenses. Alore importantly, the argument from limited "competence" is relevant only for a society in which eocial conditions seem the paramount factor in the genesis of criminal behavior. It is possible that there exist, or might exist, societies in which this is not the case, and in which it is therefore possible to deal with crime as a matter primarily to be accounted for in terms of individual problems in the lives of individual offenders. $C f$. F. TePoole, The Decision to Release a Partly or Wholly Non-Responsible Offender from Indeterminate Commitment for Treatment-In the Netherlands, 1969 (unpublished paper), at p. 110. But cf. note 38 supra (inevitability of crime as a cost of desired social arrangements). Since Packer purports to give "a model of the doctrinal content of a criminal law belonging to no particular time or place" (p. 71), rejection of Rehabilitation for mere socially contingent reasons will not do.

131. P. 56.

132. Cf. MoRkis \& HawkINs, supra note 2, at 121-22, 125-26.

133. P. 5 .

134. See, for example, the problems of definition and measurement of recidivism dealt 
modest body of knowledge of "how to rehabilitate offenders," in two senses: we know that penal methods can sometimes reduce the likelihood that a particular offender will re-offend from what it would be if he were not dealt with at all, and we know that some ways of dealing with offenders can reduce the rate of recidivism achieved by other ways of dealing with them.

Had Packer not so lightly dismissed the topic of Rehabilitation on the basis of the misrepresentation that we lack all knowledge of how to go about it, a whole range of serious and difficult questions would have presented themselves for consideration.

The concept of "danger" is central to the Rehabilitation-Incapacitation calculus. Packer uses the word as if it had only to do with predictable criminality. ${ }^{135}$ But if "dangerousness" is to be a predicate for Incapacitation and Rehabilitation, ${ }^{136}$ it must involve more than the proposition that a person is "dangerous" if there is a high enough risk that he will re-offend. By such a standard, we are all "dangerous" -with regard to parking offenses at least (and many of us for more serious things). "Dangerousness" must be a function of how far the risk for a given category exceeds that for the general population and how significant the sort of offense is. As far as the Utilitarian calculus of prevention is concerned, a relatively low risk of a very clamaging offense may render the offender involved far more "dangerous" than would a relatively high risk of a less serious offense. I make this point only because, although it is an elementary aspect of the calculus, I cannot find it anywhere in Packer's discussion. ${ }^{137}$

Prediction also is central to the Rehabilitation-Incapacitation calculus. One important role of prediction in the calculus goes to the question: what would happen if we did nothing at all to the offender -what is the risk of further offenses? What we mean by prediction

with in D. Glaser, The Effectiveness of a Prison and Parole System (1964). Morris, Impediments to Penal Reform, 33 U. CHr. L. REv. 627 (1966), discusses the impingement of ethical and legal norms on the methodological problems in penological rescarch.

135. Pp. $49-51$.

136. And also, of course, for various non-punitive measures: for civil commitment (cf. J. GolDSTEIN \& J. KATZ, Dangerousness and Mental Illness-Some Obsertations on the Decision to Release Persons Acquitted by Reason of Insanity, 70 YALE L.J. 225 (1960)); for indeterminate terms of treatment for partially-responsible offenders (cf. F. LcPoole, The Decision to Release a Partly or Wholly Non-Responsible Offender from Indeterminalo Commitment for Treatment-In the Netherlands, 1969 (unpublished paper)); for preventive pre-trial detention (cf. A. Dershowitz, testimony, Hearings on Amendmerts to the Bail Reform Act of 1966 Before the Subcomm. on Constitutional Rights of the Schata Comm. on the Judiciary, 91st Cong., 1st Sess., at 172 (1969); and A. Dershowitz, Pre. venting "Preventive Detention," N.Y. Review of Books, March 13, 1969, at 18).

137. There is a lone ofthand hint on p. 51 that "dangerousness" may be a more complex affair than the rest of the discussion suggests. 
in this respect is that of $\mathrm{N}$ offenders in predictive category $\mathrm{Q}$ defined by characteristics $A$ through $G$ (which our empirical knowledge at the time makes relevant), $X \%$ can be expected to do whatever we are interested in within time $T$. It is nonsense to speak in the way that Packer does of the "validity" of such a prediction as if prediction involved knowing whether a particular individual would re-offend if not restrained; $;^{138}$ a prediction that 90 out of a 100 people like $\Delta$ will commit an offense is no less valid when $\Delta$ happens to be in the 10 per cent than when he is in the 90 per cent. Unless we simply make a mistake, there is little doubt we can arrive at an accurate percentage readily enough. Whether it is a useful percentage depends on the sophistication of our predictive categories. The seriousness of the offense at risk and the degree of that risk, taken together, constitute the "danger," and tell us the Utilitarian loss which would result from not confining persons in the category concerned (for Incapacitation or Rehabilitation), and part of the Utilitarian loss which would result from confining them (i.e., the number of persons to be confined who would not have committed an offense).

Another role of prediction in the calculus concerns the effect of the sanction to be imposed-to what extent can we alter the future by what we do to the offender? We cannot speak as if all "danger" can be eliminated. All we can try to do is reduce the percentage whose level, in the beginning, leads us to consider the person concerned (that is, persons in his category) as "dangerous." The effectiveness of a sanctionby Intimidation, Rehabilitation, or the natural consequence of increased age-is a function of the amount of this reduction in risk and the invasion of liberty (duration and intensity) required to achieve it. The second part of the Utilitarian loss of confining persons to reduce their dangerousness lies in the invasion of the liberty of those who will re-offend despite the rehabilitative effects of punishment. This loss is most acute if the offender belongs to a category for which no known method of rehabilitation will significantly reduce the risk of another offense. To some extent, the extent of an invasion of liberty for Rehabilitation-Incapacitation can be evaluated and predicted in advance, ${ }^{139}$ but we can release a person at any time that the prediction on which the evaluation of this loss was based proves to be rurong.

All this is to say that we are dealing only with conduct by propor-

138. P. 49.

139. Packer says, "Of course, no one knows at the outset how much of what kind of therapy will be needed in his or anyone else's case ..." (p. 55) Once again, this is simply wrong. The truth is a good deal more complicated. 
tions of categories of offenders within a specific time; the Utilitarian balance has to consider not just the loss to an individual of his liberty against the loss to society due to his percentage risk of crime, but also the loss to all individuals in the category (those who would not, as well as those who would have re-offended) against the loss to society if they all were free. It is apparent that this way of formulating the problem is far more favorable to a decision in favor of liberty than one which balances an individual's liberty against a loss it is assumed he will inflict if at large. It is also apparent that the role of increased precision of prediction is, by narrowing the category so that a higher proportion of it can be expected to offend, to reduce the Utilitarian loss of detaining those who would not have offended. ${ }^{140}$ Surely this is all terribly elementary, and yet Packer seems not to have thought about what he means by "prediction."

The elements of the calculus of gains and losses involved in making judgments about Rehabilitation and Incapacitation are rather simple, if often ignored. Packer's treatment of what he calls the "behavioral" view-the view that punishment ought to be implemented according to the requirements of Rehabilitation and Incapacitation as justifying purposes-is, nonetheless, thoroughly confused. I have therefore belabored what, having been said, may well appear to be obvious, because it seems to me impossible to think sensibly about Rehabilitation and Incapacitation without a clear understanding of the analytic structure of the Preventive-Utilitarian calculus.

Packer is primarily concerned to vindicate Deterrence at the expense of Incapacitation and Rehabilitation-at least as a General Justifying Aim of the practice of punishment. But the central ethical problem with respect to Rehabilitation-Incapacitation is exactly the same for Deterrence: can we justify depriving a person of his liberty for the general good, and if so, to what extent? Packer's confusion with respect to the basic elements of the calculus of Rehabilitation-Incapacitation and his assertion that "we do not know how to rehabilitate offenders"141 leads him to overlook the fact that Deterrence is in a somewhat worse position. We probably know less about the effectiveness of Deterrence

140. See, however, A. Dershowitz's observations, in his testimony and article cited in note 136 supra, on the way in which the educative consequences of the process of deciding not to detain a person, or to detain him no longer, tend to negatively-reinforce wrong decisions to release but not wrong decisions to detain. Such one-sided perception tends to create a spurious "experience" on which worse (i.e., more restraint-inclined), rather than better (i.e., inclined only to the right amount of restraint), predictive judgments are made.

141. See p. 1423 supra. 
than we do about that of Rehabilitation, ${ }^{142}$ while the problem of evaluating the seriousness of the offense prevented (by Deterrence or by Rehabilitation) is the same, as is the problem of evaluating a deprivation of liberty. Consequently, the calculus of social benefit against individual loss is more difficult in the case of Deterrence. Furthermore, Rehabilitation is arguably of some benefit to the individual as well as to society-a claim which can hardly be made for Deterrence. It seems to me that when the danger is great and the available treatment relatively effective, Rehabilitation-Incapacitation is in a rather better position as a justification than is Deterrence.

To the extent that empirical ignorance is a serious obstacle to a satisfactory justification of punishment in terms of Rehabilitation (or Deterrence) there is a further question which has to be addressed. What do we do while ignorant? In the nature of things, we will not get better informed if we do nothing-most of the questions to which we need better answers arise only in the context of a functioning system. ${ }^{143}$ If we do not try to rehabilitate, we will have no basis for evaluating the effectiveness of rehabilitation. Packer asserts that punishment justified as a deterrent is "inevitable"14" -a complacent conclusion which troubles me as I think back on what must have appeared to be the "inevitability" of debtor's prisons. ${ }^{140} \mathrm{~A}$ far more satisfying reason than fatalism exists for continuing to make efforts toward rehabilitation. So long as we are critically self-conscious about the extent of our ignorance, so long as we never abandon the skeptical humility without which our ignorant interventions in other men's lives ceases to be a painful necessity and becomes a revolting obscenity, so long

142. Packer seems to concede this (p. 63) but appears oblivious to the impliation of the concession. Contrast MORRIS \& HAivrins, supra note 2, at 122.

143. Cf. Morris, Impediments to Penal Reform, 33 U. CH. L. REv. 627 (1960).

144. P. 249.

145. See Griffiths, supra n. 17, at $386 \mathrm{n} .98$. The ideological component of the sense of the inevitability of limited procedural choice, which I explore in that article, scems equally relevant here. Cf. note 272 and p. 1467 infra. Cf. also T. PARkien, THE UlikNown CITIZEN 149 (Penguin ed. 1966):

A doctor who repeatedly prescribed for his patients a course of treatment that denied any necessity for diagnosis of the possible cause of the siciness; that by its repetition made the sickness worse; and that showed its inefficiency by the regularity with which the patients reappeared with even worse symptoms... such a doctor would be rightly considered a dangerously inept practitioner, and vould bring upon himself both the criticism of the fellow members of his profession and the anger of the public. But those concerned with punishment and penology are allowed by socicty to continue like this. When pressed they defend themselves by arguing that they cannot think of an alternative. They use imprisonment, they say, as a last recort, because they cannot think what else to do. The sentence becomes a substitute for thought. If it were not possible to use it-if, for instance, the repeated sending to prison of habitual offenders were made illegal-then some alternative vould have to be thought of While it remains no one needs to think very hard." (Ellipsis and italics in original.) 
as we act on reasonable assumptions related to a plausible and testable theory, and so long as we test them against the information that becomes available to us, I think we ought to feel justified in proceeding with the attempt. ${ }^{146}$ In any case, anyone who purports to set out a justification for the institution of punishment has got to come to terms with the problem of action in a state of ignorance, and Packer's reliance on Deterrence does not relieve him of that burden.

Packer's attempt to put Deterrence in a separate position, as a justifying purpose, from Rehabilitation and Incapacitation rests mostly on the essentially empirical arguments I have been discussing. He also gives two arguments of another kind. When he says that only Deterrence "affords a general a priori justification for the infliction of punishment," $14 \mathrm{i}$ he seems to be suggesting that as a general rule Deterrence is the only Utilitarian basis for deciding to enforce a pro. hibition on a kind of behavior with punishment. Rehabilitation, Incapacitation, and Intimidation all require-generally-specific information about the specific offender. Packer apparently thinks it follows that they can only be relevant in sentencing not in deciding to make a kind of conduct criminal and providing for its punishment. It is probably a rare kind of conduct, to be sure, where the mere occurrence of the behavior is a sufficient indication of future dangerousness that Incapacitation (as a mode of prevention) could be the reason for providing for the punishment of all those found doing it. ${ }^{148}$ But it does not follow that only Deterrence can count as a General Justifying Aim. The "behavioral" justifications may still be included among the justifying purposes of many offenses, and even, in unusual cases, may be sufficient by themselves. If creation of opportunities for prevention of second offenses by Intimidation, Incapacitation or Re. habilitation were not included in the General Justifying Aim of punishment for an offense, it is hard for me to see by what logic they could properly come in at the point of Distribution; ${ }^{140}$ Packer wants individualized sentences, so it does not seem relevant that only Retribution and Deterrence afford a "generally postulated equivalence between

146. See F. LePoole, The Decision to Release a Partly or Wholly Non-Responsiblo Offender from Indeterminate Commitment for Treatment-In the Netherlands, 1969 (unpublished paper), at pp. 89-90.

147. P. 63; cf. also pp. 49-50, 53-54.

148. P. 50.

149. Packer several times says that questions of severity of punishment are altogether separable from questions of the justification of any punishment, and that Rehabilitation is relevant only as to the former. (E.g., p. 67.) This seems to me wrong. See note 268 infra. 
the offense and the punishment"; 100 nor can I see any reason in principle why a legislature could not make something an offense in order, among other reasons, to provide for the incapacitation of offenders, leaving it to judges to decide in which cases, given such a justification, punishment is appropriate. Furthermore, if there are essentially nondeterrable kinds of offensive behavior which some one-time offenders can be induced not to repeat, a legislature might even justifiably decide to provide for the punishment of such first offenders only to accomplish Incapacitation and Rehabilitation; so far as I can see, Packer gives no reasons for opposing such an arrangement. ${ }^{151}$ I conclude that he fails to distinguish his own position convincingly from that of the "behaviorist" justification of punishment in terms of Incapacitation and Rehabilitation.

When argument fails, one can always retreat to ipse dixitism, which is all that Packer's second non-empirical objection to the "behaviorist" position amounts to. He poses the rhetorical query: "is it quixotic to assert that man has a right to be bad?"102 This invites the rhetorical reply that it does not aspire to Quixotism, but it is pretty silly. The whole object of the criminal law is to stop man from being "bad" in the defined ways. The question is not whether we try to do so, but only how. On the question "how," Packer feels "impelled to ask whether a theory of punishment that requires acquiescence in compelled personality change can ever be squared with long-cherished ideals of human autonomy." 153 This is an obscurantist question, for, as he himself observes, ${ }^{15 \pm}$ General Deterrence, if it works at all, probably works in subtle psychological ways to prevent people from ever seriously entertaining the idea of criminal behavior, rather than by appealing to the tempted person's calculus of pleasure and pain. Why, one might ask, is social control by such manipulated internalization of

150. P. 54 .

151. H.L.A. Hart once argued that it would be paradoxical to conceive of the General Justifying Aim of punishment for an offense as designed only to prevent second offenses. H.L.A. HART, supra note 26, at 26. But he has since withdrawn from this position. Id. at 240-41. Calabresi has shown that a parallel conception in torts-compensation as the sole objective-is perverse, and for the same reason Hart gives: it wholly ignores the problem of preventing first offenses. It also, as Calabresi observes, selects an irrational category of persons (accident victims, by contrast with all victims; in criminal law, potential recidivists, by contrast with all potential offenders) for consideration. Sce G. CALABRESI, The COSTs of Accidentrs 37-38, 43-44 (1970). Nevertheless, it is entirely possible that categories of offensive behavior exist which are essentially non-detcrrable, for which effective treatment exists, and yet for which no adequate means of selecting those in need of treatment is available except the selection of known offenders. Perhaps incest is an example.

152. P. 57.

153. Pp. 57-58.

154. Pp. 42-44. 
norms so entirely different if it comes in concentrated doses called "rehabilitation"? If we know we can reduce the risk of repetition by punishment, it is hard to see why that is a priori an insufficient justification for the practice; if the methods of rehabilitation are acceptable (which is another question entirely), there seems little difference in principle between prevention by Rehabilitation and prevention by Intimidation. ${ }^{155}$ Surely the charged question whether "acquiescence in compelled personality change" can be "squared with long-cherished ideals of human autonomy"150 does not amount to a serious argument against the "rehabilitative ideal," particularly when, as we have seen, it comes on top of a factual misrepresentation concerning the possibilities of Rehabilitation. ${ }^{157}$

Nothing in his discussion of the possible Utilitarian justifying purposes for punishment seems to afford much basis for distinguishing among them a priori, as he would put it. The Utilitarian purposes may all be more or less available as part of the General Justifying Aim of particular offense categories. ${ }^{158}$ Even Deterrence requires a "leap of faith"159 and, like Rehabilitation, probably helps to justify punishment only for some crimes. ${ }^{160}$ It seems to me that we are left with the necessity of justifying the practice of punishment not in a generalized way, and not $a$ priori, but with respect to individual crimes, and on the basis of some attention to empirical fact. In such a process, there is no reason to look for a single adequate justifying purpose; we may even assume that none of the traditional purposes of punishment is sufficient by itself to offset the Utilitarian losses, and that a satisfactory justification of the practice will have to proceed crime by crime and draw Utilitarian gains from all of the traditional purposes together. ${ }^{101}$

Packer's discussion of the justification of punishment concludes on the observation that "All that I have been concerned to show is that

155. Packer observes that this is the case-although from the rather different perspective that "the experience of suffering punishment for a present offense may be the strongest rehabilitative force that we now possess" (p. 56)-but fails to draw the apparent conclusion that there is a little a priori moral difference between the two.

156. Pp. 57.58.

157. See p. 1423 supra.

158. Packer suggests that "behavioral" justifications, as justifying purposes, tend to conflict somewhat with "blameworthiness" as a principle of Distribution. (pp. 50.51) It is not at all clear that the case is any different for Deterrence. And all this really amounts to saying is that if "blameworthiness" or some other restrictive principle in implementation is an essential part of the practice of punishment, such a practice may not always be a very effective one for some "behaviorial" objectives.

159. P. 63 .

160. Cf. Chambliss, Types of Deviance and the Effectiveness of Legal Sanctions, 1967 Wis. L. REv. 703.

161. Packer does acknowledge this at p. 140, but his argument seems unaffected by the acknowledgement. 
any unitary theory of punishment is inadequate and that all theoriesnot simply deterrence-that start from the utilitarian premise suffer from the same moral embarrassment."102 "Embarrassment" seems to refer back to a remark to the effect that the Kantian objection to Deterrence-that it treats a man as a means to the general good rather than as an end in himself -is equally true of all the Preventive justifications, so that the purported benevolence of reform-minded "behaviorists" is at best a mitigation of the moral problem. ${ }^{103}$ Perhaps it also refers to his discussion of how little we know about the operation of any of the Preventive modes of punishment. At any rate, his ultimate conclusion is that the Utilitarian purposes give "a satisfactory account of the general justification for punishment,"104 but that "we are forced to recognize the moral ambiguity of punishment," whatever that means. ${ }^{105}$

From this confused and inconclusive notion of "ambiguity" Packer derives-with no intervening argument that I can find-his conclusion that the principle of "culpability" must limit the pursuit of Preventive goals. This is what he calls his "integrated theory of punishment,"160 and it is with "culpability" in Distribution that he at last successfully eludes the dilemma of being either a "behaviorist" or a Retributivist. But "culpability" in Distribution is as consistent with Rehabilitation and Incapacitation in General Justifying Aim as with Deterrence, so all Packer ultimately comes up with is the proposition that pursuit of any Utilitarian purpose must be thus limited. Except that Packer is muddled where Hart is clear, I therefore cannot see that his "integrated theory" is significantly different from Hart's argument that Utilitarian considerations are exclusively relevant as to the General Justifying Aim of the practice of punishment, while non-Utilitarian (Retributive) restrictions are morally required in the rules of implementation which determine the Distribution of punishment. In this way it is possible to avoid the Retributivist horribles without being subject to the "behaviorist" attack that one's concessions to Retributivism leave one in a position resting on a "desire to see other people suffer."107 But since Packer does not give a clear account of the reasons for restricting the pursuit of Preventive purposes, it is impossible for him to give any

162. P. 60.

163. Pp. 53-54. Unfortunately, he never comes to terms with the Kantian problemhe does not, for example, try to show how his "culpability" roles render the pursuit of Utilitarian goals consistent with the use-as-a-means objection.

164. P. 6I.

165. P. 63. Gf. p. 73, and see pp. 1397-1400 supra.

166. P. 62.

167. P. 16. 
content to the principle of "culpability" and its derivative doctrines. As we have already seen, his entire argument at this critical point degenerates into trivial circularity. I suppose a convinced "behaviorist" would describe Packer as one who, having accepted Prevention as the objective of the enterprise, then imposes inexplicable (or, at least, unexplained) restrictions upon the effectiveness of the criminal law to ac. complish it. His position may not rest on a Retributive "desire to see other people suffer" but it apparently rests on an equally irrational desire to see some arbitrary part of the full group who ought, preventively. speaking, to be suffering (or being treated, etc), left free to offend again and encourager les autres.

\section{E. The Doctrinal Consequences of "Rationale"}

It follows that there is not much to be said about Packer's account of the specific doctrinal content he assigns to "culpability."108 Furthermore, this account is so shot through with confusions and mistakes, some of the more important of which I have already discussed, that it simply will not support serious critical examination. We are rarely advanced beyond the unintelligibility of propositions such as: "These doctrines express the criminal law's compromise between the inevitability and the ambiguity of punishment."160

Packer begins with a chapter on the requirement of conduct, which he does not define (except by distinguishing it from "thoughts and emotions"170). The failure of his professed effort to derive "doctrinal content" from "integrated rationale" is particularly apparent here, because the trivial circularity of his argument against a "behavioral" criminal law-which would concern itself, in punishing an offender, ${ }^{171}$ with future dangerousness rather than past misconduct-reveals itself in a single passage which spans only two pages. ${ }^{172} \mathrm{He}$ seeks to account for the criminal law's dependence upon conduct in terms of the impor-

168. He proposes to discuss only some "representative" doctrines, which "reveal the operational consequences of the rationale." "Taken as a whole they raise all the basic problems posed by criminal law doctrine." (p. 72) This claim is pretty dubious! he does not, for example, discuss any of the doctrines concerning causation, nor those concerning criminal agency.

169. P. 72 .

170. P. 73. Cf. notes 81 supra and 187 infra.

171. Much of Packer's argument against a "behavioral" criminal law deals only with a complete red herring, because he neglects the limitation of "punishment" to "offenders." See, e.g., p. 73; and see p. 1412 supra. Barbara Wootton, whom he takes as the leading advocate of a "behavioral" criminal law (p. 27), advocates no such contradiction in terms.

172. Pp. 74-75. 
tance of respecting the individual's capacity to control-through his behavior-what happens to him in life. He raises the determinist objection that people have no more control over what they do than over what sort of people they are, and that the restriction of the criminal law to conduct therefore protects a chimera. His answer is that,

Neither philosophic concepts nor psychological realities are actually at issue in the criminal larv. The idea of free will in relation to conduct is not, in the legal system, a statement of fact, but rather a value preference having very little to do with the metaphysics of determinism and free will .... Very simply, the law treats man's conduct as autonomous and willed, not because it is, but because it is desirable to proceed as if it were. ${ }^{173}$

This passage has many faults, primarily in the area of intelligibility, but it certainly does bring him right up against the necessity of showing why "it is desirable to proceed as if it were." All he tells us is that it is desirable,

Because the capacity of the individual human being to live his life in reasonable freedom from socially imposed external constraints . . . would be fatally impaired unless the law provided a locus poenitentiae, a point of no return beyond which external restraints may be imposed but before which the individual is free ... of the ... social compulsions of the law. ${ }^{174}$

This perhaps tells us that there ought to be a point, but not that conduct-as contrasted, for example, with evil intent-ought to be that point. More importantly, it is entirely circular. We started off trying to discover why conduct is an important restriction. Respect for the capacity of self-control was the response-its existence was doubtedthe reply was that the law must proceed as if it existed-the query "why" had to be answered-and we are back to the notion that selfcontrol is important, and would be "fatally impaired" unless the law respected it. In short, we act as if self-control existed in order not to impair it. The conduct requirement is essential because it preserves "autonomy," which is important because it restricts the criminal law to conduct. ${ }^{175}$ This surely will not do-a circle so small and uninfor-

173. P. 75.

174. $I d$.

175. Packer also makes what can be read as a hint at a political Constitutional basis for the conduct requirement (compare Note, The Serpent Beguiled Are and I Did Eat: The Constitutional Status of the Entrapinent Defense, 74 YALE L.J. 924 (1965)) and/or a Holmesian tolerability basis (see p. 1403 supra): "This self-denying ordinance is what makes the criminal law tolerable as a means of social control in a free and open saciety." (p. 96) 
mative is nothing more than an ipse dixit, and after reading the passage all we really know is that Packer is attracted to the ideas of autonomy and self-control.

One of the special vices of this kind of half-concealed dogmatism is that it avoids the necessity of coming to grips with the hardest question of all: what is the idea of self-control, whose existence is being debated? Anyone who has ever tried to puzzle that one out will remember how obscure even a brief reflection makes it. ${ }^{178}$ There are at least three honorable ways, other than capitulation, to deal with the Determinist challenge to the idea of self-control. One could meet it head-on and try to vindicate the capacity for self-control. Or one could rest either on blunt ethical assertion ("I believe that respect for the capacity of self-control is morally essential") or on a genuine Utilitarian argtment for the necessity of acting as if self-control existed. Any of these approaches would be almost forced to include an account of what "selfcontrol" is.

Packer is not content to rest the conduct limitation on his "integrated rationale." A considerable part of his argument on the role of conduct in criminal responsibility is devoted to the proposition that a "behavioral" criminal law which abandoned the limitation to conduct ${ }^{177}$ would violate the principle of legality. It may be possible to make a significant argument connecting conduct and legality, ${ }^{178}$ but since Packer does not try to do so, his association of the two seems to be based only on the fact that the principle of legality is sometimes expressed in the form "conduct may not be treated as criminal unless it has been so defined by an authority having the institutional competence to do so before it has taken place."170 This form of expression is presumably accidental-related only to the fact that the existing crim. inal law is what is in mind at the time-and by no means suggests, for example, either that civil commitment of the insane violates the principle of legality or that the principle has no applicability to civil commitment.

In any event, when Packer purports to derive the conduct limitation from two corollaries of the principle of legality, he is just wrong: it does not follow the void-for-vagueness doctrine, or the rule of strict

176. See Wootton, Diminished Responsibility: A Layman's View, 76 L.Q. REv. 224 (1960) for a particularly lucid presentation of the difficulty. See 2 J.F. STErifN, A HisTORY OF THE CRIMINAL LAW OF ENCLAND 168.86 (1883), for a particularly lucid effort to give meaning to the idea of self-control.

177. But cf. note 171 supra.

178. Cf., e.g., Note, supra note 175 , at $946-48$.

179. P. 80 . 
construction of penal statutes, that the criminal law must be restricted to conduct. We can have a clear, prospective statute that involves no conduct (his own example of a statute forbidding "addiction" to narcotics demonstrates this, assuming, of course, that "addiction" is a matter only of status-which he does not deny). We can also have a vague, retroactive statute which applies only to conduct. Packer says "It is no accident that the current constitutional attack on status crimes is based on the vagueness doctrine; for status crimes represent one of the most clear-cut instances in our received criminal law of a purely behavioral emphasis on prediction."180 But it is an accident-derived from the fortuity that the vagrancy offense is both vague and a status offense. ${ }^{181}$ The attack on other status crimes, which involve no obvious departure from constitutional requirements of specificity (drunkenness and addiction), has not been in terms of vagueness at all, but in terms of the various constitutional pegs on which the conduct requirement can be hung. ${ }^{182}$

Packer's treatment of legality and conduct is spread over many pages. ${ }^{183}$ It culminates in a grand confusion of the conduct rule, status offenses and preventive detention, the principle of legality and vagueness, and the law of attempts. ${ }^{184}$ The climax comes in a paragraph which is so intricately confused that I must annotate the passage in its entirety:

To begin with, there is no such thing as a general crime of attempt. There are only attempts to commit particular crimes. [An observation which bears some argument, which seems to trace back to Thurman Arnold's Criminal Attempts-The Rise and Fall of an Abstraction, 40 YALE L.J. 53 (1930), and which is incipiently intelligible.] If I take steps to marry my first cousin in a jurisdiction that does not treat such marriages as incestuous, we can be standing at the altar with the preacher about to conduct the marriage service, and I still will not have committed

180. Pp. 96-97.

181. In fact, it is doubtful whether vagrancy, properly analyzed, is really a crime of mere status-it has been observed that it seems reducible to a prohibition "of the conduct bringing about the condition." H. Hart, The Aims of the Criminal Low, 28 LAW \& CoNTEMP. PROB. 401, 403 n. 6 (1958). For further confusion in Packer's treatment of status offenses, see note 241 infra.

182. See Robinson v. California, 370 U.S. 660 (1962); Powell v. Texas, 392 U.S. 514 (1968).

183. Pp. 79-102.

184. Packer's treatment of the conduct limitation is also fundamentally unsatisfactory because of his assumption that it is a compromise with the Utilitarian objective of prevention by punishment. It seems, however, first, to be intrinsic to the very concept of punishment and part of the practice for which a Utilitarian justification is to be given, and second, to be itself susceptible of a Utilitarian justification. See pp. 1151.53 infra; note 38 supra. 
attempted incest. [The relationship of this to the first point is obscure-either it is nonsensically irrelevant, or it calls into question the apparent meaning of that which it is intended to support, and requires us to re-read the first point as being "it is no crime to attempt to do something which is legal," which is trivial, instead of "the nature of an attempt is unique to every crime," which is not.] Here we see in operation the most basic limiting aspect of the law of attempts, its dependency on the principle of legality for its legitimacy. [So, the first point does have to be trivialized.] Contrast this dependency with the broad sweep of status offenses [which, Packer to the contrary notwithstanding, do not necessarily involve any departure from the principle of legality, since they can be precisely and narrowly drawn] as well as of the explicitly outlawed arrest on suspicion [if outlawed, it is hard to see how arrests on suspicion would violate the principle of legality, except perhaps to the extent they are condoned - a connection with the principle of legality which seems utterly different from any that the law of attempts might have; if not outlawed, it would require considerable argument to show that legal arrests on suspicion violate the principle of legality; in either event, there is no connection in particular with the conduct requirement, which is what the whole paragraph is about] and the durability of the conduct limitation in the criminal law becomes manifest. ${ }^{185}$

There seem to be two simple threads of thought here. First, the law of attempts is consistent with the principle of legality because it is no crime to attempt that which is legal. Second, the law of attempts requires conduct. It is hard to imagine a paragraph in which they were more obscurely put, more wholly confused with each other, and more cluttered up with erroneous parentheticals designed only to show that there are other crimes which violate the principle of legality or do not require conduct, but failing at even that modest task. ${ }^{180}$

185. P. 100 .

186.

Note: Packer on Legality and Discretion

Packer's treatment of the principle of legality and associated problems is so wholly un. satisfactory that some further observations seem called for.

Although he never gives a careful account of what it is, or how it operates in a legal system, Packer thinks the principle of legality is of great importance-but not in what is usually thought of as its major theatre of operation, the judicial system:

In the judicial process the principle of legality is not essential to guarding against abuses of discretion because other checks accomplish the same thing .... The fact that courts operate in the open according to a system of reasoning that is subjectcd to the scrutiny of an interested audience, both professional and lay, militates agatinst any but the most marginal invasions of the values represented by the principle of legality. (p. 88)

To begin with, this passage is shot through with a basic confusion: is the principle inessential because of public scrutiny, or is it enforced by public scrutiny? And the 
passage also assumes as fact that the work of courts is effectively scrutinized, and that such scrutiny works in favor of the principle of legality. Both of these comforting assumptions are surely problematic.

It seems to me that it is probably a misrepresentation to assert baldly that judicial deviations from the principle of legality occur "rather more frequently in Great Britain than in this country ...." (p. 91) Packer seems to have only Shaw v. Director of Public Prosecutions, [1961] 2 W.L.R. 897, in mind. One could offset against that cases such as Ginzburg v. United States, 383 U.S. 463 (1960) (judicial creation of crime of "pandering"). The subject is obviously an extremely subtle and complex one, howerer, and single cases such as Shaw are of very limited relevance to an overall evaluation.

Packer's complacency with respect to the American judicial process apparently rests in large measure upon the high standard of proof in criminal cases. It "is a formidable barrier to arbitrary prosecution; it is also a formidable barrier to easy conviction." (p. 137) I do not know what sort of evidence he might think could support the claim. I wish I felt so sanguine. See Griffiths, supra note 17, at 381 n.81. And cf. M. SLAter, TuE TRIAL OF Jomo KenYaTta (1955).

It is difficult, in short, to take Packer's treatment of the importance of the principle of legality in relation to judicial proceedings as anything more than wishful thinking intermingled with political propaganda of a slightly chauvinist tinge, masquerading as scholarly analysis.

It is to prosecutors and police that the principle, according to Packer, has its most critical application. Without it, their "discretion" would be a serious danger. "The basic trouble with discretion is simply that it is lawless, in the literal sense of the word." (p. 290) His repetition of this old canard ignores what has recently been written on the subject. See, e.g., Dworkin, Judicial Discretion, 60 J. PHIL. 624 (1963); Dworkin, The Model of Rules, 35 U. CHI. L. REv. 14 (1967). Cf. J. Goldstein, Police Discretion Not to Involic the Criminal Process: Low Pisibility Decisions in the Administration of Justice, 69 YaLE L.J. 543 (1960). Furthermore, Packer's own discussion of "discretion" is permeated by confusions and contradictions. He never tells us what he means by "discretion" or by "lawless," except by implication in a sentence which is transparently circular: "If police or prosecutors find themselves free (or compelled) to pick and choose among known or knowable instances of criminal conduct, they are making a judgment which in a society based on law should be made only by those to whom the making of law is entrusted." (Id.) This is to beg two questions-whether discretion is "the making of law," and whether (whatever it is) the police and prosecutors are "entrusted" with it. Instead of dealing with these questions, Packer tells us only that it ought not be entrusted to police and prosecutors because their "personal and idiosyncratic values" should not be substituted for "the rough approximation of community values that emerges from the legislative process." (Id.) That is to beg the question about what "discretion" is, once again, by identifying it with mere personal whim, and to substitute a banal placebo for solid thought. Furthermore, Packer is not even consistent; his argument varies between the position that "discretion" is "lawless" in its very nature and the quite different position that is is only "arbitrary police and prosecutorial discretion" (p. 301, cmplasis auded) and the "abuse of discretion" (p. 290, emphasis added) to which the principle of legality" is addressed.

There is a latent peculiarity in Packer's position that while the principle of legality finds its greatest importance in relation to police and prosecutors, its actual implementation is through the courts. The idea seems to be that if the courts strictly limit themselves to what has clearly been denominated as criminal, police and prosccutors will not be tempted to speculate on what some judge might be persuaded to add, ad hoc, to the category of crimes. (Pp. 87-91) One has some difficulty seeing how a principle which operates immediately on one actor in the process can possibly be conceived to have a norc important application to those whom it affects only derivatively. Padier seems to neglect the fact that to the extent that there is judicial departure from the principle immediate evil is done-defendants are unjustly convicted. The effect on police and prosecutors may be part of the totality of reasons why we regard such convictions as "unjust," or it may be a collateral consequence of such "injustice," but I can see no way in which it could be regarded as of greater importance.

Packer's position requires him to be able to distinguish clearly between the judicial process and the police-prosecutorial process. He does not limit himself to a contingent claim for a particular system of criminal justice administration, but scems to have the idea that his discussion of legality is of general, analytic validity. As far as I can ece, his only effort to support the proposition that the distinction is a fundamental one rests upon misrepresentation of fact. He asserts that "no one has ever discovered a police or prosecutorial organization that behaves like a court"-i.e., with the judicial virtues of "the model of openness, even-handedness, and rationality." (p. 89) I do not 
Having thus sought to establish the limitation of punishment in implementation to conduct on the basis of the principle of culpability, Packer turns to consider "the difficult question of whether and to what

think that takes at all adequate account of the relatively judicialized prosecutorial function in the ideal type, at least, of the juge d'instruction system (see, e.g., Judicial Super. vision of Pre-Trial Procedure, in G. Mueller \& F. LePoole-Gruffiris, Comparative CrImINal Procedure (1969)); nor does it leave room for an account of the repeated pro. cess in English legal history whereby an initially prosecutorial function gradually becomes imbued with more and more adjudicative aspects until it becomes recognizcd as a part of the "judicial" process (see, e.g., P. Deviln, The Criminat Prosecution in ENGLAND 1-30 (1958)).

Finally, to establish the importance of the principle, Packer attempts to slow the unavoidability of police and prosecutorial organizations. His effort in this direction invokes two propositions whose truth he apparently takes to be obvious-when it is preciscly their problematic character which one would expect a scholar in the field to be cun. phasizing:

(1) In theory, he says, one could "leave the invocation of the process entirely to the initiative of the persons who claimed to have been injured. "this is of course precisely" the way the civil process for private injury works. (p. 87) But is this the way the civil process actually works? There seem to be few empirical studies of the subject (cf. Macaulay, Non-Contractual Relations in Business, 28 AM. Soc. Rev. 55 (1963)), but I expect that invocation of the civil process is far more complex than Packer's "of coursc" lets on. Consider, for example, the institutional arrangements and considerations re. flected in Brotherhood of R. Trainmen v. Virginia, 377 U.S. (1960) (cf. Zimroth, Group Legal Services and the Constitution, 76 YALE L.J. 966 (1967)) and Watson v. Employers Liability Corp., 348 U.S. 66 (1954).

(2) He asserts that a system of private prosecution would "plainly" not "serve the ends of a system of criminal law" (p. 87):

[E]nforcement would be so sporadic and happenstance that the goal of prevention would not be served. People who were injured would often not complain: bectuse they would be too busy, too lazy, too brave, too timid, or whatever. Or, though they might wish to complain, they might be unable to do so because they did not know the identity of the person who injured them. Or, though they suspected that they had been in some way injured, they might not even be sure enough of that fact to complain. (p. 88)

It may be that private prosecution is not an available alternative. But this suggestion of reasons why "It is plain [that] ... it is essential to have police and prosecutors ...." (p. 88) simply will not do. To begin with, some systems have managed rather well with a primary dependence on private prosecution. See, e.g., 1 J.F. STEFHEN, A HISTOHY of The CRiminal Law of ENGLand 493-503 (1883). More importantly here, all of the reasons Packer puts forth as obvious objections to private prosecution are in fact characteristic, according to recent investigations, of the public system we actually have. Enforcement is "sporadic and happenstance," see, e.g., J. Goldstein, Police Discretion Not to Invoke the Criminal Process: Low Visibility Decisions in the Administration of Justice, 69 YALI L.J. 543 (1960); Report of THE PREsident's Commission on LAW ENForcement ano ADMiniSTRATION OF JUSTICE $43-44$ (1967). The police seem in fact to engage in very little solving of crimes-they simply process those offenders who fall ripe into their hands, sec, $c . f_{4}$, Project, Interrogations in New Haven: The Impact of Miranda, 76 YaLE L.J. 1519, 1588 (1967); Black \& Reiss, Police Control of Juveniles, 35 AM. Soc. REv. 63 (1970). Most significantly of all, a recent study shows that the very criteria Packer mentions as likcly to affect private decisions in fact strongly affect police decisions whether to initiate even the most tentative steps of the process-see Black, Production of Crime Rates, 35 AM. Soc. Rev. (Aûg. 1970). Cf. J. Goldstein, supra.

It is difficult not to conclude that before the applicability of the principle of legality to the various stages of the criminal process can sensibly be discussed, it is neccssary not only to have a clear idea what the principle is, what it ought to preclude, and what the "model" of its effective operation would be, but also what the actual characteristics of the functioning of the process are; and also how some roles in the process differ from others, and how the criminal process differs from other official dispute-settlement pro. cesses. It is impossible not to conclude that Packer's treatment of the principle of legal. ity fails conspicuously in all of these critical respects. 
extent factors other than the actor's conduct should be taken into account in determining his criminality." 187

He begins by describing "two analytic approaches to the question of mens rea."188 One, "the positive approach, attempts to identify particular states of mind and to attribute them to each of the material elements constituting the definition of particular criminal offenses." 189 The other, "which we may call the negative approach," treats the proscribed "forms of conduct as being prima facie criminal unless the conduct takes place under certain circumstances having to do with the actor's state of mind"-that is, is subject to recognized "categories of justification and excuse."190 Packer's understanding of the issue between these "approaches" is as follows:

There is much learned disputation about the comparative merits of these two approaches. The positivists, if I may use that term, accuse the negativists of being sloppy; the negativists accuse the positivists of being rigid. The dispute is academic, in the pejorative sense of the word. Which approach one takes, or what combination of the two approaches one takes, depends on the analytic function that is being served at the moment. If one is engaged in drafting a criminal code, which must prescribe precisely what has to be proven to convict of crime and precisely what distinctions separate one crime from another ... there can be no doubt that the positive approach is much the superior. If, on the other hand, one is attempting to discern after the fact the true inwardness of judicial decisions, particularly in a criminal law system that does not include a highly developed set of legislative prescriptions, it seems equally plain that the negative approach is superior. ${ }^{101}$

This passage contains more than its fair share of unintelligibilitywhat, for instance, do "sloppy" and "rigid" refer to? Whatever could

187. P. 104. Packer's failure to describe what he means by the slippery vord "conduct" is particularly troublesome when he comes in this chapter to discuss mens rea, which (on his own view) has meaning only in relation to conduct. He gives more indications in this chapter than in the preceding one as to what he has in mind by "conduct," but by no means do they all point in the same direction. At least four possibilities suggest themselves: (1) "conduct" means "some more or less specific act or omiesion" (p. 103)-i.e., is just another word for the old-fashioned voluntary act requirement: (2) "conduct" means "an action or omission and its accompanying state of mind," whatever that means, cf. MODEL PENAL CODE $\S 1.13$; (3) "conduct" refers to the nontcehnical sense of "to act," in which it is a stand-in for any action verb, and the conduct requirement performs only the function of preventing punishment when the accused has not done anything at all; (4) "conduct" is used in the sense in which Glanville Williams uses "actus reus"-i.e., to refer to all elements of an offense except the mens rea element (see G. Williams, Criminal Law-The General Part 16.21 (2d ed. 1961).

188. P. 105.

189. Id.

190. Pp. 106-07.

191. Pp. 106-07. 
"the true inwardness of judicial decisions" be, and after what "fact" would we want to discern it? The heart of the matter is, that Packer seems to have no idea what the problem is. Smug functionalism ${ }^{102}$ cannot smooth over a dispute between two "approaches" when the essence of one is to deny the existence of the entity which is the essence of the other. The "positive approach" gives names to supposed empirical entities known as "states of mind" and makes criminal liability turn on their presence vel non in particular cases. The "negative approach" denies that the supposed "states of mind" have any identifiable referent in human experience.

Packer, who thinks the "positive approach" enables one to "prescribe precisely what has to be proven to convict of crime" and "reveals the complexity of the idea of mental element," ${ }^{193}$ never defines what he and the "positive approach" mean by a "state of mind," and does not explain how "negligence" and "recklessness" could possibly be names of anything called "states of mind" (since they involve implicit reference to a standard of conduct). Whatever a "state of mind" may be, is it possible to take "acting knowingly" as referring to one?-is knowledge a "state of mind"? "Intention" perhaps might, in some of its senses, be thought of as the name of a "state of mind," 104 but is this true of its central use in the criminal law? The gist of the "negative approach" is that there is no single entity- "state of mind"-present in the heads of all persons who act intentionally. "Intentionally" is a mere stand-in for the nonexistence of a collection of excuses ("did he do it intentionally?" elicits the response, "well, it wasn't by accident, or by mistake" - and to require that an act be done intentionally before liability attaches does not call for the discovery of a specinl "state of mind" in the actor's head, but only indicates that the appropriate circumstances of accident and mistake will excuse). ${ }^{105}$ Trouble comes when "intentionally" is hypostatized into "intention" and it is inferred from the existence of such a noun that the entity whose name it purports to be must exist somewhere in people's heads. ${ }^{100}$

This dispute is far from "academic." If we decide that the "negativist" position is right, then we are not only saved from the futile

192. Cf. notes 62 and 68 supra, and note 241 infra.

193. P. 106.

194. E.g., in H.L.A. Hart's sense of "further intention" and "bare intention," H.L.A. HART, supra note 26, at 117 . The point is that to say " $\mathrm{X}$ intended to dispose of the corpse" is to refer to something in X's mind, while to say " $\mathrm{X}$ disposed of the corpse intentionally" is not-it negatives the possibility of accident or mistake, but has no further meaning.

195. See note 38 supra.

196. Cf. T. Hobbes, Leviathan 59 (Liberal Arts ed. 1958). 
effort to reconstruct a sound account of human action from fictitious elements, but we can avoid some perennial problems in criminal law theory. We would have no need for the troublesome "presumption" that an actor "intends" the natural and probable consequences of his acts if we were not trying to put into his head a required state of mind. We would be less likely to make the mistake of contrasting negligence as a mode of culpability with the others on the ground that it is the mere absence of any state of mind and hence an inadequate basis for the assessment of fault. ${ }^{107}$ Nor could we get hung up on the supposed anomalousness of a conviction, for an offense whose mode of culpability is negligence, of an actor who clearly committed it intentionally ${ }^{198}$-if the modes of culpability simply indicate what sorts of excuses are allowable for various crimes, a crime which can be committed negligently is one as to which excuses good against intentional crimes are not accepted, but the person who commits it intentionally will surely not have available to him excuses good against a charge of negligence (e.g., "unavoidable accident"). The confusion, and the seeming anomaly, arises only because "negligence" is supposed to refer to one "state of mind" which could obviously not be in the actor's head if another "state of mind," "intention," was there.

While Packer therefore completely misses the essence of a dispute which lies at the heart of the jurisprudence of criminal law, for incomprehensible reasons which he supposes are "functional" he happens to avoid some of the worse mystification he apparently would have engaged in had he been drafting a code. He will, he says, rely "mainly on the negative approach to the problems of mens rea because that approach focuses on the categories of justification [sic] ${ }^{100}$ and excuse ... that comprise the minimal doctrinal content of a criminal law whose rationale is based on the integrated system developed in earlier chapters"200 (leaving thus wholly obscure how he could possibly approve, for legislative uses, a "positive" approach which does not focus on

197. See Wasserstrom, Strict Liability in the Criminal Law, 12 STAN. L. REv. 731, 743 (1960); and Packer (p. 127). But cf. Packer (pp. 128-29) and H.InA. Harr, supra note 26, at 145-52. See also notes 38 supra and 233 infra.

198. Cf. H.L.A. HART, supra note 26, at 259 (note).

199. Packer often, as here, confuses or assimilates justifications and excuses. See generally pp. 108-121. For example, he applies "cxcuse" to the situation of a motorist running a red light because he is taking a critically ill child to the hospital (p. 112)-which seems (unless the motorist has misevaluated the situation) a pretty clear case of justification. Justifications have nothing to do with mens rea or culpability, and the reason we accept them as defenses is very simple: we have no wish to discourage the behavior in. volved (e.g., appropriate self-defense).

200. P. 107 . 
matters that are, by his own account, crucial to the justifiability of the practice of punishment).

Packer's discussion of "mens rea or the mental element," 001 is vitiated at the start by his inattention to the meaning of a basic word. Mens rea rests, he says, on the idea of mistake-"when we say that a person ... lacked the requisite mens rea, what we mean is that he made a mistake about some matter ... that constitutes a material element of the offense." 202 "Strict liability"- -liability without regard to the doctrines of mens rea-can, he says "be defined as the refusal to pay atten. tion to a claim of mistake."203 In fact, however, the excuses that Packer has in mind go much further than mistakes, as his own examples dem* onstrate. Failure to file a tax return due to ignorance of the requirement of filing ${ }^{204}$ is no mistake. When accused of it, one would say, "I made a mistake," but rather, "I did not know." This ignorance is culpable or not depending upon our assessment of its excusability. A mis" taken failure to file, by contrast, would result from a mis-calculation of income, a mis-reading of the law, a mis-addressing of the envelope, or the like. Furthermore, Packer has left out of his account and of his examples the whole category of accidents, which, as Austin has shown, are importantly if subtly different from mistakes. ${ }^{205}$ And there is also that half of the assortment of claims of necessity, duress, self-defense and the like which is excuse rather than justification-i.e., where we do not prefer the person to have done what he did rather than suffering the alternative, but nevertheless are willing to pay our respect to human weakness and let the incident pass. Certainly these latter are not properly regarded as mistakes, ${ }^{206}$ and yet Packer agrees that they are to be

201. P. 122.

202. Id. (italics added).

203. P. 123 (italics added). This statement is wrong on its face. Packer argues that strict liability excludes "negligence as a . . mode of culpability." (pp. 123, 124) Many mistakes are rejected as defenses because they are negligent. See pp. 1445.48 infra for discussion of Packer's views of strict liability and liability for negligence.

204. P. 122.

205. J.L. Austin, A Plea for Excuses, in Philosophical Papers 132-33 (1961):

You have a donkey, so have $I$, and they graze in the same field. The day comcs

when I conceive a dislike for mine. I go to shoot it, draw a bead on it, firc: tho

brute falls in its tracks. I inspect the victim, and find to my horror that it is

your donkey. I appear on your doorstep with the remains and say-what? 'I say,

old sport, I'm awfully sorry, etc., I've shot your donkey by accillent'? Or 'by mis.

take? Then again, I go to shoot my donkey as before, draw a bead on it, fire-but

as I do, the beasts move, and to my horror yours falls. Again the scene on the door-

step-what do I say? 'By mistake'? Or 'by accident'? (Id. at n.l).

206. Except in a quite different use of the word-"it was a mistake for him to have done it" rather than "he did it by mistake."

It is true, of course, that therc can be an excuse of a mistaken belief in the cxistence of a justifying circumstance-e.g., an erroneous belief that one is about to be homicidally assaulted. 
included within the concept of mens rea. ${ }^{207}$ The modes-of-culpability excuses ("I didn't do it intentionally . . . it was an accident," etc.) are not, at least prima facie, the same as the lack-of-fair-chance-to-conform excuses ("I couldn't help it . . . I was so hungry," etc.). ${ }^{208}$

It is, in short, completely wrong and inconsistent with what Packer himself asserts, to identify mens rea with mistake. His inattention to the meaning of the word "mistake" has serious consequences: by identifying mens rea with excuse $e^{209}$ but limiting his attention to only one kind of excuse, i.e., mistake, he avoids the crucial inquiry into whether a fundamental element of the justification for invoking the criminal law is missing in the situations covered by all of the various kinds of excuses which make up mens rea, or whether some excuses are to be accounted for by quite different considerations from those responsible for others. Such an effort to come to terms with the whole category of excuses might, for example, have made it impossible for him to dismiss as merely "wrongheaded" the suggestion that the insanity defense is an intrinsic part of the requirement of mens rea.210 It might also have led him to a conception of mens rea itself somewhat more interesting and significant than the empty assertions that "culpability is an appropriate criterion for limiting the reach of state intervention,"211 that it is "hypocritical and therefore wrong" to punish for something the ordinary man might have done in the same circumstances, ${ }^{212}$ that we recognize excuses "only because we choose to indulge our sense of moral fitness"213 and because "the moral quality of an act inheres not in the act but in the actor's frame of mind with respect to

207. Pp. 108-09.

208. Cf. note 219 infra for discussion of the moral basis for these excuses.

209. Packer is not even consistent on this, however. He says that "all excuses involve mens rea" (p. 108) and that insanity is "an excusing condition" (p. 131), but denies that insanity goes to mens rea. (p. 134) This confusion may be based on his notion that the insanity defense "is not at all addressed to particular elements of the offense but rather to the actor's general mental condition" (p. 135). I have suggested elsewhere that this anti-functional approach makes it impossible to give a coherent justification for the insanity defense. Griffiths, supra note 17, at 377 n. 73 . See pp. 1448.51 infra for discussion of Packer's conception of the insanity defense.

210. P. 135. Cf. also note 243 infra and accompanying text. Packer refers to the suggestion as put forth in Goldstein \& Katz, Abolish the "Insanity Defense"-Why Noll, 72 YAIE L.J. 853 (1963). His treatment of this important article is altogether unfortu. nate. At another place he identifies it with the view that the effect of climinating the insanity defense would be to convict all those now acquitted by it. (p. 132) This is Barbara Wootton's proposal (CRIAE AND THE CRIMINAL LAW (1963)) and is exactly the opposite of Goldstein \& Katz' argument that if the defense were abolished those who now invoke it at the price of an automatic insanity commitment if they succeed (but $c$. Bolton v. Harris, 395 F.2d 642 (D.C. Cir. (1968)) would instead receive outright acquit: tals on ground of lack of mens rea.

211. P. 112.

212. P. 118.

213. Id. 
it."214 The superior "morality" of recognizing excuses "is clear," says; people who can claim them "ought to be exculpated," and will be "in any civilized legal system." ${ }^{216}$ By the end of all this, ${ }^{217}$ we know that Packer thinks recognition of some vague and unspecified category of excuses is a good thing, but we have very little idea why. What all his ipse dixitism about "morality" takes the place of is careful attention to the relationship between the requirements of a justification for the distinctive practice of criminal punishment and the consequent limitntion upon the occasions appropriate for its invocation.

In his own vindication of excuses, Packer begins with the common but necessary observation that the traditional Utilitarian accounts of them in terms of the calculus of Deterrence do not work-even if, for example, the fact that the defendant could not help what he did meant that his act was not deterrable and he needed no restraint or rehabilitation, ${ }^{218}$ it would not follow that his punishment could not help deter others from, or his acquittal entice them into, crime.

214. P. 121.

215. P. 121 .

216. P. 120.

217. The passage concerned also invokes the notion of "autonomy" with which 1 have already dealt.

218. In fact, neither of these is necessarily true at all, although Packer secms to assumc that they are. Cf. note 224 infra.

219. Pp. 108-121 passim. Cf. H.L.A. HART, supra note 26, at 18-19, 77-78, for analogous criticism of Bentham's fallacious utilitarian account of opportunity-to conform excuses (which also crops up in the Comments to the MOdeL PENAL Code-see Tentative Draft No. 4, Comments to $\$ 4.01$, p. 156). Actually, there is a somewhat more sophisticated Preventive-Utilitarian position, not subject to all of Packer and Fart's criticism, in which it is not the non-deterrability of the actor, but the fact that the deterrable objects of the law's threats do not (because of the actor's "excuse") regard themselves as in the same category with the actor, which brings the requirement of frugality of punishment into play. See, e.g., Benn, An Approach to the Problems of Punishment, 33 Putlcosorux 325, 333-34 (1958); Sprigge, A Utilitarian Reply to Dr. MaCloskey, 8 Ineuirx 264, 285 (1965); Michael \& Wechsler, supra note 38 , at 752 ff.

There is, however, a relationship between the fact that an actor was non-deterrable and a fundamental idea of justice, which is adumbrated by H.L.A. Hart (supra note 20 at 22) but which has not received the attention it deserves. If the actor was not accessible to the law's threats, then to punish him only for the sake of deterring those who were (or, in response to the more sophisticated Utilitarian account of excuses mentioncd above, for system-maintenance reasons such as eliminating the inducement to feign an cxcusccf. H.L.A. HART, supra note 26, at 19-20, 78-79 n. 43), is to use him for the general sacial good in a way more extreme than if he had had a fair chance to avoid the law's penalty. This is the issue in the moral crisis described by Melville in BILLY BUDD, surely one of the most sensitive and jurisprudentially sophisticated books ever written on the problem of criminal responsibility. The problem is essentially the same as in the case put at pp. 1455-56 infra, of the justifiability of capital punishment to enforce parking regulations fassuming, because it would deter so effectively, its rarity would make it "cheaper'). It seems that a fundamental principle of fairness in the distribution of the costs of social control is involved, analogous in its way to the idea that tax burdens ought to be "equally" distributed. See Rawls, Justice as Fairness, in Justice AND Social PoLICY (Olafscn, cch, 1961); H.L.A. HART, supra note 26, at 81. Cf. note 38 supra for a quite different, Utilitarian account of another sort of excuses: those going not to the opportunity to conform, but to the modes of culpability (cf. p. 1443 supra for this distinction). 
He never considers whether there might possibly be other Utilitarian accounts of the law of excuses. ${ }^{220}$ To the extent to which his "integrated rationale" is doing service, we must look through the fog of ipse dixitism to his concept of "culpability." Doing so, we are disappointed to find that "excuses"- their considerable variety is never refined beyond that, and indeed is obscured by Packer's mistake about "mistake" -apparently have a relationship to "culpability" so obvious that no argument for the connection is necessary. But then "culpability" itself is, as we have already seen, an entirely empty concept.221

The elimination of mens rea as an element of liability results in so-called "strict liability," about which there has been so much academic fulmination and so little judicial and legislative concern in recent years. Packer's showing that strict liability is incompatible with his fundamental principle of culpability is ironclad, of course, since as we saw he defines culpability in terms of the mens rea excuses. ${ }^{.22}$ Beyond that, his argument against strict liability repeats only the traditional rhetorical ipse dixitism, to which he adds a particularly confused version of a common fallacious Utilitarian argument. Defending the doctrine of mens rea against the Preventive claims for strict liability, he argues that "A society in which excuses were not allowed would be a society in which virtue would indeed have to be its orw reward ... If we are to be held liable for what we cannot help doing, there is little incentive to avoid what we can help doing. One may as well be hanged for a sheep as a lamb." ${ }^{\prime 223}$ But the fact that one cannot avoid punishment for things the risk of which one cannot utterly eliminate does not reduce the incentive to avoid punishment for things which one can help; Packer is assuming that strict liability means inevitable liability, which is not true.201

220. See note 38 supra.

221. See pp. 1397-1400 et seq. supra.

222. Pp. 123-127, 130-31; see also pp. 64-65. But cf. note 38 supra for criticism of the traditional analysis of strict liability which Packer uncritically transmits.

223. P. 65.

224. The infamous Mr. Prince could not, consistently with his wicked scheme, avoid the risk that the girl he took from her father's custody without consent was under 18, despite all her contrary assurances; one doubts that knowing that such 2 risk was unavoidable would have made him more inclined to take a girl he knew to be under 18. Regina v. Prince, [1875] L.R. 2 C.C.R. 154.

Prima facie one would suppose that strict liability might induce greater care than linbility for negligence-by eliminating whatever false or real hopes might arise from the fact of slippage in the administration of the law of negligence, and by encouraging un. reasonably careful conduct. But there may be subtle psychological arguments in support of Packer's assertion that strict liability with respect to the unavoidable would undermine the incentive to avoid the avoidable. He does not make them, cxcept to repeat the common assertion that "Punishment of the morally innocent does not reinforce onc's sense of identification as a law-abider, but rather undermines it." (p. 65) 
Unlike strict liability, liability for negligence can, Packer concludes, be viewed "as an extension of rather than a departure from the values associated with the mens rea concept." 225 If all he means is that mens rea comprises excuses and that liability for negligence simply recog. nizes fewer excuses than does liability for intentional conduct, this is pretty vacuous (and furthermore, it does not really distinguish strict liability, which also admits some excuses). ${ }^{220}$ If he means something more than this-as the word "values" might suggest-he does not say what it is. Once again, since he has never told us what "culpability" is, we cannot easily tell whether liability for negligent behavior could be compatible with the fundamental principle of "culpability." It is impossible to discuss his purported reconciliation of crimes of negligence with "culpability" because the passage wherein he claims to effect it conveys no meaning whatever. ${ }^{227}$

Packer's conception of negligence is contaminated by two mistakes about the nature of "negligence" which would, in any case, have made it impossible for him successfully to deal with the question of its propriety as a mode of culpability. First, his "state of mind" conception

Packer also does not address himself at all to the fact that liability for most-probably all-strict liability offenses is not absolutely but only relatively unavoidable: a inilktnat cannot utterly avoid the risk that he will faultlessly sell adulterated milk, but he does not have to be a milkman. Persons who doubt they can reduce the risk of an untoward occurrence to a low enough level will presumably steer clear of the activity, thus reducing the rate of such occurrences by those who choose to engage in it. Cf. G. Caladresi, Tile Costs of Accidents, 110, 119-23 (1970); Wasserstrom, Strict Liability in The Criminal Law, 12 STAN. L. REV. 731 (1960); note 38 supra.

Packer is particularly weak on what might be called the "economics" of criminal sanc. tions. In addition to the above mistake about the deterrent impact of strict liability, he asserts that "A man who is shown to have committed a homicide through an accident for which he was not at fault does not present a case for social protection through measures of incapacitation or reform." (p. 64) This overlooks both Wootton's point (supra note 49) that many faultless mishaps may present symptoms which, unless dealt with ("reform"t)", will predictably result in future faultless mishaps (c.g., a predisposition to violent behavior while sleepwalking-see $\mathrm{R}$. v. Cogdon, reported and discussed in Morris, Somnam. bulistic Homicide: Ghosts, Spiders, and North Koreans, 5 RES Jubtcarax 29 (1951); cf. also R. v. Kemp, (1957) 1 Q.B. 399 (defense of involuntary act due to insanity treated ats insanity defense- - with the consequences of an insanity acquittal)), as well as Calabresi's point that the rate of faultess mishaps in some activities (driving by persons over 60 , perhaps) may render those activities uneconomical (and warrant "incapacitation" $i$ ). Calabresi, The Decision for Accidents: An Approach to Nonfault Allocation of Costs, 78 HARv. L. REv. 713, 720 (1965). Cf. for other "economic" fallacies in Packer's analysis of sanctioning, pp. 1422-27 supra (Rehabilitation calculus), and pp. 1457.58 (fines) and note 330 (crime tariff) infra.

225. P. 129 .

226. See note 38 supra.

227. Pp. 128-29. Compare H.L.A. Hart's careful treatment of the negligence issute, Negligence, Mens Rea, and Criminal Responsibility, in H.L.A. HART, supra note 26; see also note 38 supra.

Packer also believes that recognition of the excuse of non-negligent mistakc of law is required by his theory, since the resulting conduct is not "blameworthy" and criminal punishment of it therefore "is objectionable for precisely those reasons that obtain in respect to strict liability." Pp. 129-30. This is all he has to say in support of his position, and there is little one can say about such a mindless disposing of so difficult a subject. 
of the culpability requirements leads him into the classic error that negligence is anomalous because "it is, by definition, the absence of a state of mind."22s But negligence is neither a "state of mind" nor the "absence" of one (whatever that could be)-it is, as a characterization of conduct, behavior which fails to meet a prescribed standard (often subsumed under the generality "due care"), and, as a mode of culpability, the recognition of some excuses against responsibility for an untoward occurrence, but not of others. Before one can decide how linbility for negligence fits into an acount of the practice of punishment, one must first keep absolutely distinct its mode of culpability aspect from its standard of conduct aspect: the "reasonable man," for example, and all the dispute about him, is relevant only to the latter aspect of negligence.

Failure to avoid the traditional confusion of negligence as a source of a standard of conduct with negligence as a mode of culpability is the second way in which Packer's conception of negligence is fundamentally inadequate from the outset. Because of it, he is worried by the fallacy that the "subjective awareness" involved in other modes of culpability is lacking from negligence. The received form of this confusion, which Packer transmits as dogma, is the supposed distinction between crimes of recklessness or intention, which are said to rest on an "internal standard" of conduct, and crimes of negligence, which involve an "external standard." 229 Even taken at face value, there are troubles with this-it is hard to imagine how we can ever tell what goes on in a man's mind except by applying general criteria to the behavior he exhibits; there is room for doubt that the whole "subjective" vocabulary means anything more than that. ${ }^{230}$ But the trouble goes beyond doubt as to the meaning of an "internal" standard. What is it about negligence which is "external"?: the standard of care-that is, the standard of permissible conduct. Is this not "external" to the potential criminal in all crimes? We do not look to the murderer to find out what conduct is prohibited by the offense of murder any more than we look to the negligent homicide to find out what constitutes negligence with respect to human life and limb. The reference to the "reasonable man" is no unfair presumption about actual actors, but a way of fixing the standard of care in particular circumstances. ${ }^{231}$ We make this confusion only

228. P. 127 .

229. P. 128.

230. Cf. O. W. Holnies, supra note 24. But cf. Sayre, Public Welfare Offenses, 33 ColuM. L. REv. 55, 56 n. 4 (1933), and notes 38 supra and 233 infra.

231. Cf. H.LA. Harr, supra note 26 at 154-55; G. CaldBresi, The Costs of acemeats 
because of the result-fixation of our law (we think "negligently" is a "state of mind" with respect to the bringing about of a result in the same way that "with intent" is ${ }^{232}$ ); if our offenses were defined as "doing an act unreasonably likely to cause $X$ " we would have no trouble seeing that of course the forbidden conduct must be "externally" delimited. The common objections to what goes by the misleading name of the "external standard" are directed to what is really only a sub-category of the tiresome maxim that ignorance of the law (the standard of conduct) is no excuse. Of course, knowledge of the standard may be more difficult for some than for others, but we do not now take account of that variation for intentional crimes either. It seems to me that in the case of both modes of culpability the "standard" is "external." And the culpability requirements, in both cases, are "internal" (to the extent that has meaning): a crime of negligence, by contrast with a crime of intention, is one in which fewer excuses excuse, but the excuses which are allowed address themselves to the circumstances and peculiarities of the actor. ${ }^{233}$

Packer's discussion of the "doctrinal consequences," in the form of excuses, of his "rationale," concludes with "A Gaveat on the Insanity Defense." Eschewing discussion of the contents of such a defense, he proposes to deal only with the question whether his theory requires "such an excusing condition." ${ }^{234}$ One wonders from the outset how it could be possible to discuss the "prior question" of the necessity of a rule without having settled on what the content of the rule is. ${ }^{2 a t}$ Utility does not demand the defense, he observes, but "the integrated rationale of criminal punishment" does. ${ }^{230}$ We have to have the defense, he says, because it is the criminal law's "chief paradigm of free will"-it is the recognition that some people are "significantly impaired

123-28 (1970) (Calabresi's phrase concerning the negligence standard, "conduct defined ex post," nicely captures the vagueness/ex post facto problem latent in crimes of negll: gence).

232. See pp. 1440-41 supra for the relation of the traditional confusion about "internal" and "external" standards to Packer's conception of "states of mind" as the subject-matter of mens rea.

233. I would suppose, for example, that non-negligent mistake of fact (i.c., where there is not a duty to know) which goes to the existence of circumstances calling for cxcrcisc of "reasonable care" or to the applicability of some other standard of conduct, excuses cvery bit as much in the case of crimes of negligence as it does in the case of crimes of intentlon. Cf. e.g., Wermeling v. Shattuck, $366 \mathrm{~Pa} .23,76 \mathrm{A.2d} 406$ (1950). Cf. note 38 infra for further discussion of the mental element in the various modes of culpability.

234. P. 131 .

235. Compare Wootton, Diminished Responsibility: A Layman's View, 76 L.Q. REv. 224, 229 (1960) ("logic might suggest that it is generally desirable to know what we are looking for before we set about trying to find it'”.

236. P. 132. 
in their volitional capacity."237 At this point he refers back to a circular argument I have already analyzed: the "philosophic controversy" over whether "human conduct is a matter of free choice" is "irrelevant," because "the criminal sanction operates as if human beings have free choice" in order to "serve purposes" even more important than Prevention (which he equates, wrongly, with Utility);238 those "purposes," however, seem to amount to nothing more than treating conduct as if it were free. ${ }^{239}$

His discussion of the necessity of recognizing the insanity defense concludes on a discouragingly familiar note of obscurantism:240

Again, it is not too important whether this [i.e., mental illness impairs some people's "volitional capacity"] is in fact the case. Nor is it too important how discriminating we are about drawing some kind of line to separate those suffering volitional impairment from the rest of us. The point is that some kind of line must be drawn in the face of our intuition, however wrongheaded it may be, that mental illness contributes to volitional impairment. How we perceive volitional impairment is a culturally conditioned matter. There is nothing immutable about it ... our attitudes toward volitional impairment can change, and the criminal law can change with them. As matters stand, however, to impose the moral condemnation of a criminal conviction on a person who is thought to have acted in a state of severe volitional impairment would be to abandon the notion of culpability in its most crucial use. ${ }^{241}$

237. Pp. 132-33.

238. See pp. 1451-53 infra.

239. P. 132. See pp. 1432-33 supra.

240. P. 133.

241. Packer's discussion of the relationship between "illness," the insanity defense and the conduct requirement is distinctly the low point of his book. To begin with, since he earlier insisted that punishment of the "ill" is inconsistent with the conduct requirement (p. 79), it is wholly unclear why any special "insanity" defense is necded for the mentally "ill": they fail the first test of culpability anyway. (Compare, herc, I. Goldstein and Katz, Abolish the "Insanily Defense"-Why Not? 72 YALE L.J. 853 (1963) and Packer's ungracious treatment of their position, p. 1450 infra.) But his apparent association of the "illness" question with the conduct limitation is a fundamentally confused one. When there is no conduct at all there is no possibility of control whether the person is sick (e.g., leprous) or not (e.g., Jewish). "Illness" as a mode of exculpation is relevant only when there is some conduct. Packer adopts this confusion from Robinson $v$. California, 370 US. 660 (1962). It came back to haunt the Supreme Court in Powell $v$. Texas, 392 U.S. 514 (1968), where the problem was the applicability of Robinson to the crime of "being drunk in a public place" - which plainly involves some conduct (so did Robinson-"being addicted in the State of California"- for that mattcr), but arguably conduct produced only as a symptom of the "illness" of alcoholism and therciore not "culpable."

Furthermore, in discussing the relationship between "illness" and conduct, Packer manifests the same irrationalist attitude toward the concept of illnes which prevails in his discussion of the insanity defense. He argues that status offenses (of whose extremcly complex nature he seems quite unaware-see, e.g., p. 1455 and note 181 sufora) vere forced upon the criminal law because of the lack of preventive alternatives, and that 
Beyond its apparent endorsement of the proposition that it is wrong to punish when we feel it is wrong, I can only read this passage as an almost self-confessed abandonment of even the pretense to intelligibility and argument.

Packer strongly rejects the idea that the insanity defense is part of the mens rea doctrine, ${ }^{242}$ but he does not tell us why the contrary view is "wrongheaded." 243 The "diminished responsibility" defense does go to mens rea, however, and "bears no relation to the insanity defense." 244 These positions evidently are the other side of the coin of his dogma that the insanity defense "is not at all addressed to particular elements of the offense but rather to the actor's general mental condition" and "is concerned not with what the actor did or believed but with what

with the expanding concept of "illness" and of civil commitment possibillties, we can now "insist on the doctrinal purity [of the conduct limitation] from which crimes of status represent so marked a lapse." (p. 79) He cites Robinson as an example, observing that the Supreme Court's argument for holding unconstitutional a statute imposing criminal penalties on a person found to be "addicted" to narcotics seems to have been that "the legislature may not make it a crime to be sick." The Court, he says, "took it for granted that narcotics addiction is an illness." Then comes the following sentence: "The question, of course, is not whether it 'is' an illness but rather how it is perceived." (Id. italics added) The more I ponder this off-hand remark, the more it dissolves into unintelligibility. But Packer outdoes himself, for this is followed by:

What would Chief Justice Marshall have said? Times change, habits of thought change, our use of words changes, and the legal process changes with them. We can now afford the luxury of restricting the substantive content of criminal law to con. duct, leaving status and prediction to other legal processes. As we shall see, that does not solve the ultimate problem but only shifts it. (Id.)

Is this some kind of ethical relativism? or does he think "illness" is a basic catcgory of perception, so that his point is an allusion to neo-Kantian speculation about the relation. ship of categories of the understanding to changing human purposes (cf. C.I. LEWIS, MIND AND THE WORLD ORDER (1929))? Certainly it would be a bit thick if he had collapsed cither of these into the "of course" which I italicized above. And is it our concept of illness, or our understanding of addiction (or mental illness), which is the subject of change he hats in mind-and if the latter, does he then mean to say only that when we learn new facts, we often have to put a thing in a different category from that which secmed ap. propriate when we were more ignorant?

The only thing it seems safe to say about this passage is that once again Packer fo evading the thing which needs to be discussed. Having argued that the limitation to conduct is of central importance, he leaves that limitation in a meaningless state by defining its contours not in terms of criteria related to its underlying pollcy and susceptible to reasoned application, but only in terms of arbitrary (as least so far as any explicatlon fs concerned) terminological habits, or fashions in moral appralsal. Why-apart from "doctrinal purity"--should "illness" exculpate? If we knew that, we would know how to go about deciding whether a given condition should be exculpatory, without being forced to rely only on whether people (what people?) happen to think of it ats a sickricessand, perhaps, we would also have a general understanding of the nature of exculpation itself, and of the notion of thnigs done out of "illness" and the insanity defense. As I have pointed out before, one of the most striking failures of Packer's book is its repeated evasion of the question why we exculpate on the various grounds he takes up, and the consequent absence of any discussion of whatever relationships there may be aniong them.

242. Pp. 134-35.

243. See note 210 supra. Characteristically, Packer substitutes pronouncement for argument: to associate the insanity defense with mens rea "is to confuse the idea of culpa. bility, which is implicated in the insanity defense, with technical culpability requifre. ments, which are not." Id.

244. Id. 
kind of person he is."245 This is wrong, if it is supposed to reflect the law as it stands, since the defense most everywhere requires a showing not only of what sort of person the actor is, but how his peculiarities were connected with his deed. Furthermore, if presented as what the law of the defense ought to be, it is offered with no supporting argument whatever, and seems an unlikely candidate for sensible doctrine since it explicitly abandons the effort to root the defense in some purpose of the criminal law, preferring instead the mystical view that illness (undefined) is a priori inconsistent with criminal responsibility. ${ }^{240}$

To conclude this discussion of Packer's analysis of the place of excuse in criminal law doctrine, some reference should be made to an important respect in which all of it is fundamentally defective. As we have seen, Packer implicitly adopts-without explicit theoretical formulation $^{24 i}$-H.L.A. Hart's distinction between the General Justifying Aim of punishment and the justification of particular rules of Distribution. ${ }^{248}$ The former, for Packer as for Hart, is Utilitarian: Prevention is the justifying purpose for the practice of punishment.910 But both of them think it is necessary, in selecting the objects of punishment, to qualify the pursuit of maximum prevention with non-Utilitarian restrictions. Both of them regard some of the principles of criminal responsibility as thus non-Utilitarian in justification, and probably counter-Utilitarian in effect.

A basic fallacy in their position, it seems to me, is that it identifies Utility with Prevention. ${ }^{250}$ The resulting, purportedly Utilitarian, calculus is as misleading as is its equivalent in torts, which, looking to only one Utilitarian purpose of accident law (reduction of secondary accident costs), concludes that no system can compare in Utility with social insurance. ${ }^{251}$ It is certainly true that the traditional PreventiveUtilitarian accounts of excuses-e.g., we ought not punish the insane because they cannot be deterred-do not hold water. ${ }^{252}$ But it seems

245. Id.

246. Cf. Griffiths, supra note 17 , at $377-78 \mathrm{nn} .73,74$.

Packer also says the insanity defense is not an "excuse in the ordinary eense" because it leads to "punishment" (i.e., civil commitment-but cf. Bolton v. Harris, 395 F.2d G12 (D.C. Cir. 1968)), albeit not to "criminal punishment." (p. 134) The argument is mistaken. It resembles his idea that an excuse is not an excuse if it "mercly" reduces the grade of an offense. See note 263 infra.

247. Cf., e.g., pp. 112, 132. But cf. pp. 66, 116.

248. Prolegomenon to the Principles of Punishment, in H.L.A. HArT, supra note 26.

249. P. 66 .

250. See, e.g., p. 132.

251. See generally G. Calabrest, The Costs of Accidents (1970).

252. See p. 1444 supra. 
to me quite mistaken to conclude that all qualifications upon Prevention are therefore anti- or at least non-Utilitarian in character. Henry Hart and others have long insisted that the criminal law is "multivalued,"253 and the non-Preventive considerations that H.L.A. Hart and Packer cite as the basis for Distributive limitations seem to me not "Retributive" at all, as they seem to think, but merely Utilitarian with respect to purposes other than Prevention. ${ }^{254}$

Put in another and more important way, the criminal law is not just any sort of prevention practice, it is a special sort whose central concepts are punishment and responsibility. We might, for example, combat smallpox either by compulsory vaccination of all potential carriers, or by punishing anyone who, having the disease, exposes another. The "preventive" aspect of the justification of either practice would be the same, but a full justification of either would have to include the relative benefits and costs of the ways in which the effects of their rules of implementation differ. Thus, when we try to give an account of the General Justifying Aim of a practice, it is such a practice with all of its consequences for which we must be able to give a Utilitarian justification. The question we must anwer is: is it socially desirable to accomplish some prevention in such-and-such a way given the costs and other effects involved? If the answer is "yes" then we have justified that sort of a system for prevention, not Prevention in the abstract; the limitations on pursuit of Prevention built into the rules of implementation of the practice we have justified are part and parcel of the justification, not extrinsic considerations imposed in the name of non-Utilitarian values. ${ }^{255}$ If the answer is "no," it does not

253. Henry Hart, The Aims of the Criminal Law, 23 LAw AND ConteMp. Prod. 401 (1958); Michael \& Wechsler, supra note 104, at 1262.

254. Cf. H.L.A. HART, supra note 26, at 23-24, 46-49. Hart proposes as merely "moral," considerations which plainly have a heavy Utilitarian component. Hart seems to reject any kind of multi-valued Utilitarianism at one point, on the ground that we fecl regret when, for reasons of expedience, we abandon an important rule of implementation, and that therefore such a rule cannot be accounted for in terms of mere Utility (for why would we feel regret in maximizing Utility?) and must be a fundamental principle (of Distribution). Id. at 12. I am unable to see why regret at the cost at which a greittcr good is purchased shows that the lesser good paid for it is of a different qualitative sort. What we regret, it seems to me, is our inability to have our cake and eat it-but nelther of these purposes requires a non-Utilitarian account just because they happen to conflict. Cf. note 38 supra for a tentative Utilitarian explanation of why we want only to op. timize, not to maximize, Prevention, and how some of the law of excuses can therefore bc interpreted as striking a Utilitarian balance.

255. The same approach is taken in Benn, An Approach to the Problems of Punish. ment, 33 PHilosophy 325, 331-32 (1958). See note 84 stupra for a definitional confusion Packer gets into by overlooking the way in which a practice is justified. 
follow that Prevention is not justified in the case put, but only that Prevention with such-and-such a practice is unjustified. If we decide, for example, that it is wrong to punish the ill for the consequences of their sickness (because to do so involves and suggests a responsibility they do not have), ${ }^{256}$ it by no means follows that we will not do something else to accomplish Prevention (of the spread or nuisance of the disease). To make such a decision is surely not to abandon Utility, but to pursue it by a different (and more Utilitarian) route. Choices between practices are susceptible to Utilitarian justification because, to pick up the Henry Hart point again, each will have not only a different Utility from the others as to Prevention, but also a different Utility as to a host of other purposes which are equally connected to the ultimate good of human welfare. We choose the criminal law, when we do, because it tends to produce a more optimal mix of desirable consequences than would other available practices (e.g., civil commitment; licensing and regulation).

I think this criticism of H.L.A. Hart (and of Packer to the extent he adopts Hart's ideas) is important: Hart's position-reliance on Retribution as the justification of Distributive rules-is not only conceptually and ethically unsatisfying, but it prevents him from seeing the most telling objection to Barbara Wootton's proposals (which amount to a refusal to recognize differences between preventive systems-hence, I argue, a failure to acknowledge and preserve their differential Utilities with respect to values other than Prevention). .57

Perhaps it is in terms of his failure to analyze the "multi-valued" Utilitarianism of the criminal law that we must explain Packer's inattention, in the final third of the book, to the respects in which the criminal law may do less harm, as a preventive practice, than some of its alternatives. ${ }^{258}$

256. See note 82 supra for the problem of the lie, and of justifying a lic, and p. 1396 supra on the nature of the justification of a practice. I do not think my position here rests on a "definitional stop" (cf. H.L.A. HART, supra note 26, at G). Packer occasionally says things which might be read as hints in the direction for which I am contending, though probably they are only rhetorical flourishes-e.g., "if culpability means anything in the criminal law, which is to say, if "criminal" means anything ...." (p. 138).

257. See note 38 supra.

258. Many of the arguments that F.L.A. Hart, Packer, and others have advanced in favor of the concept of culpability as a limitation upon the implementation of punishment seem to be equally good as arguments in favor of using the practice of punishment (if it is implemented in accordance with such a restrictive limitation) instead of other practices to accomplish prevention. 


\section{F. The "Rationale" and the Problems of Proof and Proportionality}

Part One of the book concludes with a chapter on "Proof and Proportionality." A specially high standard of proof, Packer asserts without argument, is "part of the minimal doctrinal content of the criminal law."259 In particular, if the mens rea requirements are to have any "vitality" they must be "part of what the prosecution must prove beyond a reasonable doubt . .." whenever the defendant has proferred "some evidence supporting the excuse."200 This latter qualification suggests that his notion that the "positive" theory of mens rea -the theory that offenses should be defined to include the "states of mind" to be proved-ought to be the basis of a well-drafted code has not carried over into practical application; if it had, one would expect a "state of mind" to be the same sort of object of proof as the question whether the defendant had a gun in his hand, and the burden of going forward as to its existence to rest equally on the prosecution.

As to proportionality, Packer says that "The integrated theory of punishment to which we are committed requires an integrated ap. proach to the goals of punishment .... Punishments must be indiviclualized but within limits ... having to do ... with deterrence and with judgments about comparative morality ...."201 The participants in the punishing process-legislatures, judges, correctional authorities -have different competences with respect to the various goals of punishment. ${ }^{262}$ A legislature can choose only a few rough categories (finer distinctions must be left to particular cases) and "the severity of the available punishment should be proportioned to the seriousness with which the offense is viewed." ${ }^{263}$ Although he does not articulate the

259. P. 137 .

260. P. 138.

261. P. 140 .

262. Pp. 140-43.

263. P. 143. It would seem that not only must offense categories, and the rules of liability of the General Part, conform to the justifying purpose of the practice (as quall. fied in implementation by principles of Distribution), but also that any particular applica. tion of punishment must, if it is to be justifiable, be consistent with the general justifica. tion of the practice. It is therefore peculiar that Packer takes such a casual view of the delegation of sentencing discretion to judges and correctional authoritics (sce pp. 10\%. 145), neglecting both the difficulty of squaring this with the principle of legality, and the apparent inconsistency of an argument which demands strict standards of justification of a practice in the abstract but appears indifferent whether those standards will support the actual terms exacted of prisoners. If Rehabilitation, for instance, is an insufficient justification for the use of any punishment at all, it is impossible for me to sec how lt could be a sufficient justification for the exaction of a ten-ycar rather than a five-year punishment.

A similar peculiar conception of the justification of punishment seems to underlic Packer's manifest lack of interest in the question what crime a person is punlshed for, 
principle involved, Packer obviously believes that cven if merely Preventive considerations go the other way, more serious offenses must be punished more severely, and vice versa. ${ }^{204}$ But a mistake about the Preventive position keeps him from seeing precisely the point at which a "proportionality" principle is required. It is not the case that a "behaviorist" would ignore the seriousness of the offense in contemplating Incapacitation and Rehabilitation, nor that a Deterrence enthusiast would measure punishment only in accordance with temptation rather than the seriousness of the offense. ${ }^{205}$ In both of those variants of Utilitarianism, the cost of punishment is recognized, and is weighed against the importance of the amount of suppression of the offense to be accomplished by the punishment contemplated. No compos mentis Preventionist (of either sort) could advocate hanging for parking offenses, though it might be superlatively effective. Prevention is not worth such a cost. The hard problem is: suppose by hanging one offender a year for overparking we could deter as effectively as by fining a million offenders $\$ 1$ each, and suppose we decided that that would be a less "costly" way of accomplishing the required amount of deterrence, all things considered; what principle is it that tells us that to do so would be wrong? ${ }^{260}$ It seems to me that the principle is essentially one of Distribution:207 the requirement of fairness in justice ${ }^{268}$ precludes us, in making use of a person for the general good, from doing so in a way which makes him bear an outrageous proportion of a social cost (deterrence) that could readily be

so long as it is "justifiable" to punish him for some crime. He says that "All excuses involve mens rea; but not all mens rea problems involve excuses," (p. 108) because some mens rea pleas do not wholly absolve the offender, but merely reduce the grade of his offense. This seems ridiculous to me. Lack of the required intent is none the less an absolute excuse for murder because it is not an excuse for manslaughter. The lack of an appropriate excuse is part of the justification for the imposition of the punishment provided for a particular offense, and the nature of the problem of justifiction does not change merely because the offender concerned might be guilty of some other-related or unrelated-offense which does not allow the same excuse. The imposition of punishment does not thereby become a problem of mere "grading" rather than of "excuse." The MODEL PENAL CODE's authors were afflicted with the same notion-that defenses which leave an accused vulnerable to a lesser offense involve only "grading" and that the question of liability for the greater offense is really one of mere "form." See, e.g., TEvistive DrafT No. 4, Comment to $\$ 2.03$, at 134 (1955).

264. Pp. 139-40. This position seems to conflict with one earlier taken by Packer in Making the Punishment Fit the Crime, 77 HARv. L. REv. 1071, 1077-78 (1964). There he said that "the notion that the rationality of general deterrence has to be qualified by the ideal of proportionality in the individual case" has an "odd ring," and "individualization of punishment appears hardly to be a constitutional principle." Given the division of competence he now contemplates, it is hard to see how the constitutional rationality and proportionality required of decisions at the legislative stage can have no application to the sentencing stage of the process. See note 263 supra.

265. Pp. 139-40. See pp. 1422-27 supra.

266. It is an exquisite pleasure as a laborer in the vineyard of criminal law jurisprudence 
more equally shared. ${ }^{269}$ Whether this can be translated into straightforwardly Utilitarian terms I do not know, ${ }^{270}$ but surely it is the heart of the proportionality problem, and Packer misses it altogether.

My conclusion is that virtually every argument worthy of attention in Part I of his book is a more or less garbled version of Hart's position, and that to the extent that Packer departs from or adds to Hart's ideas, his account becomes more rather than less confusing and inadequate.

- particularly as a teacher-occasionally to be able to counter would-be "relevance" or "desert island" dismissals of ethical problems such as that described in the text, not with painful and subtle argument but with physical evidence. To that end I reproduce the following photograph, from an unknown original source (date: 1928), uncovered by D. Olasov in the picture collection of the New York Public Library under the heading "Punishment: Beheading":

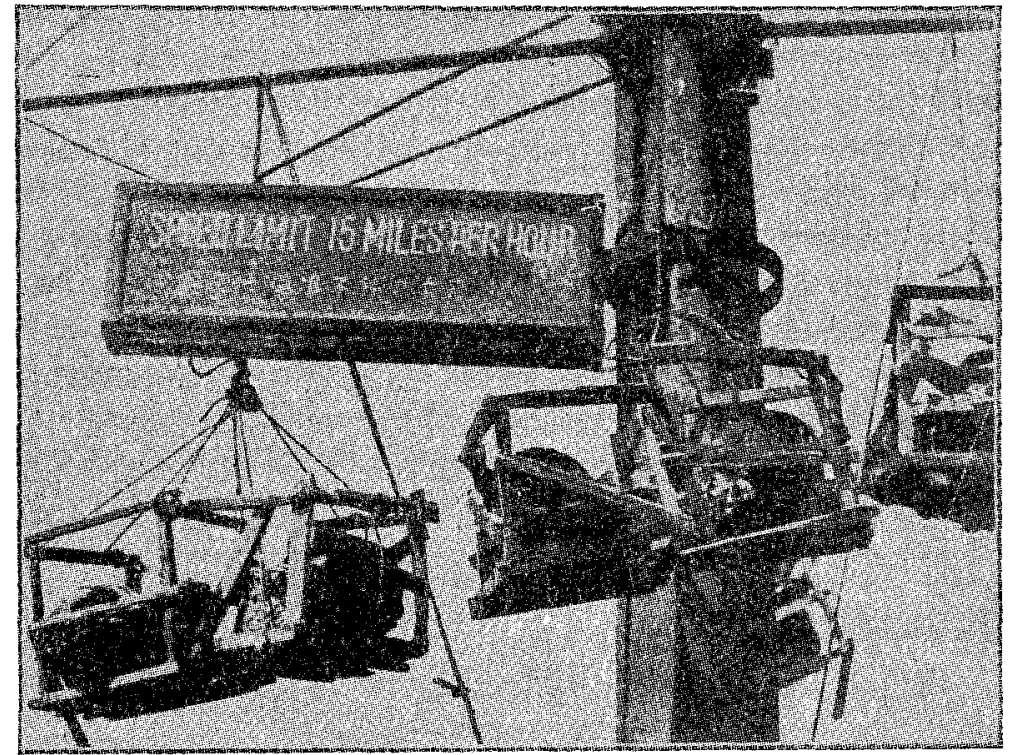

La représsion contre les excès de vitesse à Pekin: têtes de chauffeurs contrevenants exposées au-dessous de l'écriteau qui prescrit le maximum de vitesse pour les automobiles.

267. Cf. H.L.A. HART, supra note 26, Prolegomenon to the Principles of Punishment. 268. See J. Rawls, Justice as Fairness, in Justice AND Social Policy (F. Olafson ed. 1961).

269. Cf. Griffiths, supra note 17, at 411-12, n.178; see also note 219 supra.

270. Cf. Rawls, supra note 268; Wolf, A Refutation of Rawls' Theorem on Justice, 63 J. PHIL. 179 (1966); Dworkin, Does Law Have a Function? A Comment on the TwoLevel Theory of Decision, 74 YALE L.J. 640, 646 (1965). I do not mean to be suggesting, by my criticism of H.L.A. Hart's and Packer's Preventive version of Utilitarianism, that I am convinced that a better-formulated Utilitarianism can handle all the problems of the jurisprudence of criminal responsibility. 


\section{Advice to the "Rational" Legislator}

The last third of the book addresses itself to the question: "what are the criteria that ought to guide the exercise of legislative judgment regarding the appropriate occasions for invoking the criminal sanction?" granted the limitations that the "rationale of the criminal sanction" and the "series of limiting norms" which emerge from the "clash of values" in the criminal process (liberty versus efficiency) jointly impose upon the "power of the state over the individual?"2t1 Packer's sensible response to this question can be summarized as: don't make something a crime unless it is justifiable to punish infractions to secure obedience, and unless it is possible to enforce the prohibition without incurring excessive sacrifices of other values (money, dignified police practices, and the like).

\section{A. Alternatives to Criminal Punishment}

Packer begins with "the question of alternatives" to criminal punishment in enforcing necessary rules of conduct. But while he insists that the rational legislator should look to such alternatives, his own treatment of them is wholly inadequate and tends to the misleading conclusion that there is very little potential in them. ${ }^{272}$

The alternatives, he says, are compensation, regulation, and treatment. Of compensation, he observes that it is "a useful sanctioning device," but he does not discuss the situations in which it might be useful; he is content to observe that "the vagaries of litigation between private parties," $272 \Delta$ and the fact that the object of compensation is not to control behavior but to shift the losses occasioned by certain kinds of conduct to the person engaged in that conduct, make the device in-

271. Pp. 249-50.

272. A number of features of Packer's thought appear to be responsible for the short shrift which, despite his substantial claims, he in fact gives to the possibility of alternatives. As we have seen, he seems to understand alternative systcms of control only in terms of the received mythologies about them (see note I86 supra), andwhether due to ignorance of the varieties of methods which in fact exist, or to some ideological incapacity to entertain the possibility of difference-suffers from the fatalistic illusion that the essential features of our system of punishment are inevitable (see note 145 supra and p. 1467 infra). He also manifests a kind of scholarly ficld chauvinism. Thus he transmits as profound truth the banal clain of the criminal lawyer that the criminal $\mathrm{law}$ is the "paradigm case of the controlled use of power within a society." (P. 5) Compate F. Allen, The Borderland of Criminal Justice 35.36 (1961). Is it really such a paradigm? What about education? (Cf. Plato, The Rerublic, passim.) Or tax? (Cf. B. Bittker, Tax I, Yale Law School, passim.) Or tort and contract? (C). G. Calabresi, The COSTS OF ACcidenTS (1970).) I cannot see that any of these has a spe. cial claim to the title of paradigm.

272A. P. 252. Cf. note 186 supra. 
adequate to control behavior like drunk driving. Givil fines avoid these impediments but are also "clearly" an inadequate alternative to the criminal law in the case of drunk driving, because "the drunk driver's perception of unpleasant consequences is not altered by making the public rather than the injured party the beneficiary of a monetary exaction."273 No empirical evidence is adduced; but even as a matter merely of logic this argument will not wash. A fine differs from a tort judgment not only in beneficiary (and, incidentally, in measure), but also in the fact that it is attached (especially in a "danger delict"274 like drunk driving) to conduct rather than to the consequences of conduct. A fine therefore follows not the fortuity of damage but the constant of transgression. Furthermore, even in the case of consummated accidents, his argument does not work, because a fine would presumably be cumulative with rather than alternative to tort liability.

For Packer's argument against the adequacy of fines to work, he must seek support elsewhere than in a false analogy to torts. It may be that the low risk of detection for accident-free drunk driving, taken together with a probable difference in psychological impact between threats of fines and threats of prison, give to fining, as a sanction, a very low deterrent effect. But given how little we know about all these things, and how little we know about the operation of deterrence, I do not think Packer can legitimately conclude his discussion simply by asserting that "It is mainly in situations where economic gain is the objective of the antisocial conduct we seek to inhibit that monetary exactions are a useful sanction."275 Fines may have more potential for non-"economic" offenses than he allows, and the assumption that fines are peculiarly effective for certain kinds of acquisitive crimes (tax evasion and antitrust, perhaps, but not bank robbery?) is, so far as I know or can infer from Packer's treatment of the question, based only on middle-class sentimentality concerning the "economic" rationality of middle-class greed. ${ }^{278}$

Regulation he treats only in the form of licensing. It works to prevent careless airline piloting, but (absent intolerably abrasive intrusions) cannot work to prevent drunk driving. License revocation following a simple civil proceeding could be substituted for criminal

273. $1 d$.

274. See J. Andenaes, The General Part of the Criminal Law of Norway 99.100 (1965).

275. P. 252 .

276. Pp. 251-53. Cf. Lemert, The Behavior of the Systematic Check Forgor, 6 Socint. ProbleMs 141 (1958). 
punishment ${ }^{277}$ although it would have to be backed up with criminal penalties for driving without a license. Packer's treatment of this possibility is confounding. He says it would be attractive because revocation is a far less onerous deprivation than imprisonment and the stigma of criminal conviction. But, he says, "we have no assurance" that it would work (this is a typical instance of his rhetorical styleit is, of course, equally true that we have "no assurance" that it would not work, nor that anything else does work). "For many people . . . even thirty days in jail may impose less actual hardship than the permanent or extended loss of the privilege to drive a car." They would be inclined to drive despite revocation, taking the small risk of detection; we should have failed adequately to deter or prevent drunk driving, and we should also have failed to avoid ultimate resort to criminal punishment (for the few that we caught). This is at least dangerously close to saying that license revocation is attractive because is is more lenient than criminal punishment, but unworkable because it is more severe. The whole passage suffers, in addition, from Packer's failure to distinguish between revocation as an incapacitative measure (is there a higher risk of drunk driving among those who have done it once? even if they are driving without a valid license?) and revocation as a deterrent measure. Nor does he bring up the question whether, given the central role of the automobile in modern life, it is really any longer appropriate to deal with a driver's license as a "privilege"-whether, in short, it is not important to treat revocation as "criminal punishment" and attach the protections of the criminal process whenever the right to drive is to be taken away on account of misbehavior. 2 i8

Treatment as an alternative to punishment he considers in the form of civil commitment. There are plenty of good reasons to doubt that treatment is a plausible or desirable general substitute for punishment. ${ }^{279}$ Packer's argument to that effect is nonetheless a triumph of obscurity and confusion. ${ }^{280}$ For the "metaphor of disease" to fit the facts, he says, there must be "adequate measures of therapy" and

277. Packer uses "punishment" (p. 254) but he must mean "criminal punishment"since unless we are subordinating the prevention of first oftenses to the prevention of recidivism (see note 151 supra), deterrence would have to be part of the objective of revocation.

278. Pp. 253-56. Cf. Reich, The New Property, 73 YaLE L.J. 773 (1964).

279. See pp. 1396, 1412-13, 1451-53, and notes 62 and 63 supra for discussion of Packer's failure to analyze the nature of the justification of a practice: in the case of "treatment" his argument is, in part, inadequate because he does not compare the Utility of punish. ment and treatment as practices.

280. Pp. 256-57. 
"those afflicted must in the general run of cases view themselves as suffering from a disease of which they wish to be cured." 281 Since he gives no independent reasons for imposing these conditions upon the substitution of treatment for punishment, he apparently thinks they inhere in the concept of a disease. This is not the case. There are many incurable diseases-and no one doubts that they are clear, cen* tral-meaning cases of the term "disease." Even putting the case of children to one side, not only is it not true that the generality of persons suffering from anything properly called a "disease" must wish to be "cured" (even leaving out of account all of the difficulties in ascertaining the meaning of a "wish" to be cured) ${ }^{282}$ but there seem to be well-recognized diseases of which it is not even true that most sufferers regard their condition as undesirable.283 Packer also says it is "obvious" that treatability and the sense of suffering from a disease are closely linked, and that the existence of effective treatment leads to a willingness to endure it. Neither half of this assertion holds much water: incurability need not of itself undermine the sense of being diseased, and curability need not necessarily induce either the desire for cure or the sense of illness. ${ }^{284}$ These errors are important, because on the basis of faulty analysis of the common meaning of "disease," Packer is seeking to set limits upon what ought to be deemed a disease and be dealt with by "treatment," among the vast category of criminogenic conditions. He wants us, for example, to consider addiction a disease only if his two conditions are met-but he gives no argument for such a limitation. He seeks, in short, to beg the central question: what should be done with such people? That his way of putting the problem is not only inadequate, but even positively dangerous to the very values he wants to protect, becomes obvious if one reflects for a moment on the situations in which it is not at all true to say that "Only minimal compulsion, to deal with the singularly stupid or the singularly recalcitrant, is required when a believable therapy exists." (Italics added.) Lack of race prejudice in the Union of South Africa, and undue libertarianism in the Soviet Union, are criminogenic conditions. It is by no menns in-

281. P. 256.

282. There is always a cost in being "cured"-in pain, inconvenience, ctc. if nothing more-which the afflicted person (perhaps insufficiently weighing the cost which his "disease" inflicts on others) may prefer not to pay.

283. Tuberculosis once was supposed to accentuate beauty; and tape worus appar. ently have been used to lose weight.

284. Low-level narcotic addiction is prevalent in many societies (including our own, if cigarettes and coffee are included as addictive); alcoholism is supposedly very wide. spread, but socially adaptive, in France. Packer himself appears to accept narcotics ad. diction as a disease. P. 256. 
conceivable that effective "cures" exist or will be devised. Whenever that should happen, Packer gives us very little with which to resist the apparent determination by those two countries that the conditions are "diseases." the Russians and South Africans actually believe what they say, ${ }^{280}$ but nevertheless "minimal compulsion" is not the description of "treatment" in such a state of affairs which first comes to my mind. What we desperately need, and what Packer conspicuously does not provide -despite his claims ${ }^{287}$-is some analysis of the circumstances in which society is justified in trying to change a person, physically or mentally, against his will. Mistaken fiddling with "the metaphor of disease" does not meet this need.

From faulty-and largely irrelevant-premises about the concept of disease, Packer proceeds by non sequitur. Compulsory treatment "simply cannot be seriously regarded as an altemative to the criminal sanction," he says, because it is either an outcome of the criminal process (he seems to have insanity acquittals in mind as well as civil commitment of narcotics offenders) or it is enforced with threats of punishment (if addicts are required to commit themselves for cure on pain of punishment). The first point I think I understand, although it does not seem conclusive against treatment as an alternative that it is imposed during the criminal process. The second point I do not understand, since it seems to amount to saying that compulsory treatment is not really treatment because it is compulsory. It seems to me that it is perfectly sensible to describe punishment and compulsory treatment as alternative responses to a particular situation, and that a system which consistently chose the latter would be far different from one which chose the former, even if punishment were the ultimate way that treatment was enforced. However this may be, there is

285. I refer to what seems recently to have been the Gse with respect to General Grigo renko, in the Soviet Union. Cf. also, "Soviet Assailed for "Psychintric' Imprisonment," N.Y. Times, April 21, 1970, p. 4 (re report by Amnesty International). For South Afric, see N.Y. Times, May 11,1969 , p. 14. An article, entitled "Ban on Interracial Sex Relations is Under Attack in South Africa," describes various criticisms of the statutory prohibition of interracial sex relations, including the following: "A pro-Government critic of the act, L.C. Stwanepole, a senior lecturer in psychology and criminology at the University of South Africa, suggested that those involved in interracial sexual relation. ships should be dealt with like alcoholics-in clinics, because they were obviously victims of psychological disturbance. His views were echoed by Dirk Richard, cditor of the Afrikaans paper Dagbreek, who called for a "new approach' to the act."

286. Compare with the Russian and South African notions referred to in note 285 supra, a recent press release of the Joint Commission on Miental Health of Children, stating in its first sentence: "Racism is the number one public health problem facing America today." (Feb. 14, 1968).

287. See p. 251 : he suggests he will map out the "jurisprudence . . . of sanctions." 
an obvious third possibility for the imposition of treatment, which Packer overlooks: ordinary civil commitment. This does not arise from a criminal proceeding, and it is enforced by direct application of force, not by punishment. Why, then, in Packer's own terms, is it not an alternative to punishment? Packer concludes that we cannot escape "the hard fact that the criminal sanction has no adequate substitute as a sanction of last resort," 288 which seems to me neither true (as in the case of ordinary civil commitment) nor particularly interesting (because we should be more concerned with first than with last resorts).

Packer's treatment of alternatives to criminal punishment concludes with a brief discussion of "the alternative of doing nothing." the possibilities of significant prevention of any particular sort of offensive behavior, the costs of achieving it, and the limited social resources available, the "rational" law-maker should always squarely confront the question whether doing little or nothing is not the best course available to him. So long as Packer sticks to this sort of "policy-oriented" common-sense, he is on solid enough-if rather uninteresting -ground. Occasionally, however, he purports to dress common-sense up in would-be jurisprudence, and is given to saying things like "We can have as much or as little crime as we please, depending on what we choose to count as criminal." ${ }^{200} \mathrm{He}$ is apparently unaware of the implications of the idea, prevalent in sociological literature, that the identification and suppression of crime perform essential social functions going far beyond what a simplistic Benthamite calculus of prevention includes-that reacting to deviant behavior is necessary to the maintenance of a society and must be understood symbolically as well as economically, and that it may therefore not make much sense to talk about the allocation of crime control resources as if only the supply and demand of widgets were involved.201

288. P. 257.

289. Pp. 258-60.

290. P. 364 .

291. See note 111 supra. At another place, advocating the repeal of laws criminalizing private consensual sexual activity, Packer's failure to consider the full significance of criminalization in a society renders what he says patently unresponsive to the argument he is trying to meet. In reply to the claim that eliminating a criminal prohibition (e.g., of consensual sexual activity) will be taken to express social approval of the conduct in question, he says (among other things): "It does not pay a statute much of a compllment, a Justice of the Supreme Court once remarked, to say that it is not unconstitutional. It may also be said that it does not express much approval of a behavior pattern to say that it is not criminal." (p. 304) This may be well-taken, but it is quite unresponsive to the question put-how repeal will in fact be taken. Even in the case of Supreme Gourt rulings, it is necessary (at least for a political scientist and probably for jurisprudes as well) to distinguish legal import from political effect. See A. BICKET, THE LENST DAN. GEROUS BRANCH 129-33 (1962). The analogous distinction in criminal law is fundanental 


\section{B. Law and Morals}

Packer next considers the relationship between law and morals as a source of limits on the appropriate use of criminal punishment. He argues on the one hand, that for prudential reasons only "conduct that is viewed, without significant social dissent, as immoral" should be made criminal. ${ }^{292}$ Vagueness apart, the passage is fairly innocuous, except insofar as it naively suggests that for the criminal law to engage in "building up ... a body of opinion about morality ..." is somehow "totalitarian." 293 On the other hand, he argues that "immorality clearly should not be viewed as a sufficient or even a principal reason for prescribing conduct as criminal." ${ }^{204}$ His treatment of this idea adds nothing but imprecision and some fatuous rhetoric ("morals belong to the home, the school, and the church; and we have many homes, many schools, many churches. Our moral universe is polycentric" ${ }^{\prime 295}$ ) to the well-known debate on the issue. ${ }^{290}$

\section{G. Practical Considerations}

After considering alternatives, and the relationship of criminal proscriptions to moral prohibitions, Packer discusses some practical considerations a wise legislator should worry about before deciding to establish (or to decline to repeal) a cateogry of crime. It contains some good common sense. But much of what Packer writes is beside the point, because it is not addressed to the question of intrinsic limits on the use of the "criminal sanction," but only to a number of objections to the way the "criminal sanction" is currently employed. It is, for example, commonly observed that some current legislation is offensively vague, but the question of limits arises only when it is possible to show that there are some subject-matters which, by their very nature, do not lend themselves to adequately precise formulation.

The most interesting "limit" Packer invokes is that we should

to an understanding of the latent functions of criminal proscriptions (and de-proscriptions). See J. Gusfiedd, Syaibolic Crusade (1963).

292. Pp. 261-64.

293. P. 263. As in note 111 supra, I do not think it is necessary to disagree with F.I.A. Hart that the criminal law ought not be used to strengthen social norms concerning "mere immorality"-but surely it does not follow that there is anything wrong vith using it to build up and strengthen norms against socially harmful immorality. Cf. also pp. 1429-30 supra.

294. P. 265.

295. Id.

296. See, e.g., H.L.A. HART, LAw, ImeRTY aNd Morality (1963); P. Devin, Tur ENFORCEMENT OF MORALS (1959). 
eschew triviality in the objects of the criminal law. That which really needs restraining, but is relatively unimportant, should be dealt with by "civil penalties." 207 This "limit"- strictly applied-would do away with a goodly amount of the average criminal code and with even more, as Packer notes, of the products of local and administrative bodies. This would be all to the good. The trouble enters with his argument for the principle of non-triviality, his application of the principle to inchoate crimes, and his criterion of triviality.

In arguing against triviality, as elsewhere, Packer assumes that the aspect of moral condemnation in the criminal law is a good thing. Hence his opposition to trivial crimes: "The more indiscriminate we are in treating conduct as criminal, the less stigma resides in the mere fact that a man has been convicted of something called a crime." ${ }^{208} I$ have already discussed the problems which his unquestioning adoption of "stigma" or "moral condemnation" as central to the criminal law involve. ${ }^{299}$

Packer suggests that the triviality principle has a special application to inchoate crimes-that "increasing the radius of the criminal law in the interest of early intervention is a very risky business." 300 It is certainly true that there are many problems with inchoate crimes. Some have nothing to do with the triviality of the conduct in question-the difficulty of framing clear definitions of offenses, the further removed the conduct is from the ultimate value to be protected, for example, and the difficulty of achieving fair and relatively full enforcement (which Packer mentions). The problem which consumes Packer is the supposed triviality inherent in a low probability of ultimate harm, particularly when offset by some desirability in the conduct concerned. His example is a New York City ordinance against smoking in bed in hotel rooms.

The trouble is that Packer does not approach his subject with the kind of system which we legitimately expect of a professed emulator of Bentham. He never brings into focus all of the connected considerations bearing on the problem. The current emphasis of the criminal law on the accomplishment of the ultimate evil involves a triviality (and unfairness and ineffectiveness of enforcement) of its own. The only aspect of a state of affairs over which an actor has direct control

297. Pp. 270-77.

298. P. 273.

299. See p. 1416 supra.

300. P. 270. 
is his behavior. ${ }^{301}$ Whether that behavior be intentional or negligent, or neither, with respect to the ultimate evil, its relationship to that evil is a statistical one. ${ }^{302}$ To make liability turn on the actual occurrence of the evil is to make it turn on a fortuity over which the actor has no additional control. The effort to distinguish fortuities which "might have" occurred from those which "could not have" is what causes the intricacy and idiocy of the law of attempts. With respect to negligent crimes, which involve the same emphasis on the fortuity of the ultimate evil, the bad effects are ever clearer. Reflection by Packer on Commonwealth $v$. Welansky, ${ }^{303}$ for example, might have been illuminating-and have required a quite different treatment of the relationship between triviality and inchoacy. In Welansky, a nightclub owner was sentenced to a 12-15 year term for the violation of various duties of care relating to the safety of his clientele-and for the fortuity that, at his club, among many others, and on one particular night, among thousands, the risk materialized and some 500 persons burned to death in the resulting fire. It is hard to believe that consistent enforcement of safety standards (perhaps with the aid of the criminal law), without regard to the fortuity of catastrophe, would not safeguard human life far more effectively than a barbaric punishment exacted from a sacrificial victim selected at chance every 20 years or so. ${ }^{304}$ There is a triviality, as well as an ineffectiveness, which resides in allowing fate to allocate punishments of the magnitude involved in Welansky. And if we can distinguish respect for law-including, I would suppose, appreciation of its fairness and humanity-from bloodlust approval of what takes place through legal forms in a moment of general hysteria, ${ }^{305}$ I wonder whether cases like Welansky promote respect, or whether, by cultivating an altogether antithetical attitude toward the law (as a sort of unaesthetic Aztec propitiation of Eumenidean gods), they do terrible damage to the kind of respect Packer has in mind. ${ }^{306}$ There is, then, perhaps something to be said against making criminal liability turn on the occurrence of the ultimate

301. This is subject to several caveats-cf., e.g., p. 1434 supra.

302. See note 38 supra.

303. 316 Mass. 383, 55 N.E.2d 902 (1944), discussed in Griffiths, supra note 17, at 411-12 n.178. Cf. H.L.A. Hart, The Morality of the Criminal Law 51.53 (1964).

304. It seems that the previous catastrophic fire in the same city (Boston) had occurred about 20 years before. Convictions had not been secured, and there was some popular determination that that not happen again. See Veltfort \& Lee, The Cocoanut

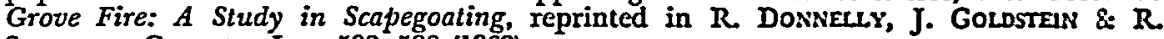
Schwartz, Criminal Law 592, 593 (1962).

305. See Veltfort \& Lee, supra note 304.

306. Cf. p. 1455 \& note 266 supra, for the problem of fairness in the Distribution of punishment. 
evil, ${ }^{307}$ and against Packer's unexamined assumption that the principle of non-triviality necessarily points in that direction.

Finally, there is Packer's criterion of triviality. He argues that an offense presumptively violates the triviality "limit" unless we can contemplate a normal sentence of more than 3 months. This is connected with his earlier claim that there are special "perplexities that attend our use of short-term imprisonment." 308 I do not believe that Packer is right in insinuating that the Deterrent case for such sentences is more problematic than for longer sentences; ${ }^{309}$ my own intuition is that, per unit of deprivation, such sentences probably are far more effective than long ones. The point I want to make here, however, is that there is quite a different sort of argument in favor of short-term imprisonment, which Packer never mentions. Since I take it as a fact that serious antisocial behavior is rather well distributed in a society, there is a value, it seems to me, in spreading exposure to the criminal law around as equally as possible. Welansky did not murder at retail, but he did expose people to the risk of death at wholesale. I have argued above that perhaps we should hold him responsible for the risk rather than for its chance materialization. I want now to add that perhaps we should hold him criminally responsible for the risk (even if we think only a single day in jail would be sufficient) so that neither he nor we will indulge the illusion that, unlike his fellow-man who is an arsonist, he is not a criminal-sort-of-person but a businessman-sort-ofperson.

Triviality, in short, is an admirable principle. Packer, however, has told us neither why it is admirable, nor to what it applies, nor how we can tell it when we see it.

\section{Application of the "Limiting Criteria"}

There follow two chapters in which Packer first applies his criteria to four offenses which demonstrate "the optimal use of the criminal sanction" (murder, rape, aggravated assault, and robbery), and then to various kinds of conduct which do not "warrant invocation of the

307. See Glazebrook, Should We Have A Law of Attempted Crimes 85 L.Q.R. 28 (1969).

308. P. 275.

309. At two different places Packer delivers himself of the offhand assertions that short-term imprisonment is of dubious "usefulness," "imposes severe social costs," and could only "plausibly" serve the end of Deterrence. (pp. 142, 276) He avoids sayingt exactly what he means, and refers to no evidence whatsoever. It seems safe to say that the truth is far more complicated than he suggests. Cf., e.g., O. Brum \& S, WHEELrF, SOclalization AFTER ChILpHOOp 91.92 (1966). 
criminal sanction." $310 \mathrm{He}$ later confesses that some of this discussion "may well be thought to have labored the obvious" but he invokes Holmes to the effect that "education in the obvious" is what is needed. ${ }^{311}$ I would say, on the contrary, that it is the superficially "obvious" which prevents any significant progress in our understanding of criminal law. ${ }^{312}$ Packer's pedestrian, unspeculative approach tells us nothing that the editorial writer of the New York Times does not already know. Surely that sort of knowledge of the "obvious" has demonstrated its bankruptcy by now. No one will be awakened from his dogmatic slumber by what Packer has written.

There is no point in tracking Packer's discussion in these two chapters, but a few things do deserve mention. One of his main arguments in favor of the use of the "criminal sanction" against the four offenses he cites as examples of its "optimal use," is that "[P]unishment is not demonstrably ineffective." optimistic view of human nature" to entertain the idea that the "criminal sanction" is unnecessary to keep them under control. ${ }^{314}$ And furthermore, "There is no reasonable alternative . . . ." 315 All of this is subject to the observation that other societies (different from our own, to be sure) seem to manage with various alternatives to criminal punishment, ${ }^{316}$ and that (as far as I know) no one has really ever seriously addressed the question whether ours could too. ${ }^{317}$ Another argument he makes in favor of using the "criminal sanction" for the four offenses is that "The third criterion [suppressing it will not inhibit socially desirable conduct] is so clearly met that no comment is required."318 Like so much of the book, this is true enough in a general sort of way; but one wonders whether the peripheral problems of euthanasia, 310

310. P. 296.

311. P. 301.

312. Compare Griffiths, supra note 17, for discussion of the role of ideology and "the obvious" in criminal procedure scholarship.

313. P. 298. To paraphrase an observation he makes in another connection, it is not a very powerful argument for punishment in the hard-core use of its justifiability to be able to say only that no one has jet proven its uselessness. See note 291 supra.

314. Pp. 298-99. "The abandonment of the criminal sanction ... . would be tantamount to the dissolution of society." (p. 301)

315. P. 300.

316. Cf. Schwartz, Social Factors in the Development of Legal Control: A Case Study of Two Israeli Settlements, 63 YALE L.J. 471 (1954).

317. But cf. B. F. SKINNER, WALDEN Two (1948). See also notes 145, 272 supra, on the problem of the sense of inevitability in criminal law scholarship.

318. P. 299.

319. Cf. G. Williams, The Sanctity of Life and the Criminar Law 311-350 (1957); Michael \& Wechsler, supra note 38, at 739-40; H. Arannieia, Criainal Justice and Sociá Reconstruction 13-17 (1946); Repouille v. United States, 165 F.2d 152 (2d Cir. 1947, per L. Hand). 
self-defense, ${ }^{320}$ justification by necessity, ${ }^{321}$ and the like-to take the case of murder as an example-do not demand some "comment." "asa The law's general incapacity to evaluate individual instances of conduct in terms of their ultimate social utility is probably at its most extreme in the criminal law-sometimes for good reasons (e.g., the intrusiveness required for case-by-case evaluation is often believed to do more harm than good ${ }^{323}$ ) and sometimes for bad (e.g., exaggerated ideas about how deterrence works, and a fear of weakening it by suggesting avenues of escape from liability $\left.{ }^{324}\right)$. On the whole, it is precisely in the qualifications one has to put on propositions that are simple and "clear" to Packer that the interest and difficulty of the criminal law reside.

Sex and morals offenses occupy a large part of Packer's discussion of uses of the "criminal sanction" which do not meet his criteria. $\mathrm{He}$ deals with all of them-deviant sexual behavior, obscenity, and prostitution-with the idea that it is legitimate to punish behavior which creates "a substantial risk that someone might be offended" (if such offense actually occurs). ${ }^{325}$ Offensiveness, he thinks, is an "objective issue." 326 Particularly in the case of obscenity, I have qualms about whether-fully analyzed-Packer's notion would work. The concept of general offense as a limit on public expression is not consistent with ordinary First Amendment assumptions. ${ }^{327}$ Packer likens public smut to a "psychic assault"328_ but we do not protect people from political or religious "psychic assault" as a general rule, nor does mere public display of smut seem to be focused on a particular individual in an assaultive way analogous to libel or slander. "Offensiveness" as a test will not be easy to administer. Obviously the tenderest sensibilities cannot be protected, and Packer to the contrary notwithstanding, there is nothing very "objective" about the notions of "unreasonable offensiveness" or "the man of ordinary sensibility" which would presumably have to become the basis of obscenity law. I have the same doubts

320. Cf. People v. Tomlins, 213 N.Y. 240, 107 N.E. 496 (1914).

321. Cf. Regina v. Dudley \& Stephens, 14 Q.B.D. 273 (1884); Fuller, The Case of the Speluncean Explorers, 62 HARv. L. REv. 616 (1949). Cf. also R. v. Bourne, [1938] 3 A11. E.R. 615 (justification for abortion). See Michael \& Wechsler, supra note 38, at 735.51 (and particularly $751 \mathrm{n.176}$ ) for a general treatment of the desirable activities on which the law of homicide potentially impinges.

322. Cf. also pp. 1451-1453 and note 38 supra, for discussion of the Utilitarian basis of excuses.

323. Any proposal to legalize euthanasia, for example, will probably have great diff. culty overcoming this problem.

324. See Dudley d Stephens, note 321 supra, for an example.

325. P. 311.

326. Pp. 325-26.

327. See T. Emerson, The System of Freedom of Expression 500 (1970).

328. P. 326. 
about his idea that purveying "questionable material" or "hard core pornography" to children can easily be prohibited, after the fashion of liquor. ${ }^{329}$ The point is that alcohol needs very little defining.

Abortion is another crime which does not meet Packer's criteria. The effort to control it by the criminal law creates only a "crime tariff." 330 The law should punish only abortions by "unqualified prac-

329. Id.

330.

Note: Packer on the "Crime Tariff"

Packer apparently regards the notion of a "crime tariff" as a prudential counter-indication for the use of the "criminal sanction," as one of his major contributions to the scholarship of criminal law. His treatment of it in this book is largely a reprint of an earlier article, The Crime Tatiff, 33 AMERICAN ScholAR 551 (1964). The notion is that if criminal prohibitions are applied to something which is essentially a line of commeree with relatively inflexible demand (the provision of abortions, drugs, gambling, ctc.), the effect is not to suppress the traffic, but to raise the price.

Packer's scholarly claims for the "crime tariff" require him to go beyond such obvious common sense, but when he does so his argument becomes so confused and ill-considered that the usefulness of the notion as a sort of crude rule-of-thumb is wholly obscured. He says, having defined a "protective tariff," that although we do not usually think "of these blights [i.e., victimless crimes] as commodities protected by a tariff ... it is easy" to demonstrate that they are just that." (p. 278) I think brief reflection shows, on the contrary, that at best the use of the word "tariff" is metaphoric. A tariff adjusts the price relationship between two sources of a commodity (domestic and forcign). The criminal law does not regulate competition, it eliminates it as a matter of definition, and it leaves the entire field to those willing to pay the "tariff"-there being, it viould seem, no real analog to a "protected" commodity at all. Thus abortion laws make all abortions of the forbidden kinds illegal-not just those performed by persons who othervice would compete with the "protected" abortionists (it will hardly do to regard the commodity on which the "tariff" is levied as the analog to the protected commodity in a true tariff situation). Tariffs do not make the life of the commodity or its protected dealers dangerous-they do not raise the price of mushrooms by randomly selecting cvery 100th mushroom dealer for punishment. Differences of this kind entirely vitiate the borrowed respectability with which Packer tries to cloak his argument: phrases like "economists tell us . . ." (p. 277) or "cconomic theory explains this phenomenon . . . " (p. 279). The argument-that victimless crimes are of doubtful wisdom-is a common and sensible one; it does not gain much from the intellectual disingenuousness of padding it with superficial "economic theory."

Furthermore, there are subtler problems with Packer's position of which he is apparently unaware. He says that the narcotics laws raise the price of drugs obtainable by those willing to take the risk. This kind of situation does not exist where the object of crime is not a commodity in commerce with a price that can be driven up, he says. "We do not make bank robbery more attractive by punishing the bank robbers whom we manage to catch. The potential gain is unaffected by the offsetting risk of punishment." (p. 281) This looks true at first blush, but on reffection it seems pretty clear that it is not true. If we had no effective laws against bank robbery, I am inclined to doubt that there would be much in banks to rob. The crime of robbery is intrinsic to the institution of property, and it is property which is the object of robbery. To some extent, the attractiveness of robbery is surely an increasing function of its illegality-at least up to some point an increase in the effective penalty (or, of course, in the chance of being cught) must correlate with an increase in the obtainable pot. I expect the same is also true, in a less "economic" sense, for crimes like murder and rape-human life and the integrity of the person gain importance because (in part, at least) they are protected. Alurder and rape, as crimes, derive thereby their intense attraction. Except that the criminal law happens to apply after instead of before the point at which the "inclasticity of demand" has been broken down by the magnitude of effective penalties, there may be very' little "economic" difference between ordinary crimes and those which Packer discusses.

I am inclined to believe that the felt appropriateness of robbery, rape and murder as offenses lies in the fact that we want very much to dignify the institutions in which 
titioners." A woman's right to obtain an abortion should be left to "the evolving mores of the medical profession." 331 It seems to me, on the contrary, no one other than a woman and her mate have any proper concern in the matter, but that the one thing that is plainly worse than general social intervention is ad hoc intervention by doctors.

\section{Retrospective Remarks on Method}

Thus far in this review I have addressed myself primarily to the substance of Packer's argument. On the whole, the conclusion I draw is that his argument fails at almost every critical point. As I noted at the outset, however, there is a more basic respect in which the book is disappointing: method. ${ }^{332}$ The elements of argument are so carelessly dealt with in the book, that it seems almost a misrepresentation to analyze its substance-to do so is either to pretend that something is an argument, when the vacuity of its parts renders it a void, and to dignify with criticism something which cannot bear it; or it is to run the risk that the substance one deals with is not Packer's at all, but one's own imposition of order upon suggestive nonsense-much as one can read all sorts of meaning into Jabberwocky. To mitigate the danger of such misrepresentation, I stated at the outset (but without any effort at demonstration) that the cumulative failures on the level of method largely vitiate the level of substance. It seems proper now to return to that theme, and to indicate more specifically the basis for that assertion.

they play central roles. The felt inappropriateness (to those who feel it), on the other hand, of gambling or narcotics as offenses, lies in the fact that their prohibition is not intrinsic to any larger entity we wish to dignify-we have no desire in suppressing narcotics to bestow value on some institution to which refraining from drugs is essentílal, the way we do with the value of property by limiting the ways in which it can be acquired. (Abortion, according to this line of thought, is in a rather different category from the simple vices, like drugs and gambling, since forbidding it is often said to be essential to maintenance of the sanctity of life.)

One can take this line of speculation one step further. By forbidding robbery, we define the nature of the valued institution of property by limiting the modes of acquisitionthereby bestowing value on property itself. Maybe the narcotics laws, analogously, are best analyzed as a part of the institution of "Puritan pleasure," which limits the permissible ways of achieving bliss, thereby bestowing value on bliss and inducing men to strive for it in the approved (and presumably "desirable") ways. Cf. E. GoFfman, STIGMA 144 (paper ed. 1963) (analyzing deviant groups as "represent[ing] failures in the motivational schemes of society"); R. Merton, Social. Theory AND Socind STructure 134 (1957) (aberrant behavior may be regarded sociologically as a symptom of "dissociation between culturally prescribed aspirations and socially structured avenues for realizing those aspirations"); J. GuSFieId, SYMBolic Crusade (1963). The real point of the attack upon narcotics laws, then, is that the attackers reject the desirability, or at least the present characteristics, of "Puritan pleasure."

331. Pp, 342-44.

332. See pp. 1391-93, 1394-97 supra. 
To begin with the problem of words: we have seen his carelessness with fundamental words like "purpose" and "justification," take"334 and "excuse"335 and the critical ways in which what he writes consequently never has even the possibility of becoming a successful argument. ${ }^{336} \mathrm{He}$ uses crucial words in several importantly different senses, ${ }^{337}$ and does so even after having himself taken great pains to define them-as in the case of the word "punishment."33s Finally, he manifests a lack of respect for the integrity of language: rather than deal with an issue as a matter of substance-can probation be considered treatment rather than punishment"3339 what constitutes an "illness" for purposes of the insanity defense or the conduct limitation?330 -he dismisses it as "merely verbal," as if the words involved had no meaning whatever.

The book is thoroughly defective in logical structure. I discussed at some length Packer's failure to pay careful attention to the logical model of the kind of argument he undertook. ${ }^{341}$ Throughout the book one of the most serious difficulties in trying to follow Packer is his inattention to the most elementary canons of logical organization. A concept will be shown to be essential before it has been defined or its contents described. ${ }^{342}$ Sometimes that latter task never is performed. ${ }^{343}$ The implicit notion that it is possible to give a justification of $\mathrm{X}$ independently of what it consists of-even to display indifference as to

333. See pp. 1395-96 and notes 32 and 34 supra.

334. See pp. 1441-42 supra.

335. See note 199 supra.

336. Slightly less critical errors with words are epidemic in the book (e.g., "prescribed" for "proscribed" (p. 103); "assumed" for "presumed" (p. 137); "covert use" for "covert function" (p. 295); "statistical" for "quantitative" (p. 302)).

The reader also has to cope with a number of annoying and confusing mistakes on a level only just above the typographical. For example: "By culpability, I mean those aspects of human conduct, as defined by the legal system, that serve, or ought to serve, as excuses from criminal punishment." (p. 64) The reader who is struggling to come to terms with the circularity of a definition of culpability in terms of punishability, when culpability is an aspect of the justification of punishment, see pp. 1397-1400 supra, may perhaps be forgiven some disgust when he finds his job of unravelling made even harder because "culpability" is here defined as the presence, rather than the absence, of excuses. Similar traps await him with the phrase "if we viewed conduct as a prerequisite rather than as merely evidentiary" with regard to criminal liability when the reverse is apparently meant (p. 73); and when he is told that bigamy probably has "the lowest ratio of reported appellate court opinions to actual prosecutions of any crime" when the highest ratio is meant. (p. 313) When Packer says that his claim to discuss a set of doctrines which "raise all the basic problems posed by criminal law doctrine" is "not an immodest one," surely he means it is not modest. (p. 72).

337. See pp. 1394-95 supra.

338. See pp. 1411-12 and note 171 supra.

339. See notes 62,68 supra.

340. See p. 1449 supra.

341. See pp. 1394-96 supra.

342. See pp. 1397-1400 supra ("culpability").

343. See p. 1448 supro ("insanity defense"). 
the latter question-is endemic in the book. Packer is also given to defining a concept like "criminal punishment" over a span of hundreds of pages. Beginning with an apparent definition, he then adds qualification, crucial new elements, and the like, when the concept reappears later on-all the while violating the definitions he has given before-so that the reader never really knows what the concept consists of. ${ }^{344}$ And the frequency with which what he writes at the most central points of the book turns out not to be argument, but only the sort of trivial circularity we saw in the case of the concept of "culpability" reflects, I think, Packer's apparent indifference to the demands of even minimal rigor.

The book is logically defective on the level of detail as well. To recall but one example, Packer's discussion of strict liability is vitiated by a simple and obvious error in the application of the calculus of Deterrence, which leads him to the mistaken conclusion that strict liability is, even in theory, less effective as a deterrent than liability for intentional or negligent behavior. ${ }^{345}$ An even more extreme problem in the book, however, is the frequency with which his inattention to what he is writing leads him beyond the most charitable limits of intelligibility - perhaps the grossest example of this is the passage on the relationship of the principle of legality, the conduct limitation, and the law of attempts, which I reproduced and annotated earlier. ${ }^{340}$

At many of the places where, in such a book, one anticipates argument on some point or another, Packer produces instead either an inherently dubious proposition preceded by "of course" or some similar indication that he does not regard argument as called for, ${ }^{347}$ or a piece of received dogma transmitted without the benefit of critical reexamination. ${ }^{348}$ At other places, a misrepresentation of fact is central to the argument he puts forth. ${ }^{349}$ But above all, it is Packer's regular use of ipse dixitism instead of ethical argument which makes it impossible

344. See pp. 1414-17 supra ("criminal punishment"), and pp. 1411-13 supra ("punisl1. ment").

345. See p. 1445 supra. Cf. also e.g., pp. 1434-38 (relation of principle of legality to conduct limitation) and pp. 1419-20 (Retributivism is "unverifiable") sttpra.

346. See pp. 1435-36 supra. Cf. note 84 supra.

347. See, e.g., notes 186 (nature of discretion, necessity of police and prosecutorial organizations treated as obvious), 68 and 241 (merely "verbal" character of a dispute treated as obvious), and 330 ("crime tariff" treated as obviously analogous to protective tariff supra.

348. See, e.g., pp. 1401-02 ("hypocrisy"), pp. $1447-48$ ("external standard" in negligence), and notes 186 (discretion) and 38 and 222 (nature of strict liability) supra.

349. See, e.g., p. 1423 (Rehabilitation) and notes 186 (non-adjudicative character of police and prosecutorial organizations) and 309 (short-term imprisonment) supra. 
to entertain much respect for his book. His vindication of the conduct limitation, of the allowance of excuses, and of the importance of respect for the capacity for self-control, and his dismissal of "behavioralism," 350 for example, are all accomplished, as we have seen, with more or less obvious ipse dixits.

\section{Conclusion}

It seems to me there are two categories within which one might evaluate Packer's book: as a contribution to scholarship, and as a piece of propaganda for reform.

Evaluated according to scholarly canons, the book is a disappointment. It is true, as I said at the outset, that the possibility of a satisfactory amount of criminal responsibility probably does not presently exist; little or no advances have been made in the past hundred years, and traditional scholarship is quite evidently making no progress. This is a time for great charity toward every piece of work which holds any promise at all. Even careful reworking of the traditional material (the sort of thing H.L.A. Hart has done so well) is not to be undervalued, since at least it makes very clear exactly where we are, and how much - how very little, rather-we can do with the intellectual apparatus we now have. Perhaps traditional jurisprudential scholarship as we know it will turn out to be a misguided enterprise. But without adumbrating that kind of question, one is at least entitled to insist that when the old bricks are to be rearranged a little, one more time, the quality of the bricklaying must not be allowed to deteriorate. In particular, the pervasiveness of ipse dixitism is a sign of Packer's failure to do what he attempted-that is, to construct an argument.

As a piece of propaganda the book seems unlikely to have much effect. The proof of this sort of pudding is entirely in the eating, but my guess is that very little taste will develop for Packer's lifeless and pretentious presentation. Beyond that, the book is simply anticlimactic. Three hundred sixty-six pages of "rationales" and the like labor mightily (if not illuminatingly) to come up with a timid conclusion which is surely the gist of every "sophisticated" cocktail party conversation on the subject in the land:

The process cannot function effectively unless the subject matter with which it deals is appropriately shaped to take ad-

350. See, respectively, pp. 1432-34, 1443-44, and 1499-30 supra. 
vantage of its strengths and minimize its weaknesses. The prospect of spending billions of dollars, as the federal government now seems prepared to do, on improving the capacity of the nation's system of criminal justice to deal with gamblers, narcotics addicts, prostitutes, homosexuals, abortionists, and other producers and consumers of illegal goods and services would be seen for the absurdity that it is if we were not so inured to similar spectacles. Our national talent runs much more to how-to-do-it than to whatto-do. We sorely need to redress the balance, to ask "what" and "why" before we ask "how." 351

Amen, one adds (albeit with caveats). But I doubt there are many people who need to read this book to expose themselves to that conclusion. ${ }^{852}$

351. P. 366.

352. Contrast MoRris \& Hawkins, supra note 2. Anyone who is looking for a book on the crime problem to mail to his local politician would be infinitely better of with this excellent little book than with THE LiMITS of THE CRIMINAL SANCTION. It is well-organized, well-written, forceful, and clear. It makes no pretentious jurisprtidential clalins but it is nonetheless thorough, careful and accurate with respect to the problems it dis. cusses (compare, e.g., its treatment of the prediction and danger calculus, $\mathrm{id}$. at 78, 185.02, or of the phenomenon of deterrence, $i d$. at 253.61, with Packer's inadequate and mis* leading treatments of the same subjects). According to its advertisers, professor Sanford Kadish has described it as "the distillation of the best thinking on the subject in the straightest talk the public has heard in a long time." (N.Y. TiMEs Book REvirw, lieb. 15,1970, p. 31). 